\title{
URBAN FOREST ASSESSMENT IN BANGKOK, THAILAND
}

By

MONTRI INTASEN

\author{
A Thesis \\ Submitted in partial fulfillment of the requirements for the degree \\ MASTER OF SCIENCE \\ IN \\ NATURAL RESOURCES (URBAN FORESTRY) \\ College of Natural Resources \\ UNIVERSITY OF WISCONSIN \\ Stevens Point, Wisconsin
}

December 2013 
APPROVED BY THE GRADUATE COMMITTEE OF:

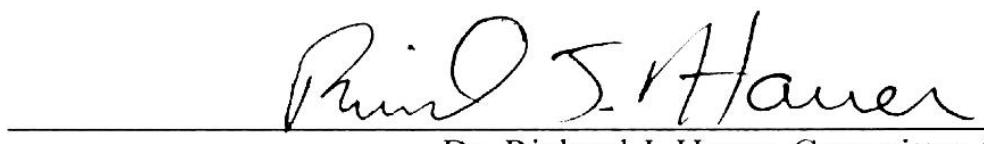

Dr. Richard J. Hater, Committee Chairman Associate Professor of Urban Forestry

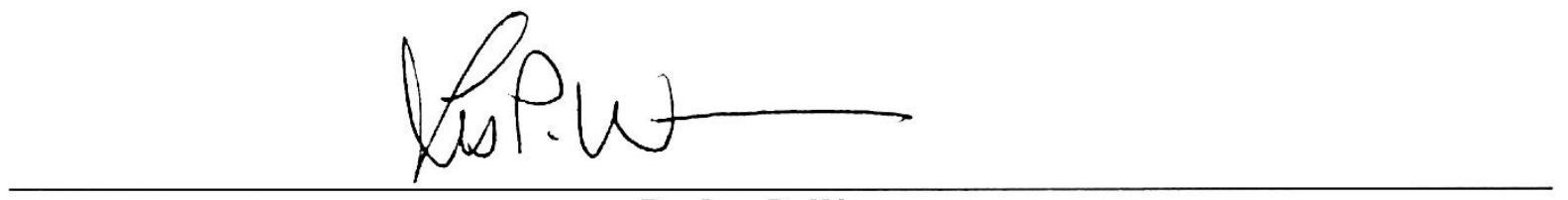

Dr. Les P. Werner

Associate Professor of Urban Forestry

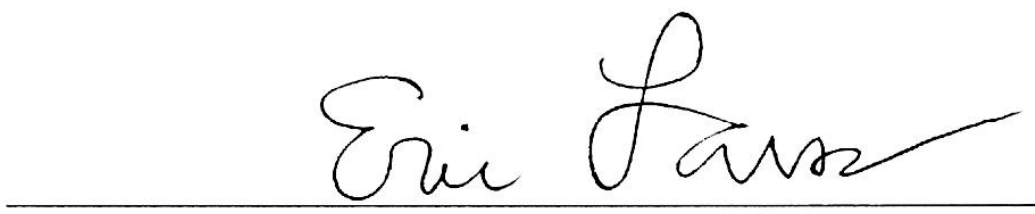

Dr. Eric Larsen

Professor of Geography 


\begin{abstract}
Urban forest assessments have been implemented in many cities worldwide to evaluate the urban forest structure and function. This study is the first step to institutionalize urban forest assessments in Thailand. Thus, the objective of this study was to conduct a pilot urban forest ecosystem assessment for Thailand, determine the urban forest value, and pilot study the appropriateness of adapting i-Tree Eco in Thailand. A stratified random sampling method was used to collect the field information. All data from 184 sampling plots were analyzed using iTree Eco for the urban forest structure, function, and value. The urban forest assessment in Bangkok showed a diverse mixture of 48 tree species. The three most common tree species which contributed $34.1 \%$ of total tree population were Polyalthia longifolia Sonn $(15.7 \%)$, Mangifera indica L. (13.0\%), and Pithecellobium dulce (Roxb.) Benth (5.4\%). The majority of trees (approximately 70\%) were $<23 \mathrm{~cm}$ in diameter. Nearly equally numbers of trees were in the $\leq 7.6 \mathrm{~cm}(24.4 \%), 7.7-15.2 \mathrm{~cm}(23.9 \%)$ and 15.3-22.9 $\mathrm{cm}(21.5 \%)$ diameter classes. An estimated 2,504,000 trees $($ S.E. $=408,646)$ exist in the Bangkok study area and these trees provide an $8.6 \%$ canopy cover. These trees store an approximate total of about 310,000 metric tons of carbon $(\$ 7,000,000 \mathrm{USD})$, which represent the equivalent of decreasing the $\mathrm{CO}_{2}$ in the atmosphere by about 16,000 metric tons/year (\$370,000 USD). The estimated annual ecosystem service benefits for air pollution removal of $\mathrm{PM}_{10}, \mathrm{NO}_{2}, \mathrm{O}_{3}, \mathrm{CO}$, and $\mathrm{SO}_{2}$ were about $\$ 200,000$ USD (6.17 million THB). The total pollution removal was estimated at 738 metric tons/year. The greatest effect of pollutant removal in the Bangkok urban forest study area was with particulate matter $\left(\mathrm{PM}_{10}\right)$ and 418 metric tons removed annually that was approximately half of the calculated value.
\end{abstract}




\section{ACKNOWLEDGEMENTS}

I would like to express the deepest appreciation to my committee chair, Associate Professor

Richard J. Hauer, who has gave me the opportunity to perform this research, encouragement, and advice. I am grateful for his patience during this research and his support. Without his guidance, understanding and much great advice, I could not have finished my thesis research in time.

I would like to thank my committee members, Associate Professor Les P. Werner and Professor Eric Larsen, whose confidence in me led to the timely completion of this thesis.

I am particularly and sincerely thankful to all who contributed in this project in one way or another, my colleagues at Royal Forest Department, my former professors at Faculty of Forestry, Kasetsart University, survey crews, and friends. Thank you.

The financial support of the Royal Thai Government, University of Wisconsin-Stevens Point, and Wisconsin Arborists Association is very much appreciated.

Finally, for my families who have supported me throughout this entire journey I thank you. 


\section{TABLE OF CONTENTS}

COMMITTEE SIGNATURE PAGE

ABSTRACT

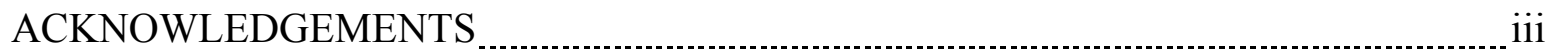

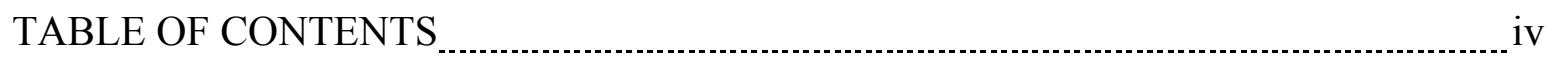

LIST OF TABLES

LIST OF FIGURES _ _.................. vii

CHAPTER 1: LITERATURE REVIEW

Introduction $\ldots$

Urban Forest Composition

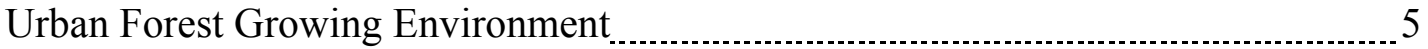

Urban Forest Structure, Function, and Value $\ldots$

Urban Forest Assessment

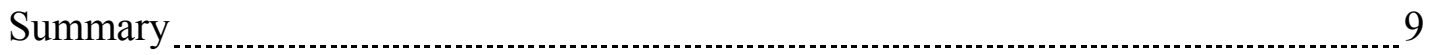

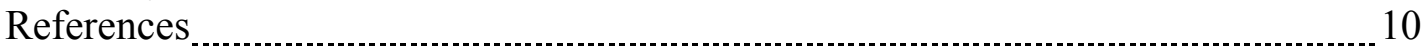

CHAPTER 2: METHODS

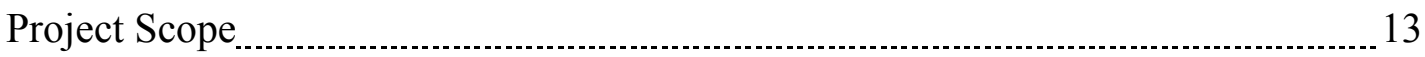

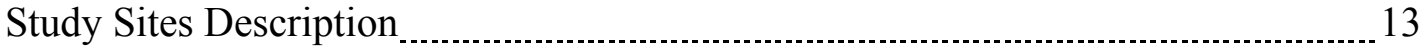

Experimental Design $\ldots \ldots \ldots \ldots \ldots \ldots$

Field and Analysis Methods

References

CHAPTER 3: URBAN FOREST ASSESSMENT IN BANGKOK, THAILAND _............. 24

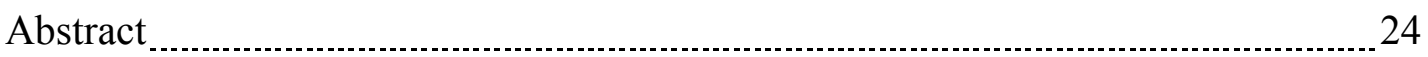

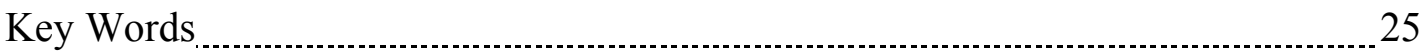

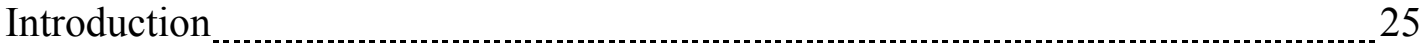

Methods

Results

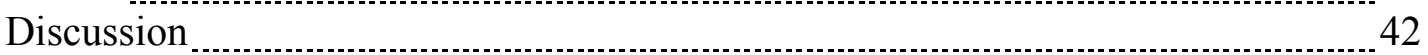

Conclusion

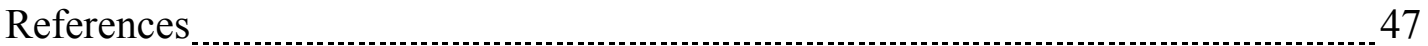


Summary

Future Implications

APPENDIX A - Tree Species 54

APPENDIX B - Information Submitted for Analysis 56

APPENDIX C - Sampling Technique 57

APPENDIX D - Data Collection Sheet 71

APPENDIX E - The Variables of Plot, Shrub and Tree for the i-Tree Eco data collecting. 75

APPENDIX F - i-Tree Ecosystem Analysis Bangkok 77

Summary 77

Tree Characteristics Of The Urban Forest 78

Urban Forest Cover \& Leaf Area 80

Air Pollution Removal By Urban Trees 81

Carbon Storage And Sequestration 82

Oxygen Production 83

Structural And Functional Values 84

Relative Tree Effects 85

Comparison Of Urban Forests

APPENDIX G - Land Use's Population Density, FAR and BCR Regulation 87 APPENDIX H - CTLA's Tree Appraisal Method 88 


\section{LIST OF TABLES}

Table 1. Study area, percent, and number of sample plots stratified by land use classification.

Table 2. Data quality standard and checked result (adapted from i-Tree Eco manual Version 4).

Table 3. Key findings of 2013 Bangkok urban forest assessment. 36

Table 4. Percent of ground cover type in Bangkok, 2013 by land use classification. 39

Table 5. Number of trees, carbon storage and sequestration, leaf area and leaf biomass of the 10 most abundant tree species. 


\section{LIST OF FIGURES}

Figure. 1. Bangkok urban forest assessment land use classification, Bangkok, Thailand.... 29

Figure. 2. Percent of tree population in Bangkok in 2013 by diameter class. 38

Figure. 3. Percent of tree species by population, leaf area, and importance value in Bangkok. 38

Figure. 4. Species origin of the Bangkok urban forest in 2013. 39

Figure. 5. Annual pollution removal by volume and value. 40

Figure. 6. Pollution removal by month for urban trees in Bangkok in 2013. 41 


\section{CHAPTER 1}

\section{LITERATURE REVIEW}

\section{Introduction}

The history of culturing trees that comprise the urban forest goes back thousands of years (Miller, 1997). Trees in urban forests are managed for their aesthetic qualities and environmental services. The economic values of urban trees varies and depends on attitudes of the people, often from aesthetics, commerce activities, health benefits, landscape selection, and environmental contributions (Miller, 1997).

Determining the value of the urban forest is facilitated through an urban forest assessment. Urban forest assessments provide a broad picture of the forest composition and structure and resulting ecological services. Ecological services include removal of air pollutants, carbon captured and stored, reduced energy use, and storm water storage (USDA Forest Service, 2011). Data collected from an assessment can assist urban forest planning and the assessment of urban forest management goals (Miller, 1997).

The concept of urban forestry was formally defined by Jorgensen (1970) in the 1960's. Prior to that activities and practices (e.g., tree selection and tree planting) consistent with urban forest management are reported 5000 to 6000 years ago (Campana, 1999). Definitions of both the urban forest and urban forestry as a field of study have evolved. Carlozzi (1971) suggested that "all forestry is urban forestry in an urban society". Similarly Stewart (1975) defines "urban forestry is the application of basic forest management principles in areas subject to concentrations of population." Sanders and Rowntree (1984) gave the definition of the urban forest as "all outdoor vegetation within the legal boundary of a city, including herbaceous, shrub 
and tree canopy layers.” Dunster and Dunster (1996) describe urban forestry as "a specialized form of forest management concerned with the cultivation and management of trees in the entire area influenced and/or utilized by the urban population.” Miller (1997) defined the urban forest "as the sum of all wood and associated vegetation in and around dense human settlements, ranging from small communities in rural settings to metropolitan regions."

According to the above definitions, we can assume that urban forest practices in Thailand have been long established. The use of trees in Thai cities occurred as far back as 1283, a time period that coincides with the development of the Thai alphabet. A recorded inscription shows a sweet-palm tree (Borassus flabellifer L.) was planted in "Sukhothai", the first capital city of Thailand in the 13th century for religious and ceremonial purposes (Dumrongthai, undated). Many other trees associated with Buddhism such as Ficus religiosa L., Ficus bengalensis L., and Cochlospermum religiosum (L), Alslon were planted under the royal patronage. Hopean odorata Roxb. was planted along canals in the second capital city of Thailand, "Ayutthaya" (1351-1767), for trading and as a source of wood to build warships. At the same time Ficus racemosa L. was being planted at the palace pavilion and in the temple area. Between 1767 and 1976, H. odorata was planted along the canals in Bangkok (the fourth capital city of Thailand, 1946-present) which now become the oldest urban trees in the city. King Rama V (1869-1890) had an initial goal to plant the trees along the major streets in Bangkok. The tree species such as Tamarindus indica L., Swietenia macrophylla King, Swietenia mahagani L., Pterocarpus indicus Willd and Diospyros mollis Griff were widely used as street trees. At the same time, the tree species such as Alstonia scholaris Marshall, F. religiosa, Diospyros decandra Lour, Diospyros pubicalyx Bakh and Pterocarpus macrocarpus Kurz were widely introduced in the city's temples (Dumrongthai, undated). 
The use of urban forest assessments in Thailand is lacking. As a result, limited information exits to assist with the development of effective urban forest management plans. A limited pilot street tree assessment occurred in Bangkok, Thailand in 2000 (Thaiutsa et al., 2008). The codification of urban forestry is in national legislation that states tree planting in the city is important for preserving and maintaining the beauty of the city (Dumrongthai, undated). In 2005, the Royal Forest Department (RFD) launched the urban community park program in order to increase green areas in municipalities around the country. There are about 70 urban community parks in Thailand. In 2008, RFD had its pilot urban forestry demonstration site at the Bang Kachao area, Samut Prakarn province (Dumrongthai, undated).

\section{Urban Forest Composition}

The structural composition of an urban forest is important for understanding urban forest function. The composition of the urban forest may be the product of unregulated or unplanned planting by individuals or related to tree selection based on the intended contribution to the urban forest (McBride, 2008). Tree species selection is influenced by the intended purpose or function, popularity, public policy, economics, and a predisposition to threats (e.g. flood, fire, and plant disease) that affect urban trees (Grey and Deneke, 1986).

The purposes of having trees in the cities include shade, visual screening, aesthetics, wind protection, fruit, or wood products (Miller, 1997). In some areas, the composition of the urban forest also reflects a popular species in the community. In the U.S., sugar maple trees (Acer saccharum Marshall) are popular in the northeast, Modesto ash trees (Fraxinus velutina Torr) on the west coast, and historically American elms (Ulmus americana L.) in the east and midwest (Grey and Deneke, 1986). 
In Thailand selecting trees for an intended purpose is no different than other parts of the world. For example, trees with favored Thai names such as golden shower tree (Cassia fistula L.), jack fruit (Artocarpus heterophyllus Lam), and mango (Mangifera indica L.) are commonly found in residential landscapes. In contrast, trees with unfavored Thai names and spirit connotations won't be found in residential house sites. Example trees include Bodhi tree ( $F$. religiosa), iron wood or Takian (H. odorata), and kapok tree (Bombax ceiba L.) as it is believed spirits reside in these trees. For example, the female spirit Nang Takian is believed to reside in the Takian tree and thus planting near homes or felling the tree for wood is not desired (DOAE, 2009). White plumeria (Plumeria obtuse L.) is usually planted in groups in public areas because of its broad crown and fragrant flower. Interestingly, white plumeria is not normally planted on residential properties because one of its common names, "Lan-Tom", has a negative connotation in the Thai language, in this case sadness. Recently this tree has been given the Thai name "LeeLa-Wa-Dee" which translates as "beautiful movement"; thereby making it more desirable to plant near homes. Golden shower tree (C. fistula), one of the most common street tree species in Thailand, is planted for shade and beautiful yellow flowers in summer. In temple areas, sacred fig (F. religiosa) is popular because of its cultural tie to the Buddha history (the lord Buddha meditated under the Bodhi Tree).

Many cities in the United States have street tree lists for recommended tree species or regulation intended to promote acceptable species (Grey and Deneke, 1986). In Thailand, the Royal Forest Department has the national regulations over teak (Tectona grandis L. f.) and yangna (Dipterocarpus alatus Roxb.). These are not commonly found on private land, but usually planted in public areas such as streets or parks. Urban forest composition is also influenced by public policy that regulates urban development. In Thailand, development projects that require 
an Environmental Impact Assessment (EIA) often have an EIA committee that recommends the species of tree to be included or allowed within the project.

\section{Urban Forest Growing Environment}

The physical environment will dictate tree species selection. Factors such as growing space (above and below ground), soil, topography, exposure to pollution and associated gray infrastructure should all be evaluated during the species selection process. Urban space for planting or maintaining trees is limited by associated infrastructure such as buildings, above and below ground utilities, roads, sidewalks, signs, and neighboring trees. To ensure that spatial limitations are not compromised, the mature size and form of the tree should guide species selection. For example, Grey and Deneke (1986), suggest that trees with a columnar, oval, or vase shaped mature form are most appropriate along street with narrow terraces.

Soil is another variable which affects the urban tree. Urban soils are often modified from development activities. Potential tree health is impacted by soil removal, added soil fill, covering with other materials (e.g. building, cement, tar, sand. rock, etc.), or compaction that occurs during construction (Koeser et al., 2013). Compacted soil has compromised structure which results in poor root growth due to reduced oxygen and water content. (Grey and Deneke, 1986).

\section{Urban Forest Structure, Function and Value}

Urban forest structure is an important component to assess and describe the physical attributes of urban trees (Nowak et al., 2008). Example structural attributes are total tree height, canopy spread, live crown ratio, and tree diameter. Urban forest function describes the roles that urban trees play with environmental functions such as pollution removal, carbon sequestration, 
energy saving, and rainwater interception. Urban forest structure, function, and value can be used to justify and manage the urban forest.

Generally, urban forest structure is not different from other forest structure, although trees in urban areas may experience different conditions compared with trees in natural forest settings (Nowak et al., 2008). Examples of growing conditions that affect tree structure in the urban forest are space, soil volume, light, temperature, climate, nutrients, and species competition.

Several approaches are used to quantify tree populations and composition. Tree abundance measures the total number trees in the urban area. Tree species composition also factors the percentage contribution of each species to the total tree population. Tree density is the number of trees per unit area. Tree health is often assessed with a tree condition rating. Healthy trees potentially provide a higher level of function such as greater carbon dioxide uptake.

Structurally, unhealthy trees may cause property damage or human injury. Leaf area is a measure of the leaf surface area per unit ground area and is used to quantify and estimate the absorption of carbon dioxide, precipitation interception, and intercepting sun light. Tree canopy cover is a metric to measure the percentage of land area that is covered by tree canopy. Biomass reflects net carbon dioxide uptake and release from trees through its leaf drop and wood decay. Tree diversity is the number of tree species in the urban area. A greater number of tree species should result in higher overall resilience to diseases and insects (Miller 1997).

Urban forest functions such as carbon sequestration, nutrient cycling, growth, hydrology, gas flux and energy exchange are dependent upon forest structure are all measurable (Nowak et al., 2008). Urban forest functions are similar to those in rural areas. Aesthetics is an important component in urban and rural forests. In urban forests, trees for timber products or harvesting 
fruit is possible, however, it may cause perceived issues with managing trees for wood products. Urban forests influence hydrology functions through rainfall interception, reduced water runoff, and water quality improvement. Additionally, water vapor exchange that occurs between the atmosphere and leaves during photosynthesis can reduce temperature at the meso-climate scale and cool urban areas. Gas and energy exchange is another function of urban forest. Urban trees remove carbon dioxide through sequestration in biomass and release oxygen. Trees reduce air pollution that should improve air quality for the health of people in urban areas (Nowak and Crane, 2000; Nowak et al., 2008).

The removal of air pollutants such as $\mathrm{CO}, \mathrm{SO}_{2}, \mathrm{NO}_{2}$, and $\mathrm{PM}_{10}$ along with $\mathrm{CO}_{2}$ sequestration by urban trees is increased with more leaf area. A study of the Chicago urban forest in 1991 found urban trees in the study area removed about 5,575 metric tons of pollution per year. A more recent study in 2012 found the urban tree population in Chicago removed about 18,080 metrics ton of pollution per year (Nowak, 1994; Nowak et al., 2012). The large healthy trees had a pollution removal capacity about 60-70 times more than small trees because of their greater leaf area. Species that tolerate pollution are more likely to remove pollution. Planting those species can help to remove more pollution especially if planted in areas with high pollutant concentration areas such as a road side (Nowak and Crane, 2000).

Economic values are derived from urban forest functions. These include social values such as aesthetics and benefits to human health. The estimate of urban forest values can be positive or negative and depends upon the species of the tree, location and people's attitudes toward their urban trees (Nowak and Crane, 2000; Nowak et al., 2008). For example, tree or branch fall as a result from decay, wind, snow, or other events can damage property or cause human injury. Low hanging branches can be harmful to a pedestrian. On the other hand, an urban 
tree study in Portland, Oregon U.S. showed that a tree in front of a house increases the sale price by an average of $\$ 7,130$ and can help to reduce about $\$ 25.16$ of electrical cost monthly in the summer time (Donovan, 2010). The annual value of urban trees removing pollution in Chicago was estimated at \$9.2 million in 1991 and \$183 million in 2012 (Nowak, 1994; Nowak et al., 2012).

\section{Urban Forest Assessment}

The management of urban forests is concerned with the overall administrative, economic, legal, and social aspects to meet specified goals and objectives (Miller, 1997). Urban forest management involves the establishment and care of woody and associated vegetation (Miller, 1997). Western Illinois University (undated) defined the management of the urban/community forest as "management of natural resources in urban and rural community environments. This includes the wildlife, aquatic resources, turf, flowers and shrubs and, of course, the trees". Knowledge about an urban tree population is gained through an urban forest assessment and this information is used to determine if urban forest management outcomes are being met.

Urban tree populations can be quantified by measuring every tree or by sampling. Measuring all trees may be useful for a small area and is potentially the most accurate way to determine urban tree structure. In a large area, measuring every tree is possible but requires a large investment in time, people, and money. Urban forest assessment through sampling is based on measuring a limited number of individual trees that will represent the entire tree population.

A recent study of Chicago's urban forest by Nowak et al. (2010) demonstrates the potential that urban forests have to affect human health and environmental quality. The study

details of those benefits, and the Chicago urban forest assessment provides needed information 
and supporting data for policy makers to create urban forest management plans. Other examples of urban forest assessments include the city of Milwaukee (2008) and the Washington D.C. (2010) using the i-Tree Ecosystem Analysis program (USDA 2008a; USDA 2008b). This methodology was also used in Arlington, Texas and the analysis documented the significant urban forest contributions to property values (about 20\%) and the economic benefits of street trees to local businesses via people spending more time in local businesses areas (USDA Forest Service, 2013).

The social aspect of urban forests varies in each city, in part depending on local population involvement. Urban society is diverse and this is manifested in attitudes and interest in urban trees. Social aspects should consider participation, needs of the poor, gender aspects, cultural and religious aspects, and local knowledge and attitudes (Jane, undated).

\section{Summary}

An urban forest assessment is a broad picture of the forest ecology of an urban site. Data collected during the assessment includes tree characteristics and land cover; from which functional attributes such as air pollution removal, carbon storage, and energy savings can be calculate. The goal of urban forestry is the creation and management of green space and the associated functional attributes to enhance the quality of life within communities (Miller, 1997).

Urban forest assessments have been prefaced in many cities worldwide. Likewise, a comprehensive urban forest assessment in Thailand would be beneficial to managing the urban forest. The focus of this study was to conduct an urban forest ecosystem assessment and determine the appropriateness of adapting the i-Tree Eco software program for use in Thailand. It is hoped that this study will lead to building upon urban forest management in Thailand. 
Limited research related to urban forestry has been conducted in Thailand.

Comprehensive research on culturing urban trees and developing and integrating new methods in urban forestry are priority needs. This understanding should result in better urban forest management in the country. No assessment of an entire urban forest has occurred in Thailand. This study is the first step towards future urban forest studies in Thailand. Study results can be used to model other urban forest plans in Thailand. Thus, the objectives of this study include: 1) conduct a pilot urban forest ecosystem survey, 2) assess the urban forest in Bangkok, Thailand and 3) define the appropriateness of adaptation of the i-Tree software in Thailand. The findings of this research will assist the future planning, development and policy of urban forestry in Thailand.

\section{References}

Campana, R., 1999. Arboriculture : history and development in North America. East Lansing : Michigan State University Press. 443 p.

Carlozzi, C.A., 1971. Forestry, ecology, and urbanization. in. A symposium on trees and forests in an urbanizing society. University of Massachusetts, Amherst, August 18-21, 1971. Planning and Resource Development Series No. 17. Cooperative Extension Service, University of Massachusetts, Amherst.

DOAE, 2009. Unfavored Residential Tree. Retrieved December 1 $1^{\text {st }}, 2013$ From: http://www.agriinfo.doae.go.th/year52/knowledge/km_05-03-52.doc Department of Agricultural Extension, Thailand. (In Thai)

Donovan, G.H., 2010. Portland: Street tree and Property Values; Science Findings. Issue 126. 2-3.

Dumrongthai, P., undated. Urban Forest Management in Thailand. Royal Forest Department, Thailand.

Dunster, J. and Dunster, K., 1996. Dictionary of natural resource management. UBC Press, University of British, Vancouver, B.C. 363 pp.

Grey, G.W., Deneke, F.J.,1986. Urban Forestry ( $\left.2^{\text {nd }} e d.\right)$. New York: John Wiley and Son, Inc. 
Jane, C.E., undated. The Potential of Urban Forestry in Developing Countries. Retrieved December $1^{\text {st }}, 2013$. From: http://www.fao.org/docrep/005/t1680e/t1680e00.HTM.

Jorgensen, E., 1970. Urban forestry in Canada. The shade tree research laboratory. Faculty of forestry, University of Toronto. $16 \mathrm{pp}$.

Koeser, A., Hauer, R., Norris, K., Krouse, R., 2013. Factors Influencing Long-term Street Tree Survival in Milwaukee, WI, USA. Urban Forestry \& Urban Greening. 12(4):562-568.

McBride, J.R., 2008. A method for Characterizing Urban Forest Composition and Structure for Landscape Architects and Urban Planners, Arboriculture and Urban Forest 34(6), 359365.

Miller, R.W., 1997. Urban Forestry: Planning and Managing Urban Greenspaces ( $2^{\text {nd }}$ ed. $)$. New Jersey: Prentice Hall.

Nowak, D.J., 1994. “Urban Forest Structure: The State of Chicago’s Urban Forest.” In E. G. McPherson, D. J. Nowak, and R. A. Rowntree (eds.), Chicago's Urban Forest Ecosystem: Results of the Chicago Urban Forest Climate Project (Gen. Tech. Rep. NE-186). Radnor, PA: USDA Forest Service.

Nowak, D.J., Crane, D.E., 2000. Carbon Storage and Sequestration by Urban Trees in the USA, Environmental Pollution 116: 381-389.

Nowak, D.J., Crane, D.E., Stevens C.J., Bond, J., 2008. A ground-based method of assessing urban forest structure and ecosystem services. Arboriculture and Urban Forestry. 34(6), 347-358.

Nowak, D.J., Hoehn, R.E. III, Crane, D,E., Bodine, A.R., Dwyer, J.F., Bonnewell, V., and Watson, G., 2012. Urban Trees and Forests of the Chicago Region. U.S. Department of Agriculture, Forest Service, Northern Research Station. 106 pp.

Nowak, D.J., Hoehn, R.E. III, Crane, D,E., Stevens, J.C., Fisher, C.L., 2010. Assessing urban forest effects and values, Chicago's urban forest. U.S. Department of Agriculture, Forest Service, Northern Research Station. 27 pp.

Sanders, R.A. and R.A. Rowntree., 1984. Environmental management through urban forestry on the hillsides of Cincinnati, Ohio. Journal of Environmental Management. 19: 161-174.

Stewart, C.A., 1975. The management and utilization of urban forests. Forestry issues in urban America, proceedings, 1974 national convention Society of American Foresters, New York City, Sept. 22-26, 1974. Society of American Foresters, Washington, DC. 
Thaiutsa, B., Puangchit, L., Kjelgren, R., Arunpraparut, W., 2008. Urban green space, street tree and heritage large tree assessment in Bangkok, Thailand, Urban Forestry and Urban Greening 7. 219-229.

USDA Forest Service, 2008a. i-Tree Ecosystem Analysis Milwaukee. U.S. Dept. of Agriculture, Forest Service, North Central Forest Experiment Station. 18 pp.

USDA Forest Service, 2008b. i-Tree Ecosystem Analysis Washington. U.S. Dept. of Agriculture, Forest Service, North Central Forest Experiment Station. 18 pp.

USDA Forest Service, 2011. i-Tree Eco User's Manual v.4.1.0. Retrieved December 1 ${ }^{\text {st }}, 2013$ From:http://www.itreetools.org/resources/manuals/iTree\%20Eco\%20Users\%20Manual .pdf. United State Department of Agriculture, Forest Service.

USDA Forest Service, 2013. i-Tree Reports. Retrieved December $1^{\text {st }}$, 2013. From: http://www.itreetools.org/resources/reports.php. United State Department of Agriculture, Forest Service.

Western Illinois University, undated. Western Illinois University Urban/Community Forestry and Arboriculture. Retrieved December $4^{\text {th }}$, 2013 From: http://www.wiu.edu/users $/ \mathrm{mftlg} /$ urbanforestry.htm. 


\section{CHAPTER 2}

\section{METHODS}

\section{Project Scope}

The focus of this study was to test the i-Tree Eco software program for use in Thailand and conduct a pilot urban forest ecosystem assessment. The capital city of Thailand, Bangkok was the study area. The study area was stratified by land use based on the Bangkok Metropolis Land Use Planning Area (MOI, 2006a). A planned 200 plots were proportionally divided for a stratified random sample among each land use category. The i-Tree Eco software was used to analyze the data and quantify urban forest structure and estimate functional and economic values of the urban forest.

\section{Study Sites Description}

Bangkok is located in the central region of Thailand and covers $1,568.737 \mathrm{~km}^{2}(605.693$

$\mathrm{mi}^{2}$ ) of land area (BMA, 2013a). Bangkok is the largest urban area in Thailand with approximately 6 million people and a population density of 3,634 people per $\mathrm{km}^{2}$, as of 2010 (NSO, 2012). Bangkok is a special administrative area with 50 districts that each elect a governor (BMA, 2013b). Bangkok is a major center for business, travel, political decision making, social service, education, health, and transportation in Thailand (Chulalongkorn University, 2010). More than half of gross domestic product (GDP) of Thailand is currently created in Bangkok (BMA, 2013a).

Bangkok has a tropical climate with monsoon seasons. There are three seasons in Thailand; summer season (February - April), rainy season (May - October) and winter season 
(November - January) (BMA, 2013a). The average highest and lowest temperature in 2012 was $40{ }^{\circ} \mathrm{C}$ and $18.5^{\circ} \mathrm{C}$ respectively. While the average highest and lowest temperature between 2000 and 2012 was $38.5^{\circ} \mathrm{C}$ and $18.5^{\circ} \mathrm{C}$ respectively. For monthly averages, the highest temperature occurred in April and the lowest temperature occurred in December (TMD, 2013).

The size and density of people in Bangkok results in environmental issues such as air pollution, wastewater, solid waste, hazardous waste, and land use conversion. Bangkok has a total of 5,687 green areas representing $1.62 \%$ of Bangkok's total area (2534.1 ha). The average green area supplies $4.4 \mathrm{~m}^{2}$ of space per person. Bangkok Metropolitan Administration's governor has a policy intended to increase public and miniature park areas by 200 hectares per year from 2009 to 2012. A problem to reach this goal is land prices in Bangkok are very high, as most of the open spaces belong to private owners. The natural green areas have been declining because of development in new residential areas and infrastructure (Department of Environmental BMA, 2012).

Roadside air quality results from 11 monitoring stations show pollutants often exceed ambient air quality standards of Thailand. The 24 hour average of particulate matter less than or equal $10 \mu \mathrm{g}\left(\mathrm{PM}_{10}\right)$ ranged between 8.3-195.2 $\mu \mathrm{g} / \mathrm{m}^{3}$. One-hundred sixty one of 2,887 samples (5.6\%) exceeded the ambient air quality standard of $120 \mu \mathrm{g} / \mathrm{m}^{3}$. Ozone in Bangkok ranged between 0-153.6 ppb. However, less than $1 \%$ of the sample events exceeded the ambient air quality standard of $100 \mathrm{ppb}$. Carbon monoxide as 8 hour averages were found at 0-17.8 parts per million (ppm) with ambient standards set at 9 ppm (PCD, 2012).

Air quality results from 10 monitoring stations located in general areas show pollutants exceeding ambient air quality standards of Thailand. The 24 hour average of $\mathrm{PM}_{10}$ ranged 
between 7.1-179.1 $\mu \mathrm{g} / \mathrm{m}^{3}$. Ozone as 1 hour averages ranged between $0-172$ parts per billion (ppb) in Bangkok (PCD, 2012).

\section{Experimental Design}

The Bangkok Metropolis Land Use Planning Area has 10 land use categories (MOI, 2006a). This study assessment occurred in 8 of these categories: low density residential area, medium density residential area, high density residential area, commercial area, industrial area, warehouse area, conservation area for promoting Thai culture, and government institution area. These areas comprise nearly $60 \%$ of the total land area in Bangkok. Each category has a proportional area of $53 \%, 21 \%, 14 \%, 7 \%, 1.5 \%, 0.2 \%, 0.6 \%$, and $3.5 \%$, respectively within the assessment area. The excluded 2 land use categories are rural and agriculture areas, which account for approximately $40 \%$ of the total area of Bangkok. The commercial, industrial, and warehouse areas were grouped into a combined category, based on their small area. Thus, the study area had stratification into 6 categories; 1) low density residential area, 2) medium density residential area, 3) high density residential area, 4) commercial, industrial, warehouse area, 5) culture conservation, park, golf course, and 6) government, stadium, other area.

The Ministry of Interior's Ministerial Regulation on the Bangkok Comprehensive Plan B.E. 2549 (2006 A.D.) provides a description for each land use category (MOI, 2006b). Based on this, the low density residential area is 1-2 story single and twin homes and does not contain industrial facilities. The medium density residential area is next to or surrounded by business and high density residential area. This area includes single houses, twin houses, row houses, and condominiums with the heights not to exceed more than 5 stories. The high density residential area borders the central business area and includes office, mall, hotel, condominium, and 
apartment buildings. Single family row houses that share a common wall are also found in this area. There is no limit to the building height in this area. The commercial area is located in the city core and contains the central business district. Buildings are primarily commercial and include malls, markets, shopping, office buildings, hotels, and theaters and an international convention center. Buildings in this area have no height limit. Each land use category also has a specific population density, floor area ratio (FAR), and building coverage ratio (BCR) as show in Appendix.

\section{Field and Analysis Methods}

Urban forest data from the Bangkok study area was collected using a stratified random sampling method. To achieve a standard error rate of approximately $10 \%$, a planned 200 survey plots in the entire study area were proportionally divided among the 6 land use category in this study based on their respective land area (USDA Forest Service, 2011b). Thus, the proposed sampling plan includes 105 plots in the low density residential area, 41 in the medium density residential area, 27 in the high density residential area, 13 in the commercial area, 3 in the industrial area, 1 in the warehouse area, 2 in the conservation area for promoting Thai culture, and 8 in the government institution area. ArcMap10 was used to generate a stratified random sample for the study area. Sample plots were 0.04 ha $(0.1$ acre $)$ circular plots with an $11.34 \mathrm{~m}$ (37.2 ft.) radius in size.

In each sampling plot, data was collected to describe the urban forest structure. Plot information included plot number, address, date, crew, reference photo, reference object, measurement unit, distance to reference object, direction to object, tree measurement point, land use type, percent of tree cover, percent of shrub cover, and percent of plantable space. Tree 
information described tree number, distance and direction from plot center, species code, diameter at breast height (DBH at $1.30 \mathrm{~m}$ ), total tree height, height to crown base, crown width, percent canopy missing, canopy dieback, percent shrub cover beneath canopy, crown light exposure, distance and direction to space-conditioned residential buildings, street tree, and tree status. Shrub information included species, height, percent of shrub area, and percent of shrub mass missing.

The i-Tree Eco software program, developed by United State Department of Agriculture (USDA) Forest Service, was used to quantify the Bangkok urban and community forest. The iTree Eco model was designed to use the data from a random survey method in conjunction with local air quality, weather, electricity cost, fuel cost, and carbon value data to assess the urban forest value.

The i-Tree Eco analysis also requires air quality and weather data. Air quality data was provided by Pollution Control Department (PCD) which has 17 monitoring stations (10 in general areas and 7 in road side areas) in the Bangkok area. Hourly air quality data for carbon monoxide $(\mathrm{CO})$, nitrous oxide $\left(\mathrm{NO}_{2}\right)$, Ozone $\left(\mathrm{O}_{3}\right), \mathrm{PM}_{10}$, and sulfur dioxide $\left(\mathrm{SO}_{2}\right)$ were used in the analysis. The weather data was obtained from National Climatic Data Center, U.S. by Northern Research Station, USDA Forest Service.

The i-Tree Eco software develops functional values of the Bangkok urban forest from the collected vegetation structure. Data from the collected vegetation attributes along with air quality data, weather data, electricity cost, fuel cost, and carbon value factor was used to assess the urban forest value. See Appendix for the associated value of the above parameters used in this assessment. 
Equations previously constructed to describe tree species from i-Tree Eco were used for this study with species in or near Bangkok to estimate leaf area, leaf biomass, and average leaf area index (Nowak, 1996; USDA Forest Service, 2011a). Average leaf area index (LAI) was calculated by the regression equation for the maximum tree size based on the appropriate heightwidth ratio and shading coefficient for deciduous trees (USDA Forest Service, 2011a; Nowak et al., 2008). Shrub leaf area was calculated by converting leaf biomass to leaf area based on the measured species conversion ratio (USDA Forest Service, 2011a). Leaf biomass was calculated by converting leaf area to this value (USDA Forest Service, 2011a). Shrub leaf biomass was calculated from the crown volume occupied by leaves and measured leaf biomass factors for individual species (USDA Forest Service, 2011a; Nowak et al., 2008).

$$
\mathrm{LA}=\left[\operatorname{In}\left(1-\mathrm{X}_{\mathrm{s}}\right) /-\mathrm{k}\right] \times \mathrm{rr}^{2}
$$

Where:

$\mathrm{LA}=$ Leaf Area

$\mathrm{X}_{\mathrm{s}}=$ Average Shading Coefficient of the Species

$\mathrm{k}=$ Light Extinction Coefficient ( 0.52 for conifer and 0.65 for hardwood)

$\mathrm{r}=$ crown radius

$$
\mathrm{LAI}=\operatorname{In}\left(\mathrm{I} / \mathrm{I}_{0}\right) /-\mathrm{k}
$$

Where

$$
\text { LAI }=\text { Leaf Area Index }
$$

$\mathrm{I}=$ Light Intensity beneath Canopy

$\mathrm{I}_{\mathrm{o}}=$ Light Intensity above Canopy

$\mathrm{k}=$ Light Extinction Coefficient ( 0.52 for conifer and 0.65 for hardwood)

The LAI were used for deciduous tree that were too large to use the regression equation, then scaled back proportionally to the original crown volume. For conifer trees (excluding 
pines), average LAI per height to width ratio for deciduous trees with a shading coefficient of 0.91 was applied to the tree's ground area to estimate leaf area.

If the leaf biomass could not be calculated from the regression equation due to tree parameters not fitting into the equation, then leaf biomass was estimated by converting leaf area using species specific measurements of g leaf dry weight $/ \mathrm{m}^{2}$ of leaf area.

Carbon sequestration by vegetation and associated economic value of carbon storage was based on default i-Tree Eco $\mathrm{CO}_{2}$ emission control costs. Carbon storage and annual sequestration was estimated based on carbon emission from decomposition, the probability of a tree dying within the next year and probability of the tree being removed using the formula developed by Nowak \& Crane (2002). $\mathrm{CO}_{2}$ uptake was determined from allometric equations based on tree species, diameter, and crown light exposure (Phillips, 2011). The difference in estimates of carbon storage between year $\mathrm{X}$ and year $\mathrm{X}+1$ is the gross of carbon sequestered annually.

The standardized growth was calculated from following formula. Then, the standardized growth was adjusted based on tree condition.

$$
\mathrm{SG}=\mathrm{MG} \times(153 / \mathrm{FFD})
$$

Where $\quad \begin{aligned} & \mathrm{SG}=\text { Standardized Growth } \\ & \mathrm{MG}=\text { Measured Growth } \\ & \mathrm{FFD}=\text { Frost Free Days }\end{aligned}$

The estimated marginal social cost of carbon dioxide emission was $\$ 20.28$ per metric ton. This was multiplied by the amount of carbon storage and sequestration to estimate the monetary value of carbon storage and annual sequestration. 
Air pollution removal was calculated using tree and shrub LAI and percent tree and shrub leaf area. Local leaf-on and leaf-off dates were determined for deciduous trees according to protocols established by the USDA Forest Service (USDA Forest Service, 2011a). The hourly dry deposition of $\mathrm{O}_{3}, \mathrm{SO}_{2}, \mathrm{NO}_{2}, \mathrm{CO}$, and $\mathrm{PM}_{10}$ were calculated proportional to the vegetation canopy cover (USDA Forest Service, 2011a). Relating to transpiration, CO and removal of particulate matter were adjusted to actual LAI and the leaf-on vs. leaf-off season parameters (USDA Forest Service, 2011a). Hourly pollution concentrations (ppm) for gaseous pollutants were obtained from the PCD monitoring stations. Average daily concentration of $\mathrm{PM}_{10}$ was obtained from the PCD. Missing hourly meteorological or pollution data were estimated using the monthly average (USDA Forest Service, 2011a).

The deposition velocity formula was used to estimate dry deposition of $\mathrm{O}_{3}, \mathrm{SO}_{2}, \mathrm{NO}_{2}$, $\mathrm{CO}$, and $\mathrm{PM}_{10}$.

$$
V_{d}=\left(R_{a}+R_{b}+R_{c}\right)^{-1}
$$

Where $\quad V_{d}=$ Deposition Velocity

$$
\mathrm{R}_{\mathrm{a}}=\text { Aerodynamic Air Flow }
$$$$
\mathrm{R}_{\mathrm{b}}=\text { Quasilaminar Boundary Layer }
$$$$
\mathrm{R}_{\mathrm{c}}=\text { Canopy Resistances }
$$

$$
\mathrm{F}=\mathrm{V}_{\mathrm{d}} \times \mathrm{C}
$$

Where

$\mathrm{F}=$ Pollutant Flux

$$
\begin{aligned}
& \mathrm{V}_{\mathrm{d}}=\text { Deposition Velocity } \\
& \mathrm{C}=\text { Pollutant Concentration }
\end{aligned}
$$


The monetary value of pollution removal by trees is estimated using the median externality values for Bangkok, provided from USDA Forest Service Northern Research Station for each pollutant. These values are: $\mathrm{SO}_{2}=2,744 \mathrm{THB}(\$ 92), \mathrm{NO}_{2}=11,207 \mathrm{THB}(\$ 374), \mathrm{O}_{3}=$ 11,207 THB (\$374), CO =1,592 THB (\$53), and $\mathrm{PM}_{10}=7,482$ THB (\$249).

The effect of vegetation on energy use and consequent power plant emissions of carbon were based on tree size, distance from a building, direction to the building, climate region, leaf type and percent cover of buildings and trees on the plot. Avoided carbon emissions from power plants were calculated from the method of McPherson and Simpson (1999) and the USDA Forest Service (2011a). Any tree that was less than 6 meters or more than 18 meters from the building is not included for affecting building energy use and was not used in the calculated avoided $\mathrm{CO}_{2}$ emission (USDA Forest Service, 2011a).

The tree appraisal methods from the Council of Tree and Landscape Appraisers (CTLA) were used to estimate the urban forest structure. The full description of CTLA method is described in Appendix.

Nowak et al., (2008) described the various sampling approaches for urban forest assessments and the affect with assessing urban forest structure and subsequently urban forest functions and values. The urban forest assessment model used in this study has various limitations. Results are based on field data collection and the stratified random sampling method will distribute the plots according to portion of the strata to decrease the variance of tree population estimate. In order to collect data accurately and decrease the variation, the general plot information, shrub information, and tree information were collected as described in Appendix E. Thus, model estimates of urban forest structure, function and value will be presented with a known standard error. Also, the field data were collected during the in-leaf 
season to measure various crown parameters used to estimate leaf area, leaf biomass, and tree

health. The leaf area and leaf biomass are not directly measured in the field, but they use regression equations to estimate their values.

\section{References}

BMA, 2013a. Location and Topography of Bangkok. Bangkok Metropolitan Administration Data Center. Retrieved December ${ }^{\text {st }}$, 2013 From: http://203.155.220.230/info/NowBMA /frame.asp. Bangkok Metropolitan Administration. (In Thai)

BMA, 2013b. Bangkok Development History. Bangkok Metropolitan Administration Data Center. Retrieved December 1 $1^{\text {st }}$, 2013 From: http://203.155.220.230/info/History/ frame.asp. Bangkok Metropolitan Administration. (In Thai)

Chulalongkorn University, 2010. Bangkok Standard City Planning. Bangkok: Chulalongkorn University Press. (In Thai)

Department of Environmental BMA, 2012. Bangkok State of Environment 2012. Department of Environmental; Bangkok Metropolitan Administration, Thailand.(In English and Thai)

McPherson E.G., Simpson R.J., 1999. Carbon Dioxide Reduction Through Urban Forestry: Guideline for Professional and Volunteer Tree Planters. PSW-GTR-17. Albany, California, $237 \mathrm{pp}$.

MOI, 2006a. Ministerial Regulation on the Bangkok Comprehensive Plan Implementation B.E.2549 (2006 A.D.). Ministerial Regulation Act, 2006, Ministry of Interior of the Kingdom of Thailand. (In Thai)

MOI, 2006b. Ministerial Regulation on the Bangkok Comprehensive Plan B.E.2549 (2006 A.D.) Ministerial Regulation Act, 2006, Ministry of Interior of the Kingdom of Thailand. (In Thai)

Nowak, D.J., 1996. Estimating Leaf Area and Leaf Biomass of Open-Grown Deciduous Urban Trees, Forest Science 42(4), 504-507.

Nowak, D.J., Crane, D.E., 2002. Carbon Storage and Sequestration by Urban Trees in the USA, Environmental Pollution 116: 381-389.

Nowak, D.J., Crane, D.E., Stevens C.J., Bond, J., 2008. A ground-based method of assessing urban forest structure and ecosystem services. Arboriculture and Urban Forestry. 34(6), 347-358. 
NSO, 2012. Key Statistic of Thailand 2012. Retrieved December $1^{\text {st }}$, 2013. From: http://service.nso.go.th/nso/nsopublish/pubs/pubsfiles/Key55_T.pdf. National Statistical Office, Ministry of Information and Communication Technology. (In Thai)

PCD, 2012. Air and Noise Pollution Management Plan for Bangkok 2012- 2016. Pollution Control Department, Ministry of Natural Resources and Environmental, Thailand. (In Thai)

Phillips, D., 2011. Assessment of Ecosystem Services Provided by Urban Tree: Public lands within the urban growth boundary of Corvallis Oregon. Oregon. U.S. Environmental Protection Agency, Western Ecology Division, Corvallis, OR, 18 pp.

TMD, 2013. Meteorological Knowledge. Retrieved December $1^{\text {st }}$, 2013. From: http://www.tmd.go.th/info/info.php?FileID=23. Thai Meteorological Department, Thailand. (In Thai)

USDA Forest Service, 2011a. UFORE Methods. Retrieved December 1 ${ }^{\text {st }}$, 2013. From: http://www.itreetools.org/eco/resources/UFORE\%20Methods.pdf. United State Department of Agriculture, Forest Service.

USDA Forest Service, 2011b. i-Tree Eco User's Manual v.4.1.0. Retrieved December $1^{\text {st }}, 2013$ From:http://www.itreetools.org/resources/manuals/iTree\%20Eco\%20Users\%20Manual .pdf. United State Department of Agriculture, Forest Service. 


\title{
CHAPTER 3
}

\section{This Chapter to be submitted to Urban Forest \& Urban Greening}

\section{URBAN FOREST ASSESSMENT IN BANGKOK, THAILAND}

\author{
Montri Intasen ${ }^{\mathrm{a}}$, Richard J. Hauer ${ }^{\mathrm{b}}$, Les P. Werner ${ }^{\mathrm{b}}$, Eric Larsen ${ }^{\mathrm{c}}$ \\ ${ }^{\text {a }}$ Royal Forest Department, 61, Phahon Yothin Rd., Lat Yao, Chatuchak, Bangkok 10900 Thailand \\ ${ }^{\mathrm{b}}$ College of Natural Resources, University of Wisconsin-Stevens Point, 800 Reserve Street, Stevens Point, WI \\ 54481, United States \\ ${ }^{\mathrm{c}}$ Department of Geography, University of Wisconsin-Stevens Point, 2001 Fourth Avenue, Stevens Point, WI 54481, \\ United States
}

\begin{abstract}
Urban forest assessments have been implemented in many cities worldwide to evaluate the urban forest structure and function. This study is the first step to institutionalize urban forest assessments in Thailand. Thus, the objective of this study was to conduct a pilot urban forest ecosystem assessment for Thailand, determine the urban forest value, and pilot study the appropriateness of adapting i-Tree Eco in Thailand. A stratified random sampling method was used to collect the field information. All data from 184 sampling plots were analyzed using iTree Eco for the urban forest structure, function, and value. The urban forest assessment in Bangkok showed a diverse mixture of 48 tree species. The three most common tree species which contributed $34.1 \%$ of total tree population were Polyalthia longifolia (15.7\%), Mangifera indica (13.0\%), and Pithecellobium dulce (5.4\%). The majority of trees (approximately $70 \%$ ) were $<23 \mathrm{~cm}$ in diameter. Nearly equally numbers of trees were in the $\leq 7.6 \mathrm{~cm}(24.4 \%), 7.7$ -
\end{abstract}


$15.2 \mathrm{~cm} \mathrm{(23.9 \% )} \mathrm{and} \mathrm{15.3-22.9} \mathrm{cm}(21.5 \%)$ diameter classes. An estimated 2,504,000 trees (S.E. $=408,646)$ exist in the Bangkok study area and these trees provide an $8.6 \%$ canopy cover. These trees store an approximate total of about 310,000 metric tons of carbon $\$ 7,000,000$ USD (210.0 million THB), which represent the equivalent of decreasing the $\mathrm{CO}_{2}$ in the atmosphere by about 16,000 metric tons/year $\$ 370,000$ USD (11.1 million THB). The estimated annual ecosystem service benefits for air pollution removal of $\mathrm{PM}_{10}, \mathrm{NO}_{2}, \mathrm{O}_{3}, \mathrm{CO}$, and $\mathrm{SO}_{2}$ were about $\$ 200,000$ USD (6.17 million THB). The total pollution removal was estimated at 738 metric tons/year. The greatest effect of pollutant removal in the Bangkok urban forest study area was with particulate matter $\left(\mathrm{PM}_{10}\right)$ and 418 metric tons removed annually that was approximately half of the calculated value.

KEY WORDS: Bangkok; Urban Forest Assessment; i-Tree Eco international; Urban forest sampling.

\section{INTRODUCTION}

The urban forest has been cultured by people for thousands of years (Miller, 1997). Over time urban forestry has evolved from rudimentary practices such as tree planting and removal to more advanced urban forest practices based on urban forest assessment and management plans that add value to the built environment (Miller, 1997; Tyrväinen and Miettinen, 2000; Wolf, 2007). Management plans are based on goals developed by decision makers and the community to meet needs such as aesthetics, land use planning, and environmental services (Grey and Deneke, 1986, Dwyer et al., 2003). 
In the capital of Thailand, Bangkok, a goal to increase green area through park development and tree planting was recently developed (Department of Environmental BMA, 2012). Successfully enacting the initiative should make Bangkok a more livable city by expanding green area at an approximate rate of 200 ha per year. Challenges to accomplishing this green area initiative are high land prices, changing land ownership and land-use and a lack of information regarding the potential functional value of converting lands into green areas. Accurate and timely information on the structure and functional value of the urban forest is needed to guide Bangkok decision makers in determining the location of new urban green areas, the potential functional value of green areas, and the development of urban forest management plans (Department of Environmental BMA, 2012).

Limited formal studies exist for urban forest management in Bangkok. Thaiutsa et. al. (2008) studied urban green space, street and heritage trees in Bangkok, Thailand. The main objective was to conduct a pilot street tree assessment and to quantify Bangkok's green infrastructure. Approximately 200,000 street trees were estimated to exist in Bangkok in 2000. The study also provided suggestions on tree species selection for parks and street trees in order to maximize the potential benefits associated with trees through properly matching the tree species to the location. This resulted in the Street Trees of Bangkok book (Thaiutsa et al., 2000). Even though an urban forest management plan was not developed, the information of this study could be used to guide the city on street tree species selection.

Successful urban forest management plans add functional value to the built environment because they are based on assessments of the urban forest's structure and health, the capacity of the community to manage the urban forest, and collaborative goals developed by decision makers and the community to meet expectations for aesthetics, land use, and environmental 
services (Grey and Deneke, 1986, Dwyer et al., 2003). Functional value can be derived from estimates of environmental, economic, and social services provided by trees. Functional value is influenced to a great extent by the structure of the urban forest. Structural assessments focus on the physical attributes of trees that comprise the urban forest; including, species composition, stem diameter, canopy dimensions, tree health, tree density, and leaf area (Nowak et al. 2010). For example, healthy trees live longer and provide more services than unhealthy trees (Cullen 2005; Peper et al. 2007; Koeser et al., 2013), large trees have more leaf area $\left(\mathrm{m}^{2}\right)$ which increases the absorption of gases (i.e. carbon dioxide), interception of precipitation, and the shading of land cover and buildings from sun light (Nowak, 1996). Tree abundance reflects taxonomic diversity with greater tree diversity potentially reducing the impact of infectious tree disease and insect outbreaks (Raupp et al., 2006).

The functional value of the urban forest can be maximized through planning and sustainable management that focuses on developing appropriate forest structure, species diversity, and implementing sound arboricultural practices. For example, policy makers in the city of Chicago, IL USA, relied on data generated from an urban forest assessment using the iTree software suite from the USDA Forest Service to create urban forest management plans and to engage the community in supporting urban tree canopy initiatives by demonstrating the functional value of trees exceeded the cost of establishment and care within 9-15 years and that a $10 \%$ increase in canopy cover could reduce home-energy usage by 5-10\% (Nowak et al., 2010; Nowak et al., 2012). Similarly, data from an urban forest assessment in Perth, Australia demonstrated how species selection impacted local air quality and was used to influence public planning and policy (NUFA, 2012; Saunders et al., 2011). Jim (2008) used a multipurpose census methodology to assess urban forest structure in Hong Kong. Data surrounding the 
relationship between tree growth and city environment was used to design planting sites, select species, and adjust tree planting and maintenance practices.

Bangkok is a largest urban area in Thailand and a major center for business, travel, politics, social services, education, health, and transportation. More than $50 \%$ of the gross domestic product (GDP) of Thailand is produced in Bangkok (Chulalongkorn University, 2010; BMA, 2013a). No assessment of an entire urban forest has occurred in Thailand. The objective of this study was to conduct an ecosystem assessment of Bangkok's urban forest using the i-Tree Eco software program. The urban forest assessment of Bangkok will provide a basis to develop effective urban forest management and develop a baseline of its structure. Study results may also be used as a model approach for the assessment and development of urban forest plans in other locations in Thailand.

\section{METHODS}

Study Area

This study was carried out in Bangkok, Thailand (Fig. 1). The capital city covers an area of $1,568.7 \mathrm{~km}^{2}$ with $5,673,560$ registered people in 2012 and a population density of 3,617 people per km² (BMA, 2013a; NSO, 2012). Bangkok is about 1.5 - 2 meters above mean sea level and is located in the Chao Phraya River basin. This basin is located on the plains and river deltas that flow from north to south into the Gulf of Thailand about $30.6 \mathrm{~km}$ from the city center (BMA, 2013a). The rainy season in Bangkok occurs from May to October with the majority of rain in mid-August to mid-October. The average rain fall is about $1,500 \mathrm{~mm}$ per year. The average highest temperature in 2012 was $40.0^{\circ} \mathrm{C}$ (average highest temperature from 2000-2012 was $38.5^{\circ} \mathrm{C}$ ) with the highest temperature occurred in April. The average lowest temperature in 
2012 was $22.0{ }^{\circ} \mathrm{C}$ (average lowest temperature from $2000-2012$ was $18.5^{\circ} \mathrm{C}$ ) with the lowest temperature occurred in December (SFB, 2012). Bangkok is a special administrative area in Thailand and is subdivided into 50 districts, which are further subdivided into 169 sub-districts (BMA, 2013b). The 2006 Bangkok Comprehensive Plan classifies land use into 10 categories: 1) low-density residential areas, 2) medium-density residential areas, 3) high-density residential areas, 4) commercial areas, 5) industrial areas, 6) warehouse areas, 7) rural and agriculture conservation areas, 8) rural and agriculture areas, 9) Thai art and cultural conservation areas, and 10) government (MOI, 2006a).

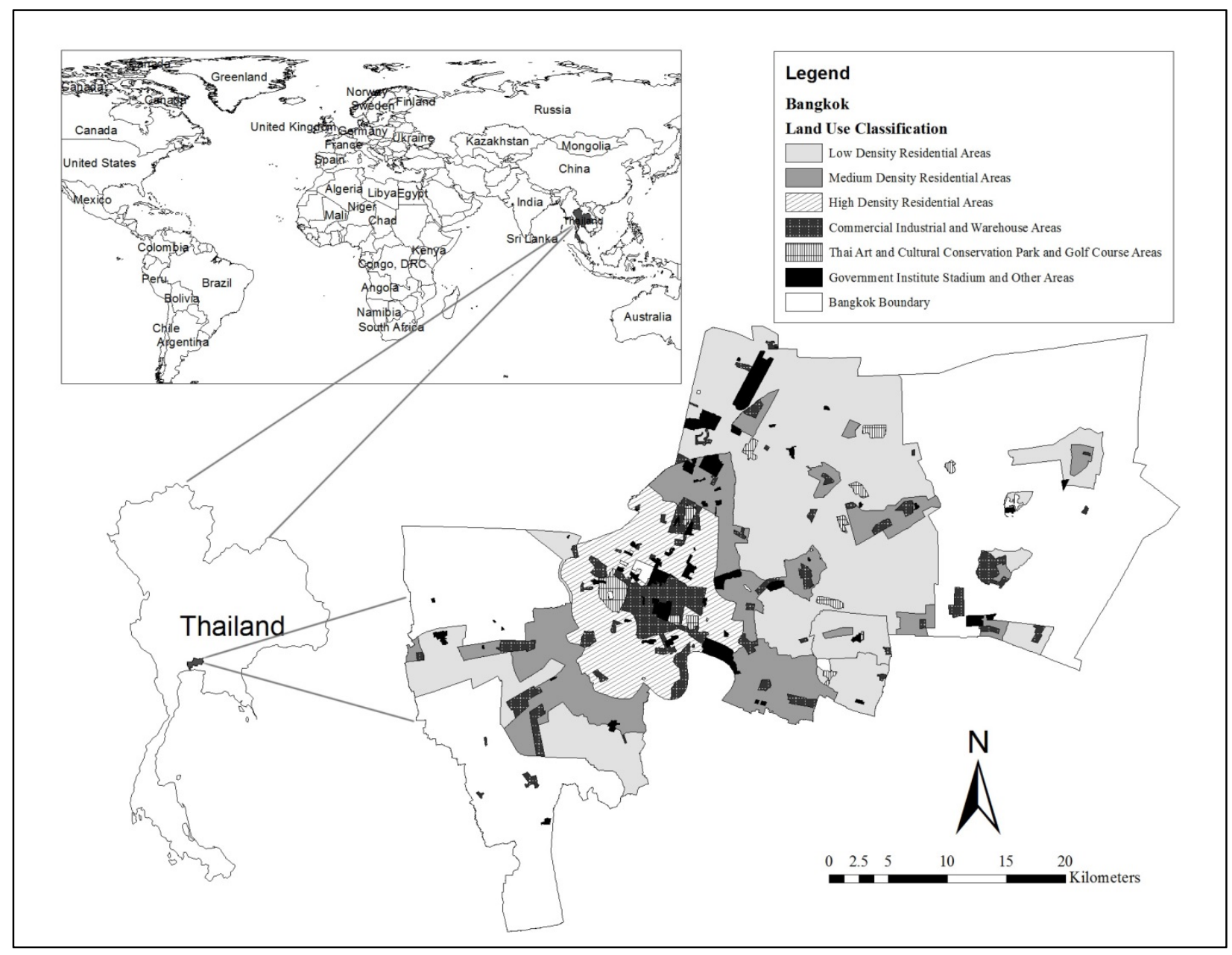

Fig. 1. Bangkok urban forest assessment land use classification, Bangkok, Thailand. 


\section{Research Methods}

In this study, the urban forest assessment included 8 of the 10 categories of Bangkok land use classifications: low-density residential areas, medium-density residential areas, high-density residential areas, commercial areas, industrial areas, warehouse areas, Thai art and cultural conservation areas, and government, institute, infrastructure areas. The 2 agricultural zoned areas were excluded from this study. Thus, the study assessed the urban forest in Bangkok that is most influenced by the urban population and built environment. These assessed areas comprise nearly $60 \%$ of the total land area of Bangkok (MOI, 2006a). Each category above has a proportional area of $30.93 \%, 12.09 \%, 7.89 \%, 3.72 \%, 0.84 \%, 0.15 \%, 0.34 \%$, and $2.09 \%$ of the 8 categories respectively of the total land area in Bangkok. The commercial, industrial, and warehouse categories were combined due to their relative similarity and small area.

During January and May 2013, urban forest attributes from the Bangkok study area were collected using a stratified random sample. A 184 sample plots of the entire study were chosen to achieve a standard error of about $14 \%$ of tree population (USDA Forest Service, 2011). Circular sample plots, 0.04 ha $(0.1$ acre), were proportionally distributed across the aforementioned landuse categories based on their respective areas (Table 1).

Table 1. Study area, percent, and number of sample plots stratified by land use classification.

\begin{tabular}{lccc}
\hline Land Use Classification & $\begin{array}{c}\text { Study Area } \\
\mathbf{( k m}^{\mathbf{2}} \mathbf{)}\end{array}$ & $\begin{array}{c}\text { Percent of } \\
\text { Study Area }\end{array}$ & $\begin{array}{c}\text { Number of } \\
\text { Plots }\end{array}$ \\
\hline Low Density Residential Area (LDR) & 485.23 & 52.51 & 97 \\
Medium Density Residential Area (MDR) & 189.64 & 20.52 & 42 \\
High Density Residential Area (HDR) & 123.83 & 13.40 & 24 \\
Commercial, Industrial, Warehouse Area (CIW) & 73.89 & 8.00 & 14 \\
Culture Conservation, Park, Golf Course (CPG) & 16.67 & 1.80 & 3 \\
Government, Stadium, Other Area (GSO) & 34.85 & 3.77 & 4 \\
\hline TOTALS & $\mathbf{9 2 4 . 1 1}$ & $\mathbf{1 0 0 . 0 0}$ & $\mathbf{1 8 4}$ \\
\hline
\end{tabular}


Plots within a land-use were randomly selected using ArcMap 10. In each sampling plot, the following data were collected: plot information, tree information, and shrub information. Plot information included plot number, plot address, date measured, crew, reference location photo, reference object, measurement unit, distance to reference object, direction to object, tree measurement point, the percentage of plot in each actual land use, $\%$ tree cover, $\%$ shrub cover, and $\%$ plantable space. Tree information included tree ID number, distance and direction from plot center to collected features, tree species, tree diameter (DBH at $1.30 \mathrm{~m}$ ), total tree height, height to crown base, crown width, percent canopy missing, percent dieback, crown light exposure, distance and direction to space-conditioned residential buildings, street tree, and tree status. Shrub information included the species, height, percent of shrub area, and percent of shrub mass missing.

\section{Analysis}

This study used i-Tree Eco V.5.0.6 to analyze and describe the Bangkok urban forest structure including tree abundance, species composition, tree density, leaf area and leaf biomass. The urban forest structure data was combined with additional data, including local weather data, hourly pollution, and an estimate of local leaf-on/leaf-off date. Bangkok air quality data (CO, $\mathrm{NO}_{2}, \mathrm{O}_{3}, \mathrm{PM}_{10}$, and $\mathrm{SO}_{2}$ ) from 2012 was supplied by the Pollution Control Department (PCD). Thailand has 17 monitoring stations; 10 monitoring stations in general areas and 7 monitoring station in road side areas, covering the Bangkok area. The pollution data from National Housing Stadium Huaykwang monitoring station was used as its location is in middle of the study area and provided the most complete pollution data among PCD's monitoring stations in Bangkok. Meteorological data were from the National Climatic Data Center for the 2012 base year. Then 
the data were analyzed to quantify the ecosystem function, including carbon storage and sequestration, air pollution removal and structure value in i-Tree Eco. Full methodologies are included in Nowak and Crane (2000) and Nowak et al. (2008).

Direct estimates for Bangkok were not included for the analysis of building energy use and subsequent avoided carbon emission because this component of i-Tree Eco is designed for U.S. building types, energy use, and emission factors which limited for the use in international applications (USDA Forest Service, 2011). Similarly, estimates of urban forest value for carbon storage and sequestration and for structural were not calculated through the International Version due to a lack of information needed to estimate those values. Estimates for the value of carbon storage, carbon sequestration, and structural value were estimated using, Miami, Florida USA as an indirect way to estimate values for Bangkok. Miami was selected for similarity in climate to Bangkok.

The i-Tree Eco model uses allometric equations from the literature to estimate carbon storage and sequestration in the study area based on field data. Above ground biomass was estimate using default equations in i-Tree Eco with total tree biomass derived using a root to shoot ratio of 0.26 . The biomass of tree dry weight was converted to the total carbon storage in the tree. Carbon sequestration was estimated using the standardized tree growth rates and adjusted by tree condition. The carbon sequestration rate was the result of carbon storage in year $\mathrm{X}+1$ minus the estimated carbon storage in year $\mathrm{X}$ (Nowak et al., 2008). The full methodologies are included in Nowak and Crane (2000a) and Nowak et al. (2008).

The i-Tree Eco used the function of dry deposition and pollution concentration to estimate the pollution removal by urban trees. Leaf area and leaf biomass of individual opengrown trees were calculated using default regression equations for deciduous urban species in i- 
Tree Eco. Leaf area index (LAI) was calculated using the tree and shrub information from the field inventory using the regression equation for the maximum plant size based on height-width ratio and shading coefficient class of the plant (Nowak et al., 2008). The pollution removal values were calculated based on the price of each pollutant in 2012 as \$53 USD per metric ton of $\mathrm{CO}$ (THB 1,592), \$374 USD per metric ton of $\mathrm{NO}_{2}$ (THB 11,207), \$374 USD per metric ton of $\mathrm{O}_{3}$ (THB 11,207), \$250 USD per metric ton of PM10 (THB 7,482), and \$92 USD per metric ton of $\mathrm{SO}_{2}$ (THB 2,744).

In this study the monetary value of carbon storage and carbon sequestration was estimated by multiplying carbon values by $\$ 22.8$ per metric ton of carbon (USDA Forest Service, 2011). Since the i-Tree Eco did not provide the component to estimate the structural value for international analysis for Bangkok, the structural value was estimated using the Council of Tree and Landscape Appraises (CTLA) formula methodology for Miami, U.S.. The dollar values presented in this study were converted from the Thai Baht using the Bank of Thailand typical conversion rate during the time of the study as $\$ 1 \mathrm{USD}=30 \mathrm{THB}$.

\section{Survey Crews Training and Data Quality Assurance}

Survey crews were upper classman forestry students from the Faculty of Forestry, Kasetsart University. Prior to data collection, students received instruction through lecture (4 hours) and field practice ( 8 hours). Training included plot establishment, data collection, survey information, plot information, reference objects, land use, ground cover, shrub cover, tree information, crown rating precautions, and final verification of collected data record keeping. Ten percent of the plots inventoried by students were randomly selected and rechecked by a field supervisor to verify that all trees on the plot were measured, tree species were identified 
Table 2. Data quality standard and checked result (adapted from i-Tree Eco manual Version 4).

\begin{tabular}{|c|c|c|}
\hline Variable & $\begin{array}{c}\text { Measurement Quality } \\
\text { Standard }\end{array}$ & Checked Result \\
\hline Land Use & $\begin{array}{l}\text { No errors, } 99 \% \text { of the } \\
\text { time }\end{array}$ & $100 \%$ correct \\
\hline \multicolumn{3}{|l|}{ Tree Count } \\
\hline$<25$ trees on plot & $\begin{array}{l}\text { No errors, } 90 \% \text { of the } \\
\text { time }\end{array}$ & $100 \%$ correct \\
\hline$\geq 25$ trees on plot & $\begin{array}{l}\text { Within } 3 \% \text { of total trees } \\
\text { count, } 99 \% \text { of the time }\end{array}$ & No rechecked plots had a tree $\geq 25$ \\
\hline Tree Species & $\begin{array}{l}\text { No errors, } 95 \% \text { of the } \\
\text { time }\end{array}$ & $100 \%$ correct \\
\hline \multicolumn{3}{|l|}{ DBH } \\
\hline Tree with $2.5-25 \mathrm{~cm}$ & $\begin{array}{l}\text { Within } 0.25 \mathrm{~cm}, 95 \% \text { of } \\
\text { the time }\end{array}$ & $\begin{array}{l}91 \% \text { of the tree DBH were within } 0.25 \\
\mathrm{~cm}\end{array}$ \\
\hline Tree with $>25 \mathrm{~cm}$ & $\begin{array}{l}\text { Within } 3 \%, 99 \% \text { of the } \\
\text { time }\end{array}$ & $100 \%$ of the $\mathrm{DBH}$ were within $3 \%$ \\
\hline Tree Total Height & $\begin{array}{l}\text { Within } 10 \%, 99 \% \text { of the } \\
\text { time }\end{array}$ & $100 \%$ of tree height were within $10 \%$ \\
\hline
\end{tabular}

correctly, and DBH, total tree height, and building interaction were within acceptable data measurement standards (Table 2). Measurement errors were corrected as encountered.

\section{RESULTS}

The urban forest inventory of Bangkok was conducted between January and May 2013 which coincided with the seasonal dormant period. A total of 184 plots located throughout the city were assessed for tree, shrub, and plot information. The crews included 3 people with an average of 5 sample plots per day collected per crew. In this assessment, $70 \%$ of the sampling plots were treeless. Of tree plots, an average 4 trees per plot were recorded. Tree abundance per plot ranged from $1-19$ trees, with $24 \%$ of those plots having only 1 tree. 
An estimated 2,504,000 (S.E. $=408,646)$ trees exist in the study area. Tree canopy cover was estimated at $8.6 \%$ in the study area with approximately 27 trees per hectare. The three most common tree species which contributed $34 \%$ of total tree population were Polyalthia longifolia Sonn (15.7\%), Mangifera indica L. (13.0\%), and Pithecellobium dulce (Roxb.) Benth (5.4\%). The remaining $56 \%$ of the total tree population included 45 tree species that individually each contributed less than $5 \%$ to the total population (Table 3). Species richness indexes were calculated with a 3.32 Shannon-Wiener diversity index and an 18.04 Simpson's diversity index resulting in the study area. Fig. 2 illustrates the diameter distribution of trees with in Bangkok. Nearly half of the trees $(48.3 \%)$ in this study were smaller than $15.3 \mathrm{~cm}$. The average tree DBH in this study was $14.6 \mathrm{~cm}$. The percent of trees that had a DBH $\geq 15.3 \mathrm{~cm}$ within each DBH class decreased as DBH class increased. Species that dominate as trees smaller than $15.2 \mathrm{~cm}$ DBH were P. longifolia (23.5\%), followed by Ficus benjamina L. (7.6\%), and Plumeria rubra L. (6.3\%). Species that dominate as larger trees $>15.3 \mathrm{~cm}$ were $M$. indica $(21.9 \%), P$. dulce $(9.6 \%)$, and P. longifolia (6.6\%). A majority of trees (approximately $70 \%$ ) were $<23 \mathrm{~cm}$ in diameter with nearly equally numbers of trees that were in the three smallest $[\leq 7.6 \mathrm{~cm}(24.4 \%), 7.7-15.2$ $\mathrm{cm}(23.9 \%)$ and $15.3-22.9 \mathrm{~cm}(21.5 \%)]$ diameter classes.

The tree species in Bangkok with the greatest importance value (IV) were P. dulce (26.0\%), M. indica (23.0\%), and P. longifolia (16.5\%) (Fig. 3). Particularly notable were Lagerstroemia speciosa (L.) Pers., Tabebuia rosea (Bertol.) DC. and Dypsis lutescens (H. Wendl.) Beentje \& Dransf. which although not in the top ten of species abundance (combined only accounting for $4 \%$ of the total tree abundance) were in the top ten of IV due to their percentage of leaf area and above average tree size. 
A total 48 tree species were identified and recorded in this study. The Bangkok urban forest is a mix of native species that existed prior to development and exotic species that were introduced by people or other means (Fig. 4). About $25 \%$ of species were native to Asia only or Asia and other neighboring continents (Asia, Asia \& Australia, and Africa \& Asia). Only 14\% of the trees were native to only Asia. Most identified species were exotic plants that originated from North and/or South America (40.1\%). Approximately 30\% of species were identified as unknown geographic origin.

Table 3. Key findings of 2013 Bangkok urban forest assessment.

\begin{tabular}{|c|c|}
\hline Feature & Measure \\
\hline Number of Trees & $2,504,000($ S.E. $=408,646)$ \\
\hline Tree Canopy Cover & $8.6 \%$ \\
\hline \multicolumn{2}{|c|}{ Most Dominant Species by } \\
\hline Tree Abundance & $\begin{array}{l}\text { Polyalthia longifolia, Mangifera indica, } \\
\text { Pithecellobium dulce, Radermachera spp, } \\
\text { Ficus benjamina }\end{array}$ \\
\hline Leaf Area & $\begin{array}{l}\text { Pithecellobium dulce, Mangifera indica, } \\
\text { Eugenia spp., Lagerstroemia speciosa, } \\
\text { Tabebuia rosea }\end{array}$ \\
\hline Tree $\mathrm{DBH} \leq 15.2 \mathrm{~cm}$ & $48.5 \%$ \\
\hline \multicolumn{2}{|l|}{ Pollution Removal } \\
\hline $\mathrm{PM}_{10}$ & 418 metric ton/year $(\$ 104,333 /$ year $)$ \\
\hline $\mathrm{NO}_{2}$ & 132 metric ton/year $(\$ 49,333 /$ year $)$ \\
\hline $\mathrm{O}_{3}$ & 128 metric ton/year $(\$ 47,667 /$ year $)$ \\
\hline $\mathrm{CO}$ & 37 metric ton/year $(\$ 1,667 /$ year $)$ \\
\hline $\mathrm{SO}_{2}$ & 28 metric ton/year $(\$ 2,667 /$ year $)$ \\
\hline Total & 738 metric ton/year $(\$ 205,667 /$ year $)$ \\
\hline Carbon Storage & 310,000 metric ton $(\$ 7,068,000)$ \\
\hline Carbon Sequestration & 16,300 metric ton/year $(\$ 371,640 /$ year $)$ \\
\hline Oxygen Production & 40,900 metric ton/year \\
\hline Rainfall Interception & $69,200 \mathrm{~m}^{3} /$ year \\
\hline Structure Value & $\$ 1.04$ billion \\
\hline
\end{tabular}


The impervious building, cement, and tar cover types that were from manmade development accounted for nearly half (47.2\%) of the ground cover in Bangkok (Table 4). Water was found on a tenth $(10.7 \%)$ of the surface in the study area. A total of $40.6 \%$ of the surface cover was herbs, bare soil, unmaintained grass, grass, and duff/mulch. The rest (1.5\%) was rock covered surface. The relatively high proportion of herbs recorded is likely due to natural plant growth on vacant spots which are scattered throughout Bangkok. Impervious surface area nearly doubled from $37.6 \%$ in LDR to $71.7 \%$ in HDR (Table 4). Building area was greatest in the GSO land type. Herbaceous ground cover was greatest in the CIW (33.7\%) and LDR (24.1\%) types. Grass was most common in the CIW (33.7\%) and LDR (24.1\%). In the LDR and MDR areas, $12.3 \%$ and $11.4 \%$ of the ground is bare soil and a potential area for green space. In contrast, in the HDR area little bare soil was detected and only covered $2.5 \%$ of the ground providing less space for potential tree planting locations.

The Bangkok study area was estimated to remove 738 metric tons/year (pollution removal density 0.008 metric ton/ha/year) of pollution (Fig. 5). Removal was greatest for $\mathrm{PM}_{10}$ with 418 metric tons/year. An approximate 130 metric tons for each of $\mathrm{NO}_{2}$ and $\mathrm{O}_{3}$ are removed annually. An estimated annual value of removed pollutants $\left(\mathrm{O}_{3}, \mathrm{CO}, \mathrm{NO}_{2}, \mathrm{PM}_{10}\right.$, and $\left.\mathrm{SO}_{2}\right)$ is about \$200,000 USD (6.17 million THB).

Seasonal pollution removal by the urban forest in Bangkok is shown in Fig. 6. The highest pollutant removal occurred in rainy months, as there is greater leaf area during this leafon period. The exception was for $\mathrm{PM}_{10}$ that has the highest removal in winter months. 


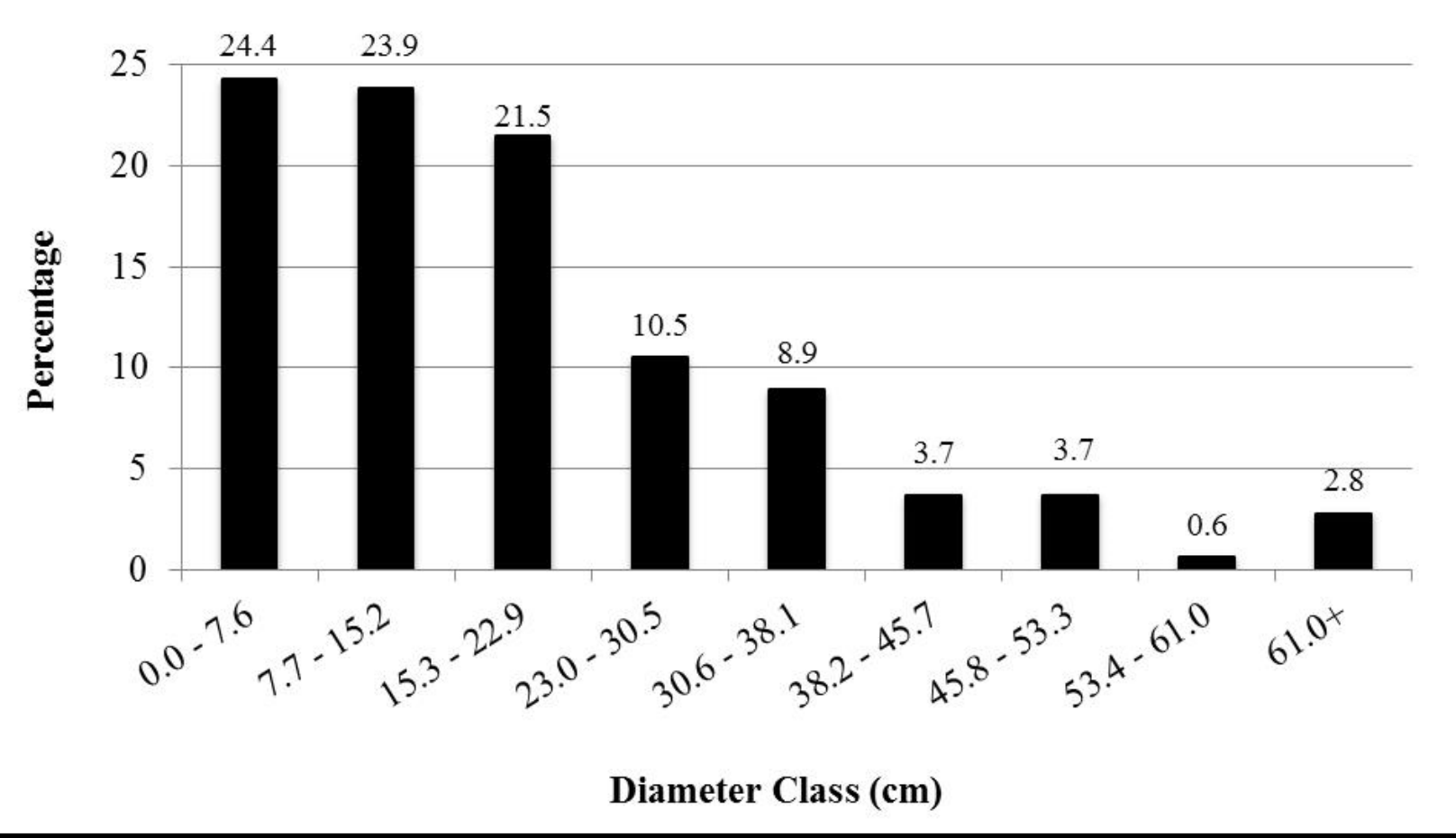

Fig. 2. Percent of tree population in Bangkok in 2013 by diameter class.

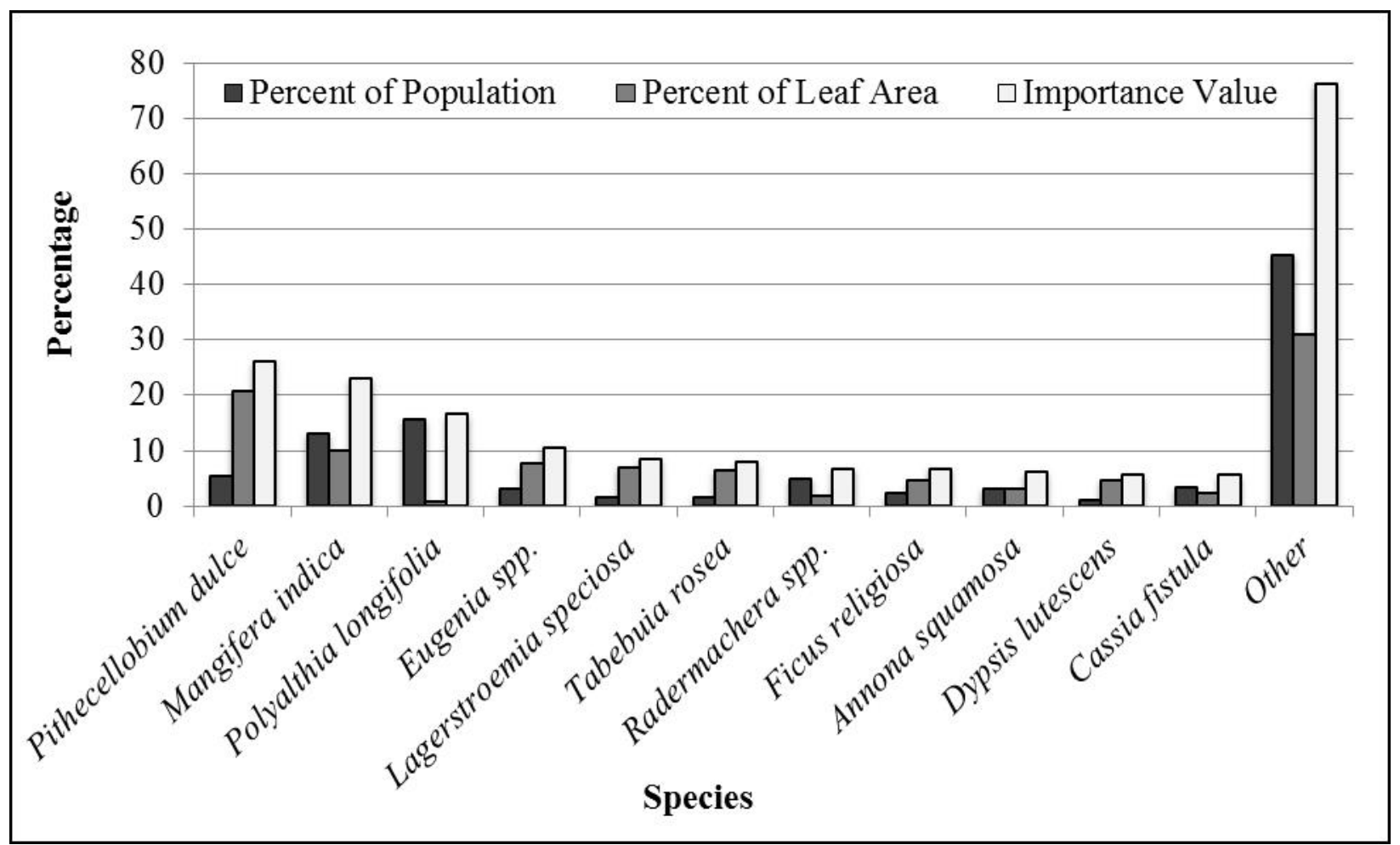

Fig. 3. Percent of tree species by population, leaf area, and importance value in Bangkok. 


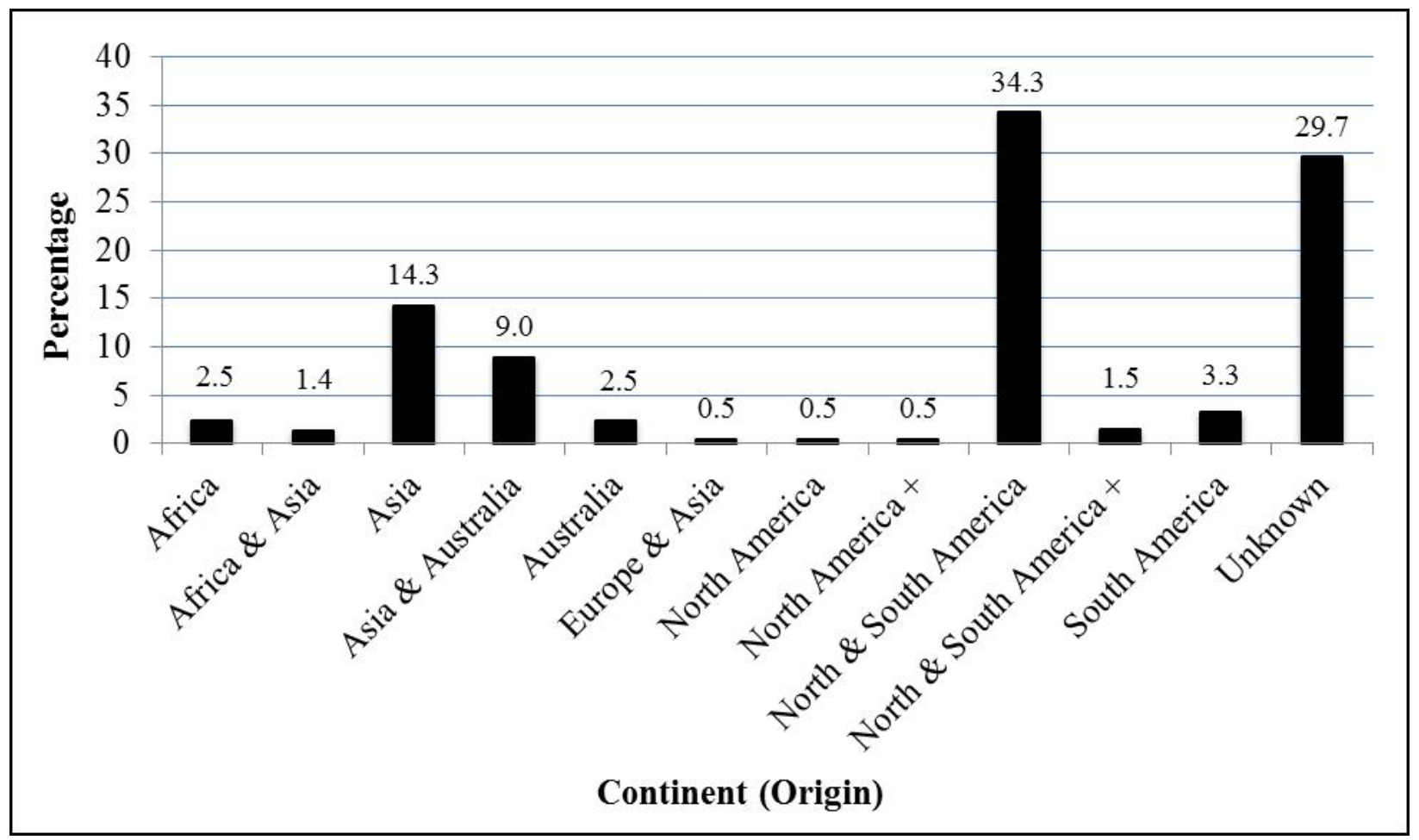

Fig. 4. Species origin of the Bangkok urban forest in 2013.

Table 4. Percent of ground cover type in Bangkok, 2013 by land use classification.

\begin{tabular}{lccccccc}
\hline & \multicolumn{7}{c}{ Percent of Ground Cover Type by Land Use Classification } \\
\cline { 2 - 8 } Cover Type & LDR & MDR & HDR & CIW & CPG & GSO & ALL \\
\hline Building & 14.0 & 26.8 & 39.0 & 19.3 & 0.0 & 50.0 & 21.5 \\
Cement & 18.3 & 22.3 & 29.2 & 20.9 & 0.0 & 31.3 & 20.9 \\
Tar & 5.3 & 3.9 & 3.5 & 8.9 & 0.0 & 0.0 & 4.8 \\
Rock & 1.1 & 1.7 & 2.1 & 3.6 & 1.7 & 0.0 & 1.5 \\
Bare soil & 12.3 & 11.4 & 2.5 & 7.4 & 0.0 & 0.0 & 9.7 \\
Duff/Mulch & 0.4 & 0.0 & 0.0 & 0.0 & 0.0 & 0.0 & 0.2 \\
Herbs & 24.1 & 17.3 & 4.0 & 33.7 & 0.0 & 0.0 & 19.4 \\
Grass & 4.7 & 1.9 & 2.5 & 0.7 & 31.7 & 18.8 & 4.5 \\
Unmaintained grass & 7.9 & 9.6 & 1.5 & 5.2 & 0.0 & 0.0 & 6.8 \\
Water & 11.9 & 5.1 & 15.8 & 0.4 & 66.7 & 0.0 & 10.7 \\
\hline
\end{tabular}

LDR: Low Density Residential

MDR: Medium Density Residential

HDR: High Density Residential

CIW: Commercial, Industrial, Warehouse

CPG: Culture, Park, Golf

GSO: Government, Stadium, Other

ALL: All Land Uses Combined 


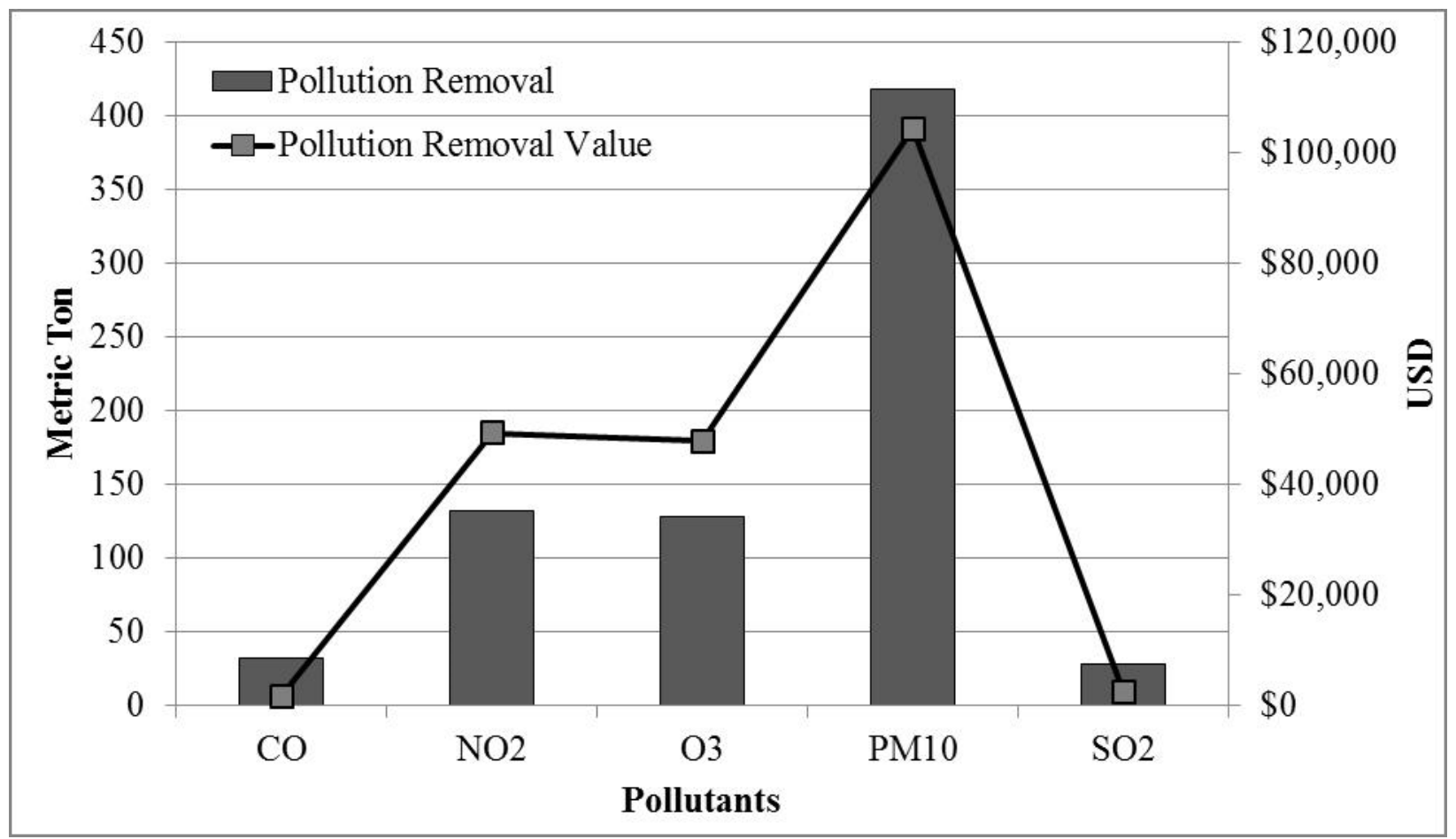

Fig.5. Annual pollution removal by volume and value.

An estimate of 309,700 metric tons or approximately 3.348 metric tons/ha of carbon was stored in the Bangkok urban forest. The gross annual carbon sequestration rate was about 16,000 metric tons/year or approximately $176 \mathrm{~kg} /$ year/ha. Net carbon sequestration is about 15,000 metric tons/year (Table 5). T. rosea, M. indica, and Samanea saman (Jacq.) Merr. were the three most important Bangkok urban trees in terms of carbon storage. Collectively, they accounted for $38.4 \%$ of overall $\mathrm{CO}_{2}$ storage. $M$. indica, P. longifolia, and T. rosea were the three most important Bangkok urban trees in terms of carbon sequestration, accounting for $36.5 \%$ of total $\mathrm{CO}_{2}$ sequestration annually (Table 5).

The estimate of total value of Bangkok urban forest in this study is $\$ 1.05$ billion. The pollution removal, carbon storage, and carbon sequestration of the Bangkok urban forest are $\$ 205,667, \$ 7,068,000$, and $\$ 371,640$ respectively (Table 3). The structure value of Bangkok urban forest value was estimated at \$1.04 billion based on Miami, USA (Table 3). 
Table 5. Number of trees, carbon storage and sequestration, leaf area and leaf biomass of the 10 most abundant tree species.

\begin{tabular}{|c|c|c|c|c|c|}
\hline \multirow[t]{2}{*}{ Species } & Number of Trees & ${ }^{1}$ Carbon $\left({ }^{2} \mathrm{mt}\right)$ & ${ }^{3}$ Net Seq $\left({ }^{2} \mathrm{mt} / \mathrm{yr}\right)$ & $\begin{array}{c}\text { Leaf Area } \\
\left(\mathrm{km}^{2}\right)\end{array}$ & $\begin{array}{c}\text { Leaf Biomass } \\
\left({ }^{2} \mathrm{mt}\right)\end{array}$ \\
\hline & Val ( $\left.{ }^{4} \mathrm{SE}\right)$ & Val ( $\left.{ }^{4} \mathrm{SE}\right)$ & Val ( $\left.{ }^{4} \mathrm{SE}\right)$ & Val ( $\left.{ }^{4} \mathrm{SE}\right)$ & Val ( $\left.{ }^{4} \mathrm{SE}\right)$ \\
\hline Polyalthia longifolia & $392,746(276,399)$ & $16,280(15,038)$ & $1,657(1,334)$ & $2(1)$ & $139(102)$ \\
\hline Mangifera indica & $326,598(92,251)$ & $42,240(13,245)$ & $2,802(816)$ & $22(7)$ & $1,637(525)$ \\
\hline Pithecellobium dulce & $135,218(76,842)$ & $24,359(14,131)$ & $926(541)$ & $45(36)$ & $3,382(2,711)$ \\
\hline Radermachera spp & $122,549(60,199)$ & $8,781(5,922)$ & $737(417)$ & $4(3)$ & $314(216)$ \\
\hline Ficus benjamina & $102,045(59,698)$ & $352(205)$ & $123(72)$ & $1(1)$ & $69(43)$ \\
\hline Plumeria rubra & $84,541(31,393)$ & $727(330)$ & $198(80)$ & $2(1)$ & $130(71)$ \\
\hline Cassia fistula & $83,160(42,311)$ & $9,934(6,078)$ & $498(251)$ & $5(3)$ & $1,276(704)$ \\
\hline Annona squamosa & $79,016(79,013)$ & $825(825)$ & $71(71)$ & $7(7)$ & 497 (497) \\
\hline Eugenia spp. & $75,646(35,508)$ & $18,199(11,857)$ & $637(318)$ & $17(14)$ & $1,242(1,084)$ \\
\hline Phyllanthus acidus & $74,265(30,120)$ & $736(416)$ & $174(85)$ & $1(0)$ & $42(21)$ \\
\hline Other & $1,028,215(796,330)$ & $187,267(163,629)$ & $7,533(6,070)$ & $114(102)$ & $10,736(9,817)$ \\
\hline TOTAL & $2,503,999(1,580,064)$ & $309,700(231,676)$ & $15,356(10,055)$ & $220(175)$ & $19,464(15,791)$ \\
\hline
\end{tabular}

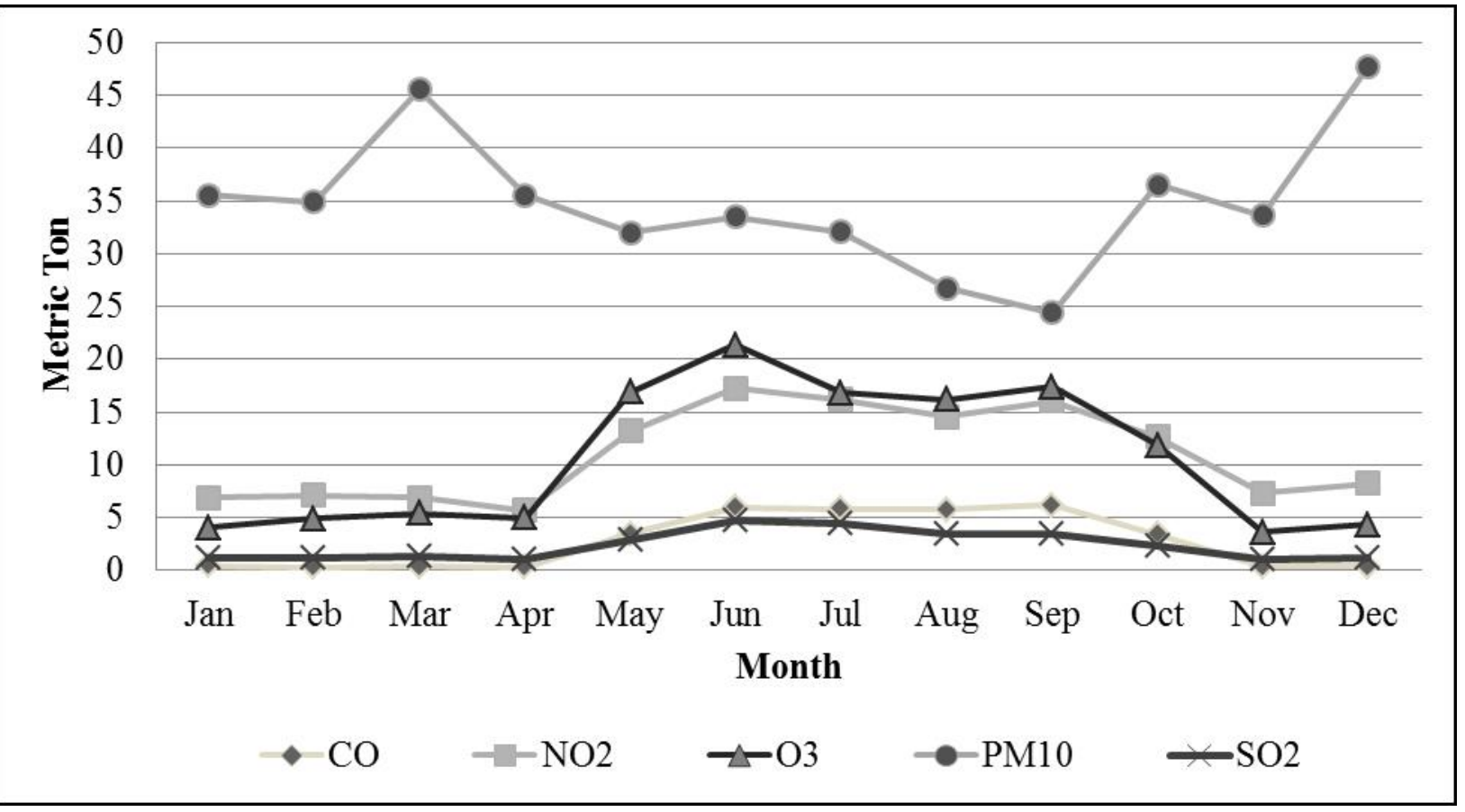

Fig. 6. Pollution removal by month for urban trees in Bangkok in 2013. 
Table 2 shows the data quality assurance results. A total 21 of 184 sample plots (11\%) were randomly rechecked. Land use, tree abundance, tree species, total tree height, and diameter measurements for trees $>25 \mathrm{~cm}$ were all within quality standards. Only tree diameter measurements for trees $\leq 25 \mathrm{~cm}$ exceeded data quality standards with $91 \%$ measured within 0.25 cm of the actual measurement.

\section{DISCUSSION}

An urban forest assessment in Bangkok, Thailand was conducted to study the structure, function, and value of the tree population. The results of this assessment combined with a previous street tree study in 2000 by Thaiutsa et al. (2008) provide an evaluation of the Bangkok tree population. Eighty-five percent of the tree species found in this study were also found in Thaiutsa et al., (2008). The 7 additional species were Barringtonia spp. (1\%), Diospyros spp. (1\%), Morus alba L. (1\%), Murraya spp. (1\%), Punica granatum L. (1\%), Combretum quadrangulare Wall (1\%), and Annona squamosa L. (3\%). These species were not used as street trees possibly due to their small size and/or fleshy fruits (Thaiutsa et al., 2000). Properties in residential areas (LDR, MDR, and HDR) with open space were found to commonly have fruit trees such as $M$. indica (13.0\%) and Eugenis spp (3.0\%). M. indica is easy to plant and maintain (Thaiutsa et al., 2000). M. indica was uncommon on streets and comprised only $0.18 \%$ of the street tree population (Thaiutsa et al. 2008). This might be due to the form of the crown and the risk to vehicles and pedestrians from falling fruit.

New housing complexes in LDR with limited open space are likely to have P. longifolia, a fast growing and low maintenance tree that is used to shade buildings, ameliorate noise pollution, block undesirable views, mark property boundaries, and fits well into a small growing 
space due to its upright columnar form (Thaiutsa et al., 2000). This species was the most common tree in Bangkok across all landscapes and Thaiutsa et al. (2008) found it as the $7^{\text {th }}$ most common street tree at $3.1 \%$ of the population. In the vacant areas, $P$. dulce were common as it tolerates drought conditions and competes well with other vegetation (Skerman and Fernado, 1977). All P. dulce in this study were found in vacant land areas. Thaiutsa et al. (2008) found Pterocarpus indicus Willd. as the most common street tree comprising $42 \%$ of the street tree population. In contrast, this species was uncommon outside of street tree plantings and comprised only $1.5 \%$ of the urban forest in this study. P. indicus was found as the most common street tree in Kuala, Malaysia comprising $34 \%$ of the tree population and was a favored tree due to ease of propagation and spreading crown (Sreetheran et al., 2011).

This study found approximately 2.5 million trees in Bangkok across the urban forest study area. Thaiutsa et al. (2008) found about 200,000 street trees. Thus, about $8 \%$ of trees in Bangkok are street trees. In comparison, a study in New York City found 11\% of the tree population was street trees (Peper et al., 2007). Approximately 10\% of trees were street trees in Chicago and these larger trees accounted for approximately $25 \%$ of the leaf area (McPherson et al., 1997). A more recent update to that seminal paper finds approximately $15 \%$ of the urban forest in Chicago are now street trees (Nowak et al., 2010). This follows nearly two decades of enhanced public parkway tree plantings and a $30 \%$ increase from 422,000 (1991) to 550,000 (2007) street trees. These results show how tree planting efforts on public lands can affect the percentage of street trees relative to the entire population is important. Promoting canopy coverage requires approaches to grow trees on private lands. The amount of land as street area is also an important part of planning for street trees. Bangkok street surface area covers $10 \%$ of the total land area. In comparison, New York City has 32\%, Chicago and Miami have 24\%, and Los 
Angeles has $14 \%$ of the total land area comprised by street surface area (Department of Environmental BMA; 2012, Manville and Shoup, 2005).

The Bangkok State of the Environment 2012 provides information and goals to overcome problems associated with air pollution, energy conservation, the preservation of plant genetics, increasing green areas for rest, and the preservation of existing green areas (Department of Environmental BMA, 2012). One of the five main strategies of BMA's master plan (2009-2020) is striving towards a green Bangkok. Public parks and street trees were identified as primary locations to promote greenspace based on Thaiutsa et al. (2008). This current study provides greenspace information for urban forests in the residential and vacant areas of Bangkok. The ground cover type information shows that Bangkok has about $40 \%$ potential plantable spaces to increase tree canopy cover. The majority of the plantable spaces are in LDR, MDR, and CIW. Development of a planting plan based on tree canopy coverage by location will facilitate the implementation of strategic tree planting (Locke et al., 2010).

One of the problems that BMA needs to solve is how to buy land from private owners to create public green area. Due to very expensive land prices in the dense areas and the rapid land use change in Bangkok, this will increase the difficultly to find such areas to create new public parks and green areas (Department of Environmental BMA, 2012). The land prices in LDR and MDR are about 10-70 times lower in comparison to the core of the city. The city center that includes business and high density residential areas has higher land prices that may sell for $\$ 7,000$ per $\mathrm{m}^{2}$ where as New York and Tokyo land price is about $\$ 25,000$ per $\mathrm{m}^{2}$ and $\$ 7,000$ per $\mathrm{m}^{2}$ respectively (Treasury Department, 2012; Haughwout et al., 2007; Global Property Guide, 2013). 
The estimated value of the urban forest in Bangkok from this study could provide the support information for decision making on budget planning and investment in urban tree management planning. The functional value using the default output for Thailand from i-Tree Eco are conservative as no estimate was calculated for energy conservation, carbon storage, and carbon sequestration value. In addition, urban forest structural value was not calculated in i-Tree Eco as a tree appraisal system has not been developed for Thailand. Estimates using a tree appraisal system (CTLA system) and carbon emission values based in a similar tropical climate of Miami, Florida U.S. were used to derive an initial estimate of these values. Thus, estimates from this approach should be interpreted with caution and serve as a first order approximation of the total urban forest value in Bangkok, Thailand.

Development of such a tree appraisal system and accounting for the tree health (condition) and tree species specific adjustments are needed research areas in Thailand to develop a potential tree appraisal approach (Grande-Ortiz et al. 2012). Energy conservation studies need to account for tree placement and its resulting effect on shading and a reduction in ambient air temperatures inside and outside of buildings. For example, Hall et al. (2012) investigated tree planting in a high-density residential area and found a tree canopy cover increase between $2.8 \%$ and $5.3 \%$ could reduce maximum surface temperatures by $0.5^{\circ} \mathrm{C}\left(0.9^{\circ} \mathrm{F}\right)$ to $2.3^{\circ} \mathrm{C}\left(0.9\right.$ to $\left.4.1^{\circ} \mathrm{F}\right)$. If those urban trees in Bangkok were located in Miami, Florida USA, the pollution removal value will increase by over two orders of magnitude from about 10 cents to $\$ 16.10$ per tree. The future study of pollution value removal by Bangkok urban trees is needed in order to reflect the real value that Bangkok urban trees provide on their function. Thus, additional tree valuation and energy conservation work in these areas would likely raise the actual annual functional value of the Bangkok urban forest from the initial estimates. 
The i-Tree Eco approach is a science based and peer-reviewed application which was designed to calculate urban forest structure, ecosystem service and values based on field data input and external data sources (e.g. weather data, pollution data, carbon emission value). The program was developed to standardize a protocol for collecting and analyzing data in urban forest area (USDA Forest Service, 2011). This is the first reported use in Thailand. The program used formulas for North American to estimate plant growth rate, biomass, shading coefficients, tree appraisal, and valuation. Future development, research, and information are needed to refine i-Tree Eco for use in study sites such as Thailand. The local improvement such as growth rates, biomass formulas, shading coefficients, building energy effects, and tree appraisal system are needed to enhance the results for more suitable to Thailand.

\section{CONCLUSION}

This first urban forest assessment project provides baseline information of urban forest structure, function, and value in Bangkok, Thailand. The structure of Bangkok urban forest was estimated based on field sampling. The function and value of the Bangkok urban forest was estimated using the i-Tree Eco species database. Limitations of assessing the complete value of Bangkok urban forest were encountered. Estimates based on U.S. tree valuation combined with findings from this study provide a $\$ 1.05$ billion value approximation of the Bangkok urban forest. In order to fully adapt the i-Tree Eco application to use in Thailand, further development and refinement of species coefficients for estimating functional values, developing a tree appraisal system for Bangkok, and integrating carbon storage and sequestration rates is recommended. 
The results of this study can lead to further development of urban forest management in Bangkok. The study serves as a model for other cities in Thailand. This study also serves as a starting point for future urban forestry research. Results from this study can raise public awareness, public participation and even add a greater attention of the urban forest for governmental agency, non-government organization, and private sector to understand the importance of urban forestry and its ecosystem service which contribute to a healthy urban environment.

\section{REFERENCES}

BMA, 2013a. Location and Topography of Bangkok. Bangkok Metropolitan Administration Data Center. Retrieved December ${ }^{\text {st }}$, 2013 From: http://203.155.220.230/info/NowBMA /frame.asp. Bangkok Metropolitan Administration. (In Thai)

BMA, 2013b. Bangkok Divide District Areas. Bangkok Metropolitan Administration Data Center. Retrieved December 1, 2013. From: http://203.155.220.230/info/divide/ frame.asp. Bangkok Metropolitan Administration. (In Thai)

Chulalongkorn University, 2010. Bangkok Standard City Planning. Bangkok: Chulalongkorn University Press. (In Thai)

Cullen, S., 2005. “Tree Appraisal: Chronology of North American Industry Guidance.” Journal of Arboriculture 31(4): 157-162.

Department of Environmental BMA, 2012. Bangkok State of Environment 2012. Department of Environmental; Bangkok Metropolitan Administration, Thailand.(In English and Thai)

Dwyer, J.F., Nowak, D.J., Noble, M.H., 2003. Sustaining urban forests. Journal of Arboriculture. 29: 49-55.

Golbal Property Guide, 2013. Japanese house prices rising strongly. Retrieved December $1^{\text {st }}$, 2013 From: http://www.globalpropertyguide.com/Asia/japan/Price-History.

Grande-Ortiz, M.A., Ayaga-Tellez, E., and Contato-Carol, M.L., 2012. Methods of Tree Appraisal: A Review of Their Features and Application Possibilities. Arboriculture \& Urban Forestry. 38(4): 130-140.

Grey, G.W., Deneke, F.J.,1986. Urban Forestry ( $2^{\text {nd }}$ ed.). New York: John Wiley and Son, Inc. 
Hall, J. M., J. F. Handley, \& A. R. Ennos, 2012. The Potential of Tree Planting to Climate-Proof High Density Residential Areas in Manchester, UK. Landscape and Urban Planning 104(3-4):410-417.

Haughwout, A., Orr, J., Bedoll, D., 2008. The Price of Land in the New York Metropolis Area. Federal Reserve Bank of New York 14(3), 7 pp.

Jim, C.Y., 2008. Multipurpose Census Methodology to Assess Urban Forest Structure in Hong Kong. Arboriculture \& Urban Forestry. 34(6): 366-378 p.

Koeser, A., Hauer, R., Norris, K., Krouse, R., 2013. Factors Influencing Long-term Street Tree Survival in Milwaukee, WI, USA. Urban Forestry \& Urban Greening. 12(4):562-568.

Locke, D.H., Grove, J.M., Lu, J.W.T., Troy, A., O’Neil-Dunne, J.P.M., and Beck, B.D., 2010. Prioritizing Preferable Locations for Increasing Urban Tree Canopy in New York City. City and the Environment, Vol.3 (2010), Iss.1, Art. 4.

McPherson E. G., Nowak, D., Heisler, G., Grimmond, S., Souch, C., Grant, R., Rowntree, R., 1997. Quantifying urban forest structure, function, and value: the Chicago Urban Forest Climate Project. Urban Ecosystems 1(1), 49-61.

Miller, R.W., 1997. Urban Forestry: Planning and Managing Urban Greenspaces ( $2^{\text {nd }}$ ed.). New Jersey: Prentice Hall.

Manville, M., and Shoup, D., 2005. Parking, People, and Cities. Urban Planning and Development: 4(233).

MOI, 2006a. Ministerial Regulation on the Bangkok Comprehensive Plan Implementation B.E.2549 (2006 A.D.). Ministerial Regulation Act, 2006, Ministry of Interior of the Kingdom of Thailand. (In Thai)

Nowak, D.J., 1996. Estimating Leaf Area and Leaf Biomass of Open-Grown Deciduous Urban Trees, Forest Science 42(4), 504-507.

Nowak, D.J., Crane, D.E., 2000.The Urban Forest Effects (UFORE) model: quantifying urban forest structure and functions. U.S. Dept. of Agriculture, Forest Service, North Central Forest Experiment Station, 714-720.

Nowak, D.J., Crane, D.E., Stevens C.J., Bond, J., 2008. A ground-based method of assessing urban forest structure and ecosystem services. Arboriculture and Urban Forestry. 34(6), 347-358.

Nowak, D.J., Hoehn, R.E. III, Crane, D,E., Bodine, A.R., Dwyer, J.F., Bonnewell, V., and Watson, G., 2012. Urban Trees and Forests of the Chicago Region. U.S. Department of Agriculture, Forest Service, Northern Research Station. 106 pp. 
Nowak, D.J., Hoehn, R.E. III, Crane, D,E., Stevens, J.C., Fisher, C.L., 2010. Assessing urban forest effects and values, Chicago's urban forest. U.S. Department of Agriculture, Forest Service, Northern Research Station. 27 pp.

NSO, 2012. Key Statistic of Thailand 2012. Retrieved December $1^{\text {st }}$, 2013. From: http://service.nso.go.th/nso/nsopublish/pubs/pubsfiles/Key55_T.pdf. National Statistical Office, Ministry of Information and Communication Technology. (In Thai)

NUFA, 2012. i-Tree Eco Australia 2012 workshops. National Urban Forest Alliance (NUFA).

Peper, P.J., McPherson, G.E., Simpson, J.R., Gardner, S.L., Vargas, K.E., Xiao, Q., 2007. New York City, New York Municipal Forest Resources Analysis. Center for Urban Forest Research, USDA Forest Service, Pacific Southwest Research Station.

Raupp, M.J., Cumming, A.B., and Raupp, E.C., 2006. Street tree diversity in eastern North America and its potential for tree loss to exotic borers. Arboriculture \& Urban Forestry. 32(6): 297-304.

Saunders, S.M., Dade, E., and Van Niel, K., 2011. An urban forest effects (UFORE) model study of the integrated effects of vegetation on local air pollution in the western suburbs of Perth, WA. $19^{\text {th }}$ International Congress on Modeling and Simulation, Perth, Australia, 1216 December 2011.7 pp.

SFB, 2012. Statistic of temperature at meteorology station, Bangkok: 2000-2012. Statistical Forecasting Bureau (SFB), National Statistical Office.(In Thai)

Skerman, P.J., ;Fernando, R., 1977. Tropical forage legumes. Food and Agriculture Organization of the United Nations, New York. 609 pp.

Sreetheran, M., Adnan, M., and Khairil Azuar, A.K., 2011. Street Tree Inventory and Tree Risk Assessment of Selected Major Roads in Kuala Lumpur, Malaysia. Arboriculture and Urban Forestry. 37(5), 226-235.

Thaiutsa, B., Jamroenprueksa, M., Pipatwattanakul, D., and Sookchaloem, D. 2000. Street Tree of Bangkok. Asksorn Siam Printing, Bangkok. 141 pp. (In English and Thai)

Thaiutsa, B., Puangchit, L., Kjelgren, R., Arunpraparut, W., 2008. Urban green space, street tree and heritage large tree assessment in Bangkok, Thailand, Urban Forestry and Urban Greening 7. 219-229.

Treasury Department, The, 2012. Land Price Estimate for Bangkok 2012-2015. Retrieved December $4^{\text {th }}$, 2013 From: http://www.treasury.go.th/ewt_news.php?nid=173. The Treasury Department, Ministry of Finance, Thailand. (In Thai)

Tyrväinen, L., Miettinen, A., 2000. Property Prices and Urban Forest Amenities. Journal of Environmental Economics and Management 39(2), 205-223. 
USDA Forest Service, 2011. i-Tree Eco User's Manual v.4.1.0. Retrieved December $1^{\text {st }}, 2013$ From:http://www.itreetools.org/resources/manuals/iTree\%20Eco\%20Users\%20Manual .pdf. United State Department of Agriculture, Forest Service.

Wolf, K. L., 2007. City Trees and Property Values. Arborist News. 16(4): 34-36. 


\section{CHAPTER 4}

\section{SUMMARY AND FUTURE IMPLICATIONS}

\section{Summary}

To achieve a scientifically based urban forest management plan, a comprehensive urban forest inventory is a good point to start with to gather basic urban tree information. This information will help to develop a plan based on current conditions and to develop a future

outcome. This thesis had two main objectives: to assess the urban forest in Bangkok, Thailand and to define the appropriateness of adapting the urban forest analysis tool i-Tree Eco in Thailand. In order to accomplish the goals of the study, a field inventory was conducted in Bangkok, Thailand in 2013. The collected urban forest structure was analyzed using i-Tree Eco V.5.0.6.

The urban forest information was collected through a stratified sampled and an estimate of the urban tree population was projected. The sample plots were randomly selected to proportionally represent the Bangkok urban forest by land area. This study shows many significant findings. There are more plantable spaces in lower and medium density residential areas than the city core. The tree species found in the city center and lower and medium density residential areas were slightly different. Trees in the city center areas tend to be older than low and medium density residential areas. In the low and medium density residential areas, Pithecellobium dulce species is common and has the greatest importance value. This species is mostly found in vacant areas which likely will result in these trees being removed when those areas are developed. The majority of trees are in a younger age class.

Trees in Bangkok provide the function of carbon storage and sequestration, pollution removal, oxygen production, building energy saving, and rainfall interception with an estimated 
$\$ 200,000$ annual value. Unfortunately, this study cannot estimate all values of the urban forest in Bangkok. A system to evaluate aesthetic tree values specific to the city does not exist. Energy conservation estimates were also not available as no data exists for Thailand to link trees to energy use. Only pollution removal values were estimated at this time through the i-Tree Eco International version 5. A first order approximation of these values were estimated through conducting an analysis through Miami, Florida which has a similar tropical climate. Future work is needed to refine i-Tree for use in Thailand.

The adaptation of i-Tree Eco to use in Thailand was appropriate with the limitations noted above. The stratified sampling technique worked well in this pilot project. Trained forestry students from Kasetsart University were able to easily implement the sampling system as directed. The analysis gave reasonable results. However, future refinement of species specific estimations of urban forest function should occur. This entails a future study to develop biometric relationships such as tree diameter and leaf area.

\section{Future Implications}

An important future implication of this study is the development and institutionalization of urban forest practices in Thailand. Integration with urban forest management and other related fields such as horticulture, landscape architecture, and public policy is needed. As a starting point this study demonstrated a method to conduct future urban forest assessments in Thailand. Basic urban tree information tells what you have as a good starting point to develop management plans from. Data quality standards as used in this study provide accuracy limits for baseline information for future planning and implementation. This study excluded the agriculture areas and conservation agriculture areas. Within these areas a mix of built environments was observed 
and these areas should be investigated to determine if they should be in an urban forest management plan. An approximate 50 to 100 sample plot in this land use type would complement the current study and identify trees in the entire Bangkok land area.

A tree appraisal system is needed to estimate the aesthetic tree value to further provide the monetary value to help develop policy decisions. There are many tree appraisal systems developed worldwide for study to adapt for use in Thailand. The application and appropriateness of each system should be evaluated for consideration if these tree appraisal approaches fit the character of Thailand.

An expectation beyond the objectives of this study is to create an urban forest management plan for Bangkok based on the urban forest assessment from this study. Implementing those plans is a next step along with evaluating the outcomes of implemented actions. Moreover, using the information from this study to educate people should enhance an understanding of urban forestry.

The success of this study can lead to its use in other cities in Thailand. As a developing country, many cities in Thailand are in a building phase. The sooner that urban greening principles are implemented through urban forest management practices into those cities, the more likely that urban green spaces will become a societal benefit that provides for a healthy community and population. 


\section{APPENDIX A - Tree Species}

Table A - 1. Tree species identified in a 2013 urban forest assessment in Bangkok, Thailand.

\begin{tabular}{|c|c|c|c|c|}
\hline Number & Species & $\begin{array}{l}\text { Percent of } \\
\text { population }\end{array}$ & $\begin{array}{l}\text { Percent of } \\
\text { Leaf Area }\end{array}$ & $\begin{array}{c}\text { Importance } \\
\text { Value }\end{array}$ \\
\hline 1 & Pithecellobium dulce & 5.4 & 20.7 & 26.1 \\
\hline 2 & Mangifera indica & 13.0 & 10.0 & 23.1 \\
\hline 3 & Eugenia spp. & 3.0 & 7.6 & 10.6 \\
\hline 4 & Lagerstroemia speciosa & 1.5 & 7.0 & 8.6 \\
\hline 5 & Tabebuia rosea & 1.5 & 6.5 & 7.9 \\
\hline 6 & Dypsis lutescens & 1.0 & 4.6 & 5.6 \\
\hline 7 & Ficus religiosa & 2.2 & 4.5 & 6.8 \\
\hline 8 & Terminalia catappa & 1.1 & 3.8 & 4.9 \\
\hline 9 & Samanea saman & 0.5 & 3.1 & 3.5 \\
\hline 10 & Annona squamosa* & 3.2 & 3.0 & 6.2 \\
\hline 11 & Acacia auriculaeformis & 2.5 & 2.6 & 5.1 \\
\hline 12 & Tamarindus indica & 1.4 & 2.5 & 3.9 \\
\hline 13 & Artocarpus heterophyllus & 2.0 & 2.4 & 4.4 \\
\hline 14 & Cassia fistula & 3.3 & 2.2 & 5.6 \\
\hline 15 & Combretum quadrangulare* & 0.5 & 2.1 & 2.6 \\
\hline 16 & Radermachera spp. & 4.9 & 1.9 & 6.8 \\
\hline 17 & Alstonia scholaris & 1.5 & 1.6 & 3.1 \\
\hline 18 & Swietenia spp. & 2.5 & 1.5 & 4.0 \\
\hline 19 & Sesbania grandiflora & 2.5 & 1.2 & 3.7 \\
\hline 20 & Terminalia ivorensis & 1.0 & 1.0 & 1.9 \\
\hline 21 & Polyalthia longifolia & 15.7 & 0.9 & 16.5 \\
\hline 22 & Leucaena leucocephala & 1.9 & 0.8 & 2.7 \\
\hline 23 & Plumeria rubra & 3.4 & 0.8 & 4.2 \\
\hline 24 & Araucaria heterophylla & 0.5 & 0.8 & 1.3 \\
\hline 25 & Psidium guajava & 0.5 & 0.8 & 1.3 \\
\hline 26 & Delonix regia & 1.5 & 0.7 & 2.2 \\
\hline 27 & Annona spp. & 1.5 & 0.6 & 2.1 \\
\hline 28 & Erythrina spp. & 0.5 & 0.6 & 1.1 \\
\hline 29 & Pterocarpus indicus & 1.5 & 0.5 & 2.1 \\
\hline 30 & Ziziphus mauritiana & 0.5 & 0.4 & 1.0 \\
\hline 31 & Ficus benjamina & 4.1 & 0.4 & 4.5 \\
\hline 32 & Moringa oleifera & 0.5 & 0.4 & 0.9 \\
\hline 33 & Michelia spp. & 1.5 & 0.3 & 1.7 \\
\hline 34 & Carmona retusa & 0.5 & 0.3 & 0.8 \\
\hline 35 & Citrus spp. & 1.0 & 0.3 & 1.2 \\
\hline
\end{tabular}


Table A - 1. (cont.)

\begin{tabular}{clccc}
\hline \multirow{2}{*}{ Number } & \multicolumn{1}{c}{ Species } & $\begin{array}{c}\text { Percent of } \\
\text { population }\end{array}$ & $\begin{array}{c}\text { Percent of } \\
\text { Leaf Area }\end{array}$ & $\begin{array}{c}\text { Important } \\
\text { Value }\end{array}$ \\
\hline 36 & Phyllanthus acidus & 3.0 & 0.3 & 3.2 \\
37 & Muntingia calabura & 0.5 & 0.3 & 0.8 \\
38 & Ficus racemosa & 0.5 & 0.2 & 0.7 \\
39 & Streblus spp. & 1.1 & 0.2 & 1.2 \\
40 & Morinda citrifolia & 1.4 & 0.1 & 1.6 \\
41 & Barringtonia spp. & 0.5 & 0.1 & 0.6 \\
42 & Punica granatum* & 0.5 & 0.1 & 0.7 \\
43 & Murraya spp. & 0.5 & 0.1 & 0.6 \\
44 & Morus alba* & 0.5 & 0.1 & 0.6 \\
45 & Mimusops elengi & 0.5 & 0.1 & 0.6 \\
46 & Diospyros spp. & & 0.0 & 0.5 \\
47 & Syzygium cumini & 0.5 & 0.0 & 0.5 \\
48 & Diospyros ebenum & 0.5 & 0.0 & 0.5 \\
\hline
\end{tabular}




\section{APPENDIX B - Information Submitted for Analysis}

Table B - 1. Information Submitted for Analysis.

\begin{tabular}{ll}
\hline \multicolumn{1}{c}{ Request Information } & Information Submitted \\
\hline Continent Name & Asia \\
Nation Name & Thailand \\
Nation Abbrev & THA \\
Main Primary Partition Type & Province \\
Main Secondary Partition Type & District \\
Main Tertiary Partition Type & Sub-District \\
Currency Name & Baht \\
Climate Region Name & Southeast \\
National Elect Emissions (kgCO $\left.{ }_{2} / \mathrm{KWh}\right)$ & 0.541 \\
Cost Of Electricity (Baht) & 3.9361 \\
Cost Of Fuels (Baht/ MBTU) & 0.42 \\
Year Of Costs & 2012 \\
Carbon Value Factor (metric tonnes per Baht) & 537,600 \\
Latitude & 660374 \\
Longitude & 1520571 \\
National Mean Min & $69.4 \mathrm{~F}$ \\
National Leaf Off Days of Year & $15-\mathrm{Oct}$ \\
National Leaf On Days of Year & $15-\mathrm{May}$ \\
National Elevation & 1.50 meter \\
National GMT Offset & 7 \\
Ozone State & FL \\
Ozone ID & 1200 \\
\hline
\end{tabular}




\section{APPENDIX C- Sample Technique*}

*Adapt from i-Tree Eco manual V.4

\section{Collecting Data}

With the plot center, plot boundaries, and if necessary, a TMP, determined, you are ready to begin data collection. In the following sections, each data field is described in detail along with information on how to enter data on paper forms or using the PDA.

\section{Survey information}

Date: Optional. Date of data collection.

Paper (sample and complete): Enter under DATE.

Crew: Optional. Name or number of crew conducting inventory.

Paper (sample and complete): Enter under CREW.

\section{Plot information}

Plot ID: Required for sample inventories. Plot ID must be a unique identifier.

Paper (sample): Enter a unique number under PLOT ID at the top of both pages

Plot address: Required for permanent plots. Street address and any notes for locating plots in areas without street addresses.

Paper (sample): Enter under Plot address.

PS Coordinates: Optional. GPS coordinates help if revisiting the site is necessary, although GPS accuracy can vary greatly, especially under trees.

Paper (sample): Record latitude and longitude under GPS COORDINATION.

Photo: Optional. Use this to keep track of photo and memory card number if photos are taken.

Paper (sample and complete): Record under PHOTO ID.

Plot sketch: Optional. Draw a sketch of plot. Note distance and direction from plot center to fixed objects; sketch fixed objects in relation to plot center.

Paper (sample): Sketch in empty space 
Plot contact info: Optional. If available, record contact person's name and phone number. For residential land uses, do not ask for this information, but if name is on mailbox, house number record it.

Paper (sample): Record name and phone number under Plot contact info.

Percent measured: Required for sample inventories. The amount of the plot that the field crew is able to access and measure, either directly or by estimation. This allows for data collection for a partial plot. For example, if $10 \%$ of the plot is obscured from view behind a building or a tall stockade fence on land that you could not get permission to access, you would record $90 \%$. (Safety concerns may also be a factor in accessing portions of the plot.) However, if you were able to look over a fence and estimate tree, shrub and ground covers and estimate DBH and other measurements for trees present on plot behind the fence, you would record $100 \%$.

Paper (sample): Record under Percent measured.

Tree cover: Required for sample inventories. The amount of the plot covered by tree canopy (in percent). You can imagine this as the area of the plot that would be shaded by trees when the sun is directly overhead, ranging from 0 to $100 \%$. Tree cover can come from trees located outside the plot, so plots not containing trees can have tree cover. [HINT: Aerial images used as plot maps can be very helpful for determining tree cover percentages.] Record $0 \%, 100 \%$, or mid-points of $5 \%$ intervals $(3,8,13,18$, etc. $)$.

Paper (sample): Enter under PLOT TREE COVER (\%).

Shrub cover: Required for sample inventories. The amount of the plot covered by shrub canopy (in percent). You can imagine this as the area of the plot that would be shaded by shrubs when the sun is directly overhead, ranging from 0 to $100 \%$. Don't double-count multiple layers of shrubs. Record $0 \%, 100 \%$, or mid-points of $5 \%$ intervals $(3,8,13,18 \ldots)$.

\section{Paper (sample): Enter under SHRUB COVER (\%).}

Plantable space: Optional. If you decided during Phase I: Getting Started: Early Decisions to measure the plantable space, estimate the amount of the plot area that is plantable for trees [i.e., plantable soil that is not under tree canopy or other overhead restrictions and where tree planting/establishment would not be prohibited due to land use (e.g., footpath, baseball field, etc.)]. Planting underneath utility wires is permitted. Record $0 \%, 100 \%$, or mid-points of $5 \%$ intervals $(3,8,13,18$, etc.). [HINT: A more accurate measurement can be obtained by using the sum of the following ground covers (collected below) as a starting point to evaluate plantable space: soil, duff/mulch, herb/ivy, maintained grass and unmaintained grass.] As the definition for plantable space is somewhat subjective, project managers should make an effort to clearly define what counts as plantable space during crew training.

Paper (sample): Enter under PLANTABLE SPACE (\%). 


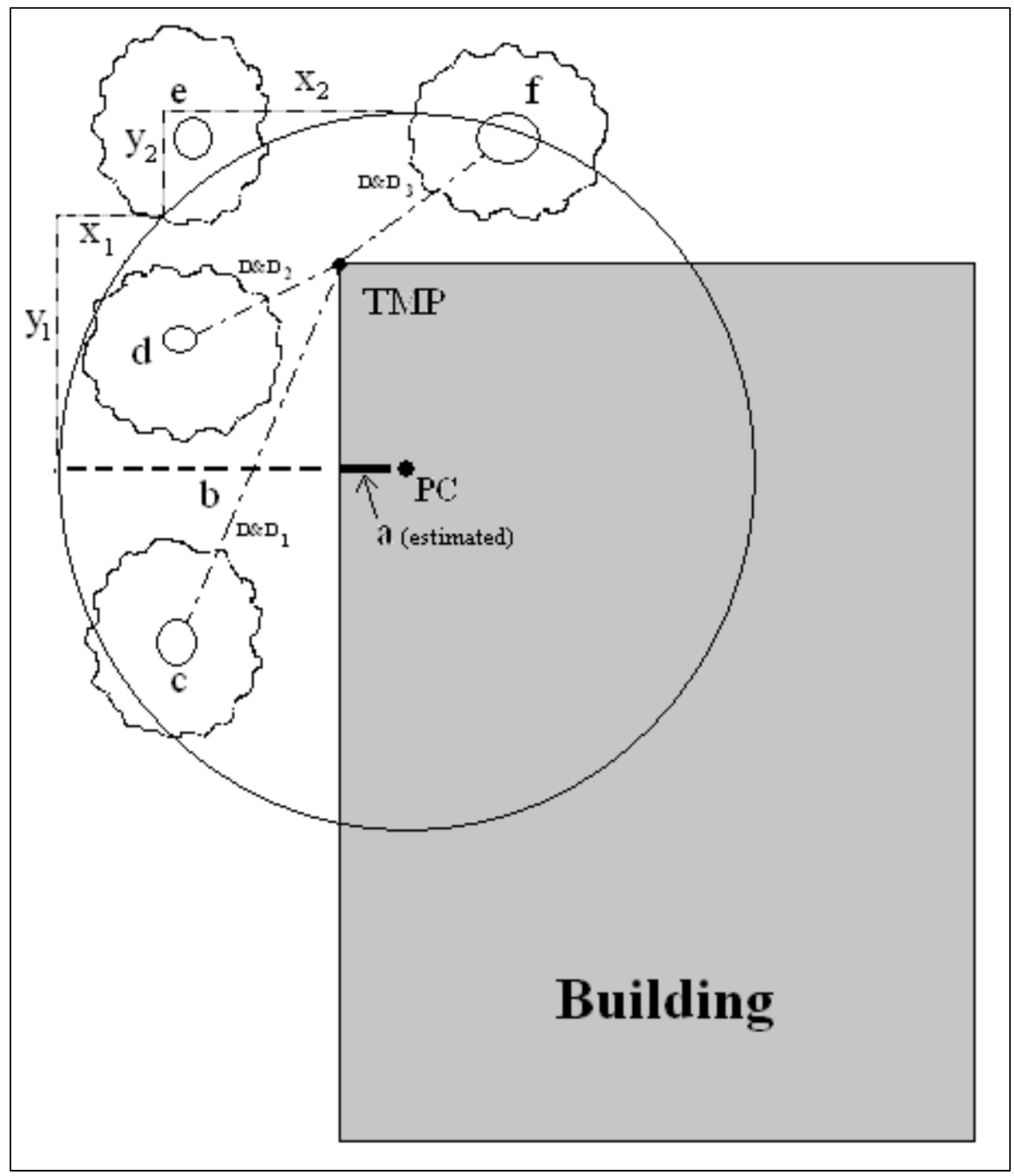

Fig. C-1. Determining a Tree Measurement Point and plot boundaries

\section{Reference objects}

Required for sample inventories. Identify at least one landmark visible when standing at plot center. Permanent plots require two, and two are recommended in all cases where the plot 
center is difficult to locate or identify. Reference objects do not have to be located within the plot. If you selected a TMP earlier because your plot center was inaccessible, it should be used as one of your reference objects.

Try to use objects that are likely to be present 5 to 15 years from now (e.g., stop signs, telephone poles, permanent structures, sidewalks/driveways). If the plot falls in a forested area and there are no man-made or permanent objects within sight, select two unique or "witness" trees (striking species or large $\mathrm{DBH}$ ) that you expect to be present on the plot in the future. Photo(s) of reference objects are helpful. Describe the reference object very specifically (e.g., telephone pole $5 \mathrm{ft}$ from left edge of driveway, when facing the house). Measure the distance and direction $\left(1^{\circ}-360^{\circ}\right)$ to each reference object from the plot center.

Paper (sample): Record the description, direction, and distance for one or two reference objects.

Tree Measurement Point (TMP): If the plot center was inaccessible, you should select one of your reference points to serve as TMP.

Paper (sample): Circle $\mathbf{Y}$ or $\mathbf{N}$ under Tree Measurement Point to identify a Reference Object as a TMP.

\section{Land use}

Actual land use: Required for sample inventories. Land use should be determined by the inventory team based on impressions out in the field (i.e., not from land use maps). This field describes how the land is being used, which is not necessarily the same as the ownership of the land.

NOTE: Eco uses these values to make adjustments to the model based on the differences in tree growth and valuation characteristics associated with predefined actual land uses. For example, a tree located in a Transportation plot will grow at a different rate than a similar tree that is located within a Golf Course or Residential plot. The actual land use categories can not be modified and are not used to stratify your study. Therefore, you will not receive a comparison of your project data based on the actual land use fields. Remember, you can use the Manage Map Land Use option to stratify your study.

The following land use types are included:

Residential (R): Freestanding structures serving one to four families each.

Multi-family residential $(M)$ : Structures containing more than four residential units.

[Note: A block of attached one- to four-family structures would be considered multifamily residential. A residential complex consisting of many separate one- to four-family structures and related greenspace would be also considered multifamily residential.]

Commercial/Industrial (C): In addition to standard commercial and industrial land uses, this category includes outdoor storage/staging areas as well as parking lots in downtown areas that are not connected with an institutional or residential use.

Park (P): Parks include undeveloped (unmaintained) as well as developed areas. 
Cemetery $(E)$ : Includes any small unmaintained areas within cemetery grounds.

Golf Course (G): Self-explanatory.

Agriculture (A): Cropland, pasture, orchards, vineyards, nurseries, farmsteads and related buildings, feed lots, rangeland, timberland/plantations that show evidence of management activity for a specific crop or tree production are included.

Vacant (V): This category includes land with no clear intended use. Abandoned buildings and vacant structures should be classified based on their original intended use.

Institutional (I): Schools, hospitals/medical complexes, colleges, religious buildings, government buildings, etc.

[Note: If a parcel contains large unmaintained areas, possibly for expansion or other reasons, treat the area as Vacant. However, small forested islands in a maintained landscape would be considered Institutional.]

Utility (U): Power-generating facilities, sewage treatment facilities, covered and uncovered reservoirs, and empty storm water runoff retention areas, flood control channels, conduits.

Water/wetland (W): Streams, rivers, lakes, and other water bodies (natural or man-made). Small pools and fountains should be classified based on the adjacent land use.

Transportation (T): Includes limited access roadways and related green spaces (such as interstate highways with on and off ramps, sometimes fenced); railroad stations, tracks and yards; shipyards; airports; etc. If plot falls on any other type of road, or associated median strip, classify according to nearest adjacent land use.

Other (O): Land uses that do not fall into one of the categories listed above. This designation should be used very sparingly as it provides very little useful information for the model. Clarify with comments in Notes.

[NOTE: For mixed-use buildings, land use is based on the dominant use, i.e., the use that receives the majority of the foot traffic. It might not always occupy the majority of space in the building. For example, a building with commercial use of the first floor and apartments on upper floors would be classified as Commercial/Industrial.]

Paper (sample): Enter codes for up to four land use types under ACTUAL LAND USE.

\section{Percent in each land use:}

Required for sample inventories. For plots that include only one land use, this value is $100 \%$. For plots that include two or more land uses, estimate what percentage of the plot each land use occupies. For example, a plot that falls on the property line between a house and a convenience store might be $40 \%$ residential and $60 \%$ commercial/industrial. Land use differences must be clearly identifiable on the plot with a clear change in human use of the land, not just its cover or ownership.

Paper (sample): Enter the percent for each land use type under PERCENT IN. 


\section{Ground cover}

Required for sample inventories. Within the plot, various materials will cover the ground (trees and shrubs are considered separately; tree stems as a ground cover are ignored). The crew should note the percentage of the plot ground area that is covered by the following materials:

Building $(\% B L D G)$

Cement (\%CMNT)

Tar (\%TAR): Blacktop/asphalt

Rock (\%ROCK): Pervious rock surfaces such as gravel, brick, or flagstone walkways or patios (without mortar). This category includes sand in playgrounds or added as topping to existing soil. Large solid rock outcrops should be listed as cement.

Bare soil (\%SOIL): Includes naturally occurring sand.

Duff/mulch (\%DUFF/MULCH): Loose organic material, leaf litter.

Herbs (\%HERB/IVY): Herbaceous ground cover, other than grass, including agricultural crops.

Grass (\%MAIN.GRASS)

Unmaintained grass (\%UNMAIN.GRASS)

Water (\%H20): Includes pools.

\section{Shrub information}

Optional for sample inventories; not available for complete inventories. You should complete this section if you decided to collect information on shrubs during the Phase I: Getting Started: Early Decisions.

For sample inventories, during Plot Information data collection, you were required to enter the percentage of the plot that was covered by shrubs. This phase focuses just on that area. For inventory purposes, shrubs should be grouped into masses of the same species and approximate height. For instance, if your plot includes five azaleas of similar heights in different areas, you can group them together and enter them as one group. A tree with $\mathrm{DBH}<1$ inch is considered a shrub. Record a maximum of twelve shrub groups. If there are more than twelve, record measurements for the first eleven, then lump the remaining shrubs into the twelfth group.

Paper (sample): For each shrub group, enter data for the four fields below under the SHRUB heading.

Shrub species: Identify the shrub species. If this is not possible, the plant must be identified by its genus at a minimum; if genus is not known, then collect a sample for identification.

Paper (sample): Enter species name or species code under SHRUBS > SPECIES. Visit the i-Tree website,www.itreetools.org $>$ Resources, for PDF and Excel spreadsheet of species code list. 
Shrub height: Measure the height of the shrub group to the nearest $0.1 \mathrm{ft} / \mathrm{m}$. Height of shrub groups of a particular species will likely differ across the plot. An average height may be used and different shrub masses grouped together where variation in height is relatively small.

Paper (sample): Enter under SHRUBS > HEIGHT.

Percent of total shrub area: Measure the percent of the total shrub area (i.e., not the total plot area) represented by this species/height combination. The total for all the shrub groups recorded on the plot must equal $100 \%$. Where there are two or more layers of different shrub species, record the percent area of the entire tallest shrub mass, but only the area of the shorter shrub mass that is not shaded (overtopped) by the taller shrub, i.e., visualize the area of the shrub masses from a birds-eye view, and report the percent of the shrub masses as seen from above.

Paper (sample): Enter under SHRUBS > \% AREA.

Percent of the shrub mass that is missing: Visualize the shrub mass of this species/height group as a volume (height $\mathrm{x}$ ground area) and record the percent of the volume that is missing, i.e., not occupied by leaves. The shrub mass leaves are assumed to start at the ground. The intent of this variable is to adjust height and area measurements to reveal actual volume of leaves and to allow you to account for voids in vegetation and inaccuracies in simple height $\mathrm{x}$ area estimates (e.g., height of mass might not be uniform). Allow for natural arrangement or spacing of leaves; however, you should investigate the interior of the shrub mass to better estimate the missing portions. In the past, crews have underestimated the mass missing by not accounting for the interior.

Percent Missing should be recorded as $0 \%$ or as mid-points of $5 \%$ intervals $(3,8,13$, etc.).

Paper (sample): Enter under SHRUBS > \% MISSING.

\section{Tree information}

Data collection for living and dead trees starts with the tree farthest to the north and proceeds in a clockwise direction. If your plot center is inaccessible and you have designated a TMP (see Inaccessible Plot Centers for more information), use it for measuring distance and direction, but remember that the plot itself does not shift to have the TMP as the center-only measure trees within the true plot boundaries based on the true plot center. All trees with $\mathrm{DBH} \geq 1$ inch should be recorded if at least half of their trunk lies within the plot.

NOTE: What is a tree? At different stages of its life, a tree can be classified as ground cover, shrub, or tree in the Eco model. The following excerpt is adapted from the journal article "A Ground-Based Method of Assessing Urban Forest Structure and Ecosystem Services" (available at www.itreetools.org under Resources $>$ Archives) and may help Eco users distinguish between available field options. 
Typically, shrubs are defined as woody material with a dbh less than $2.54 \mathrm{~cm}(1 \mathrm{in})$, whereas trees have a dbh greater than or equal to $2.54 \mathrm{~cm}(1 \mathrm{in})$. Woody plants that are not 30.5 $\mathrm{cm}$ (12 in) in height (e.g., seedlings) are considered herbaceous cover.

Trees and shrubs can also be differentiated by species (i.e., certain species are always trees or always shrubs) or with a different dbh minimum threshold. For example, in densely forested areas, increasing the minimum dbh to $12.7 \mathrm{~cm}(5 \mathrm{in})$ can substantially reduce the field work by decreasing the number of trees measured, but less information on trees will be attained.

Tree ID: Required. Each tree in a plot requires a unique ID.

Paper (sample and complete): Enter under TREE ID. Begin with 1 and assign sequentially.

Direction from plot center: Required. Direction from plot center to the tree in compass degrees/azimuths (e.g., north $=360^{\circ}$; east $=90^{\circ}$; south $=180^{\circ}$ ). If plot center is inaccessible, measure direction from TMP. Make sure that TMP info is recorded in Reference Object sections of paper forms or on PDA.

Paper (sample): Enter azimuth in degrees under DR.

Distance to plot center: Required. Shortest distance (in $\mathrm{ft}$ or $\mathrm{m}$ ) from plot center to edge of trunk at DBH, measured parallel to the ground. In heavily wooded plots, accuracy is critical to allow trees to be found in the future. If plot center is inaccessible, measure distance from TMP.

Paper (sample): Enter shortest distance to tree under DS.

Land Use: Required for sample inventories. Record the land use in which the tree is located.

Paper (sample and complete): Use land use codes defined above and enter under LAND USE.

Species: Required. If the species cannot be identified, take and number a sample, record in notebook as Plot \# XXX unknown \#1, etc. If using PDA, record as UNKN\#1, UNKN\#2, etc. Each time that same unknown is encountered on the plot, it should be recorded with the same number. Sequentially number unknowns in notebook and attempt to identify later. After samples have been identified at the office, go back and enter correct species code on paper form or in PDA. If after all references guides have been checked and identification of individual species is still difficult (e.g., due to hybridization), then record genus if possible. For dead trees, when species or genus cannot be determined, record as Dead tree unknown hardwood or Dead tree unknown softwood.

Paper (sample and complete): Enter under TREE SPECIES. If you wish to use species codes, you'll find a PDF and an Excel spreadsheet of the species code list on the i-Tree website, www.itreetools.org under Resources. 
Tree site: Optional. Record whether tree is a street tree or not (S or N).

Paper (sample and complete): Enter $\mathbf{S}$ or $\mathbf{N}$ under TREE SITE.

Status: The eight possible statuses of a tree are shown below. In an initial inventory of a project area, all trees will be identified as Planted (P), Ingrowth (I), or Unknown (U). In future inventories of the same plot, new trees will be identified as P, I, or U. Trees that were present during a previous inventory should be identified with the other status codes.

During initial inventories or when inventorying new trees in subsequent inventories, please make a concerted effort to determine whether trees have been planted [(P) Planted] or have self-seeded [(I) Ingrowth] as that information will be more valuable for future reporting and enhancements of the Eco model. Although it is not recommended, you can choose (U) Unknown if you are unable to establish whether a tree was planted or self-seeded.

$P$ : Planted — the tree was planted intentionally

I: Ingrowth - the tree self-seeded

U: Unknown — planted vs. ingrowth cannot be determined

Total tree height: Required. Measure the height to top (alive or dead) of tree (to nearest $\mathrm{ft}$ or $\mathrm{m}$ ) (Fig. 2). For standing dead trees, downed living trees, or severely leaning trees, height is considered the distance along the main stem from ground to tree top. (Do not include dead trees that are lying on the ground.)

Paper (sample): Enter tree height under HEIGHT $>$ TOT.

Height to live top: This height will be the same as total tree height unless the tree is alive but the top of the crown is dead. This variable cannot be greater than total tree height. Record to the nearest foot or meter.

Paper (sample and complete): Enter under HEIGHT > LIVE TOP.

Height to crown base: Required. Measure height to base of live crown (to nearest $\mathrm{ft}$ or $\mathrm{m}$ ). The live crown base is the point on the main trunk perpendicular to the lowest live foliage on the last branch that is included in the live crown. The live crown base is determined by the live foliage and not by the point where a branch intersects with the main bole (Fig. 2).

Paper (sample and complete): Enter under HEIGHT > CROWN BASE.

Crown width: Required. Measure crown width (to nearest $\mathrm{ft}$ or $\mathrm{m}$ ) in two directions: north-south and east-west or as safety considerations or physical obstructions allow. If tree is downed or leaning, take width measurements perpendicular to the tree bole. (Record dead trees as -1. PDA will fill in default value of -1 if Dead box was checked.)

Paper (sample): Enter under CROWN WIDTH $>$ N-S and E-W. 


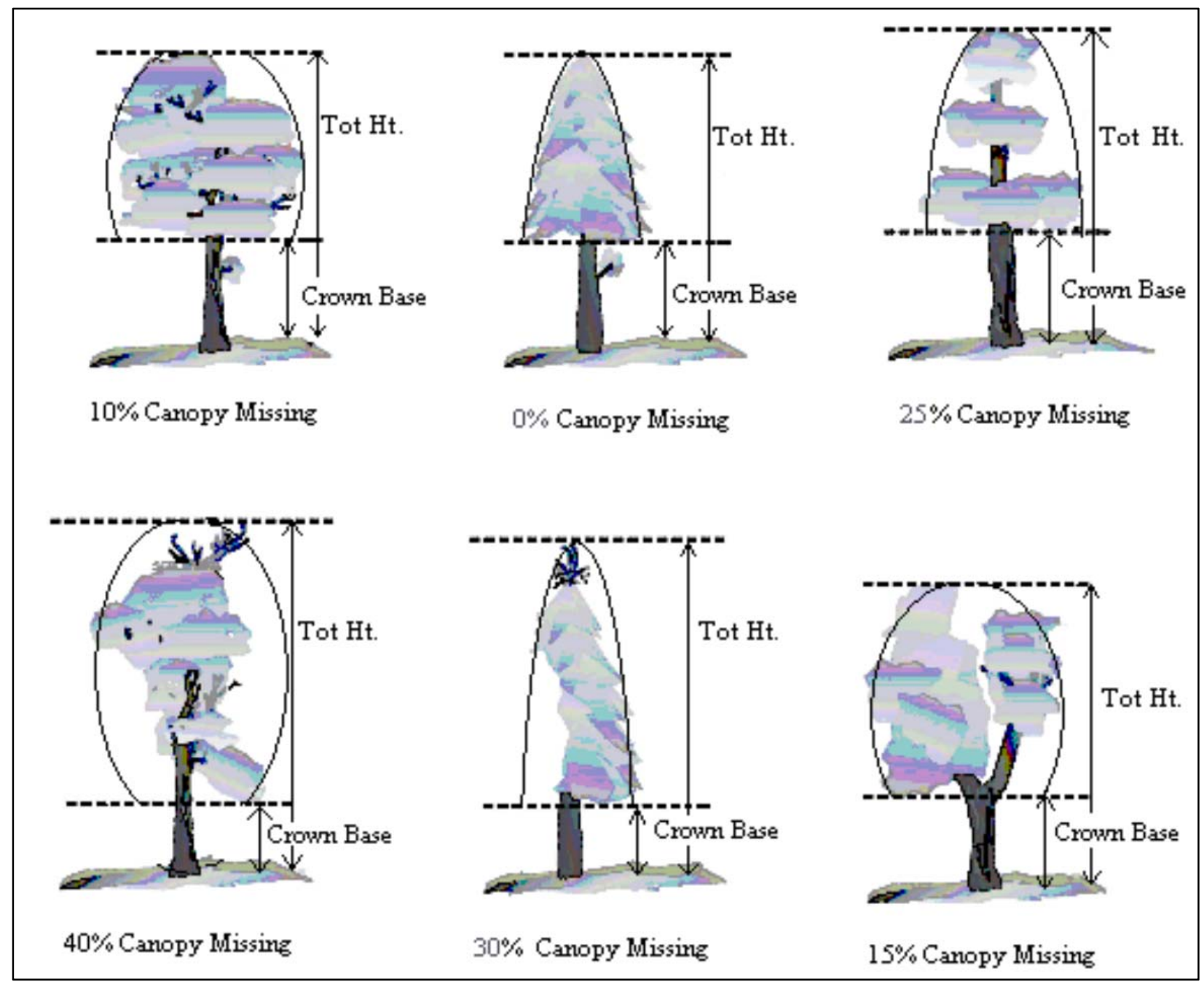

Fig. C-2. Illustration of how to measure height to crown base and percent canopy missing.

Percent canopy missing: Required. Percent of the crown volume that is not occupied by branches and leaves. Missing canopy should be measured by two people standing at perpendicular angles to the tree (Fig. C-3). Visualize the expected "typical crown outline" as a symmetrical silhouette created by the live crown width, total height, and height to base of live crown measurements. It is assumed to be symmetrical around the center point of the measured width of the tree and filled with leaves as if it were a healthy tree in excellent condition.

Now estimate the percent foliage that is absent due to pruning, dieback, defoliation, uneven crown, or dwarf or sparse leaves. Do not include normal interior crown voids due to leaf shading. Take into account the natural crown shape for the particular species (Fig. C-2).

Be sure to base your estimate of percent canopy missing on the crown that you have measured. For example, one-third of the crown may have been removed for power line clearance or the 
canopy could be very lopsided due to presence of a neighboring tree. However, the crown that remains could have a $0 \%$ missing value, if it is full. If the two observers disagree in their estimates, follow the guidelines listed below under Crown Rating Precautions.

Record percent canopy missing as $0 \%, 100 \%$ or mid-points of $5 \%$ intervals $(3,8,13,18$, etc.). (Record as $100 \%$ for dead trees. PDA has a fixed value of 100 if Dead box was checked.)

Paper (sample): Enter under \% MISS.

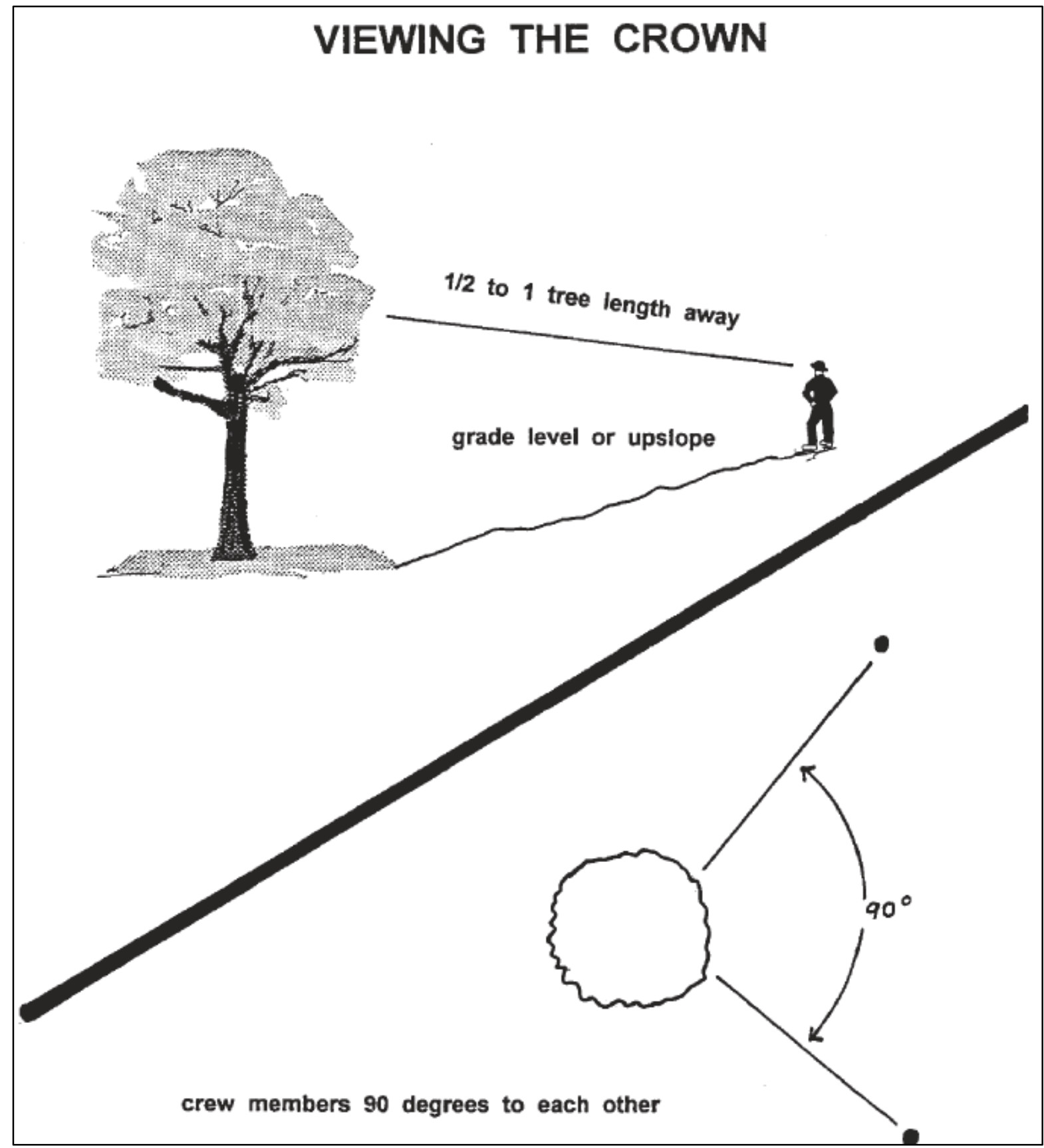

Fig. C-3. How to position yourself to measure the crown. 
Crown dieback: Required. Percent dieback in crown area. This dieback does not include normal, natural branch dieback, i.e., self-pruning due to crown competition or shading in the lower portion of the crown. However, branch dieback on side(s) and top of crown area due to shading from a building or another tree would be included. For more information, see the Forest Inventory and Analysis National Core Field Guide.

Estimate crown dieback as a percentage of the live crown area, including the dieback area. Assume the perimeter of the crown is a two-dimensional outline from branch tip to branch tip, excluding snag branches and large holes or gaps in the crown. Crown dieback is obtained by two people using binoculars. You should be conscious of lighting conditions and how light affects the day's observations, taking extra time under limited-light conditions.

Each individual should mentally draw a two-dimensional crown outline, block in the dieback and estimate the dieback area. If the two observers disagree in their estimates, follow the guidelines listed under Crown Rating Precautions.

Record crown dieback as $0 \%, 100 \%$ or mid-points of $5 \%$ intervals $(3,8,13,18$, etc.). (Record as $100 \%$ for dead trees. PDA has a fixed value of 100 if Dead box is checked.)

Paper (sample): Enter under DB.

Crown light exposure: Required. Number of sides of the tree receiving sunlight from above (maximum of five). Top of tree is counted as one side. Divide the crown vertically into four equal sides. Count the number of sides that would receive direct light if the sun were directly above the tree. One-third of the live crown must be receiving full light in order for a side to qualify. A sliver of a side receiving light does not qualify. Use the following codes:

Paper (sample and complete): Enter under CLE.

-1 : Dead trees.

0 : The tree receives no full light because it is shaded by trees, vines, or other vegetation.

1: The tree receives full light from the top or 1 side.

2: The tree receives full light from the top and 1 side (or 2 sides without the top).

3: The tree receives full light from the top and 2 sides (or 3 sides but not top).

4: The tree receives full light from the top and 3 sides.

5: The tree receives full light from the top and 4 sides.

Percent shrub cover under the tree: If you decided to collect information related to hydrology during Phase I: Getting Started: Early Decisions, this field is required. Estimate the percent of the area beneath the drip line that is occupied by shrubs. If the tree crown crosses out of the plot 
boundary, the entire area beneath the tree is still considered. Record $0 \%, 100 \%$ or mid-points of $5 \%$ intervals $(3,8,13,18$, etc. $)$.

Paper (sample): Enter under \% SHRUB.

DBH: Required. Record the tree's DBH on the uphill side of the tree to the nearest $0.1 \mathrm{inch} / \mathrm{cm}$. For trees with irregular DBHs:

Forked (multi-stemmed) tree: If the point of pith separation is above ground, the plant is considered to be one tree. Measure the DBH of up to six stems separately. If the tree has more than six stems with $\mathrm{DBH} \geq 1 \mathrm{inch}$, lower the measurement height to $1 \mathrm{ft}$ above the ground and record the diameter of up to six stems (selecting the largest and ignoring any others). If the pith union is below ground, each stem is considered a separate tree (included bark down to ground is a good indicator that pith union is below ground).

DBH measurement height: If DBH was not measured at 1.30 meters measure the height where DBH was taken.

Paper (sample and complete): Enter under HT DBH.

Direction to building: If you decided to collect information related to energy effects during Phase I: Getting Started: Early Decisions, this field is required. For trees ( $\geq 20 \mathrm{ft}$. tall) that are located within $60 \mathrm{ft}$. of space-conditioned residential buildings that are three stories or fewer in height (two stories and an attic), record the direction (azimuth in degrees) from the tree to the closest part of the building. For multi-family dwellings, treat all the units in the building as a single building. The building does not have to be located on the plot. The energy analyses are currently set to run for typical building types and climate zones of the United States. Up to three buildings can be recorded using the paper forms; an unlimited number of buildings can be recorded with the PDA. Standing dead trees that meet the above conditions should be included.

Paper (sample): Enter the direction to the three closest buildings under TREES NEAR BUILDINGS $>$ D1/D2/D3.

Shortest distance to building: If you decided to collect information related to energy effects during Phase I, this field is required. For buildings recorded above, measure the shortest distance from the tree to the closest part of the building (in $\mathrm{m}$ or $\mathrm{ft}$ ). Standing dead trees that meet the above conditions should be included.

Paper (sample): Enter the distance to the three closest buildings under TREES NEAR BUILDINGS $>$ S1/S2/S3.

Finishing Up the Plot or Site

For complete inventories, continue entering trees until all trees on the site have been inventoried. Check thoroughly to be sure all required fields are complete and all entries are reasonable. 
For sample inventories, continue entering trees until all trees on plot have been accounted for. It is the responsibility of each crew to complete all variables before leaving the sample plot. Before leaving the plot, check thoroughly to be sure all required fields are complete and all entries are reasonable. For PDA users, once all trees have been entered, click Exit/Done and check the box on the Plots window next to Mark Completed. You're ready to move on to the next plot.

\section{Inaccessible plot centers}

In some cases, your plot center might fall in a location that is inaccessible, such as within a building or in the middle of a highway. The following describes how to determine plot boundaries and location of trees when plot centers are inaccessible (note that the numbers in the example only apply to 0.1 acre plots) .

Determine ' $a$ ' by estimating the approximate location of the true plot center from the aerial photo or map. Then calculate ' $b$ ' by subtracting ' $a$ ' from the plot radius (e.g., $37.2 \mathrm{ft}$. for a 0.1 acre plot). Then ' $b$ ' is the distance from the plot boundary to the building wall.

To outline the general plot boundary walk parallel to the building for $26.2 \mathrm{ft}(y 1)$, then perpendicular to the building for $11 \mathrm{ft}(x 1)$. This would represent a point along the boundary approximately $45^{\circ}$ from the start. If you then walk $11 \mathrm{ft}(y 2)$ parallel to the building's edge, and $26.2 \mathrm{ft}(\mathrm{x} 2)$ perpendicular, the next plot boundary would be reached; representing a point $90^{\circ}$ along a circle from your starting point.

To locate the trees that are in-plot more easily, the crew should first determine the plot boundaries as described above, and then pick a point from which distance and direction can easily be measured to serve as the Tree Measurement Point (TMP). In the figure, a corner of the building has been chosen as the TMP (the TMP should be recorded in the notes, e.g., northwest corner of building).

Remember to only record trees that are within the radius of the true plot center. Trees $c, d$, and $f$ are all within the true plot boundary and must be inventoried. Tree $e$, on the other hand, is within $37.2 \mathrm{ft}$ of the TMP, but not of the actual plot center. Therefore, it lies outside the plot boundary and is not tallied. 


\section{APPENDIX D- Data Collection Sheet}

Collecting Survey Plot Information

\begin{tabular}{|l|l|l|l|l|}
\hline Plot ID: & Date: & Crew: & GPS Coordinates: & Photo ID: \\
& & & \\
& & & \\
& & & \\
\end{tabular}

Project Name: Bangkok, Thailand 2013

\section{Plot Address: \\ Plot Address:}

Notes:

Plot Contact Info:

Name and Title:

Phone \#:

Plot Sketch:

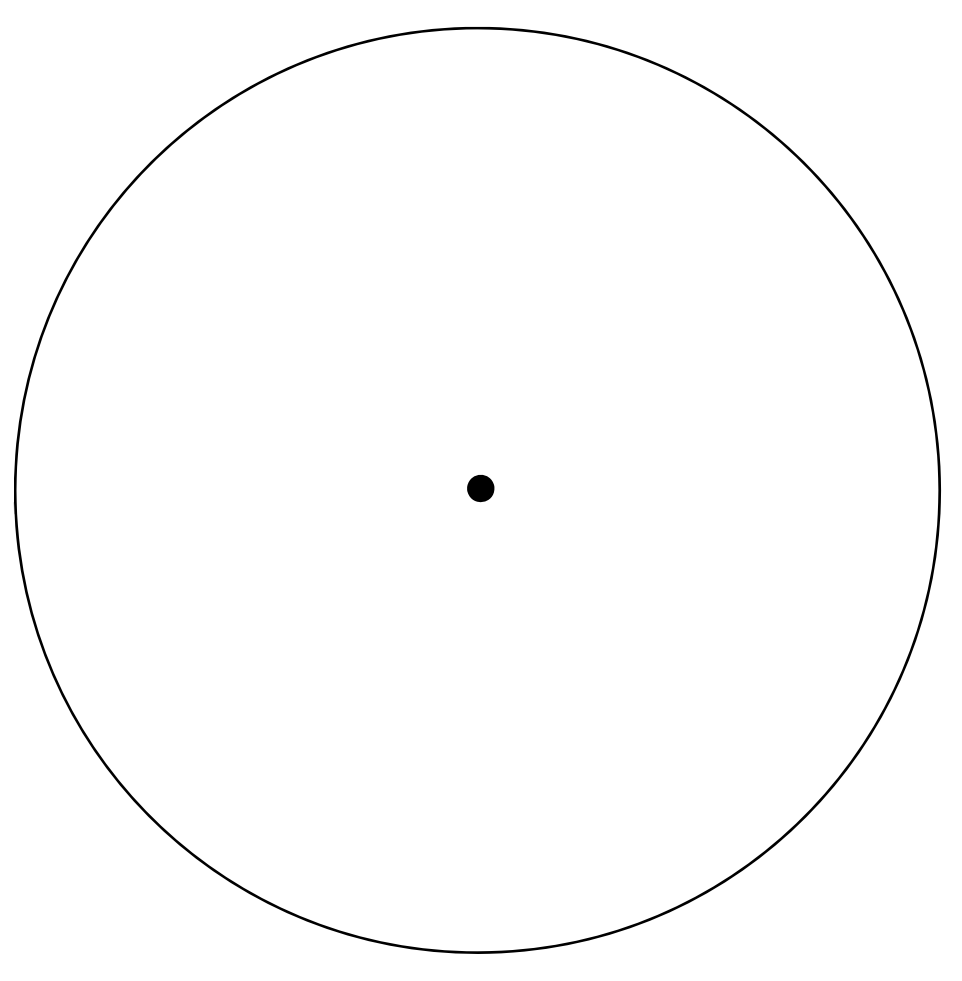


Determining reference objects/landmarks, and if needed, an alternative to the plot center (Tree Measurement Point)

\section{Reference Object 1 Description:}

Distance to Reference Object 1: (m.)

Direction to Reference Object 1: (degree)

Reference Object 2 Description:

Distance to Reference Object 2: (m.)

Direction to Reference Object21: (degree)

Tree Measurement Point (TMP): $\quad$ Yes or No

(Circle Yes or No, and if Yes, circle which Reference Object was used)

\section{Reference Object 1 Used $\quad$ Reference Object 2 Used}

Measurement Unit: Meters

Percent Measured:

Land Use:

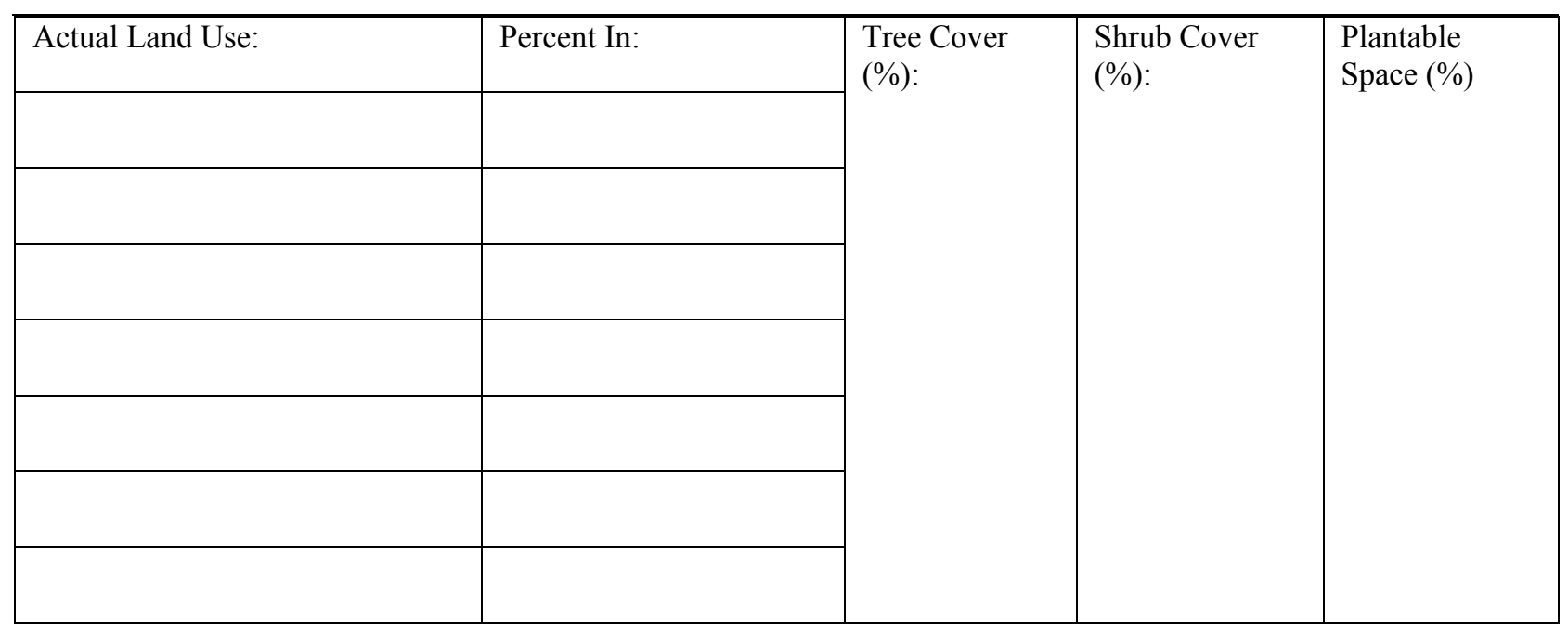


Ground cover:

\begin{tabular}{|l|l|l|l|l|l|l|l|l|l|}
\hline \%BLDG & \%CMNT & \%TAR & \%ROCK & \%SOIL & $\begin{array}{l}\text { \%DUFF/ } \\
\text { MULCH }\end{array}$ & $\begin{array}{l}\text { \%HERB/ } \\
\text { IVY }\end{array}$ & $\begin{array}{l}\text { \%MAIN } \\
\text { GRASS }\end{array}$ & $\begin{array}{l}\text { \%UNMAIN } \\
\text { GRASS }\end{array}$ & \%WATER \\
\hline & & & & & & & & & \\
\hline
\end{tabular}

Shrubs:

\begin{tabular}{|l|l|l|l|}
\hline Species & Height & \% Area & Miss \\
\hline 1. & & & \\
\hline 2. & & & \\
\hline 3. & & & \\
\hline 4. & & & \\
\hline 5. & & & \\
\hline 6. & & & \\
\hline 7. & & & \\
\hline 8. & & & \\
\hline 9. & & & \\
\hline 10. & & & \\
\hline 11. & & & \\
\hline 12. & & & \\
\hline
\end{tabular}




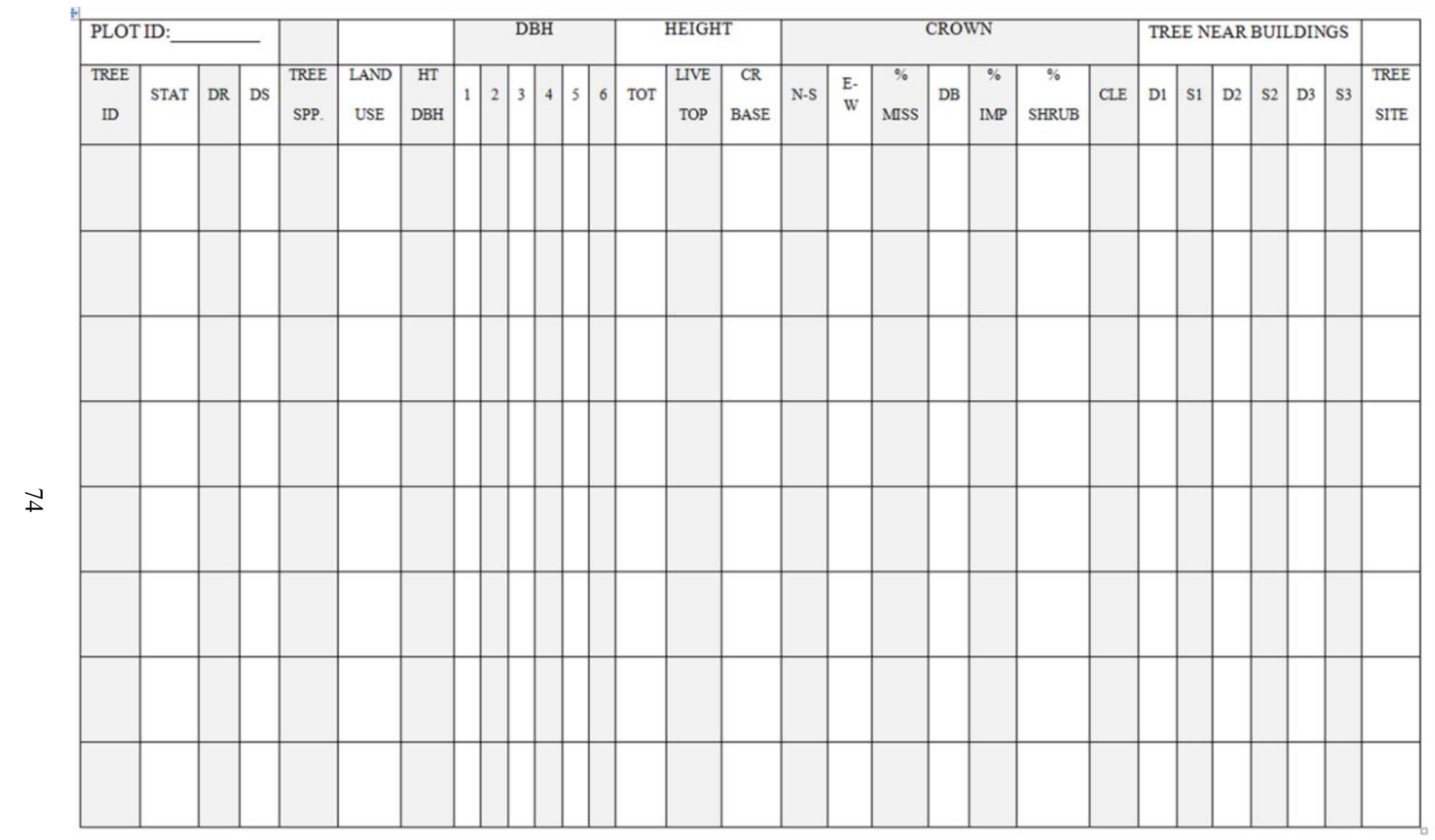




\section{APPENDIX E - The Variables of Plot, Shrub and Tree for the i-Tree Eco data collecting}

Table E -1. The Variables of Plot, Shrub and Tree for the i-Tree Eco data collecting.

\begin{tabular}{|c|c|}
\hline Variable Collected & Data Description \\
\hline \multicolumn{2}{|l|}{ Plot Level Variables } \\
\hline Plot ID & Unique identifier \\
\hline Date \& crew & Project management information \\
\hline GPS coordinates & $\begin{array}{l}\text { Used to help locate plot. (Note- GPS functionality is not integrated as } \\
\text { part of Eco application) }\end{array}$ \\
\hline Photo ID & Used to help identify plot or document plot attributes \\
\hline Plot address & Used for locating plot \\
\hline Plot contact & Relevant Information for field crews to gain access, etc. \\
\hline Measurement units & Units for all measurement in the plot: metric $(\mathrm{m} / \mathrm{cm})$ or English $(\mathrm{ft} / \mathrm{in})$ \\
\hline Reference objects & $\begin{array}{l}\text { At least (2) objects that will assist in locating plot center for future plot } \\
\text { re-measurement }\end{array}$ \\
\hline $\begin{array}{l}\text { Direction to reference } \\
\text { object }\end{array}$ & Direction (DR) from plot center to each reference object (degrees) \\
\hline $\begin{array}{l}\text { Distance to reference } \\
\text { object }\end{array}$ & Distance (DS) from plot center to each reference object (ft or m) \\
\hline $\begin{array}{l}\text { Tree measurement } \\
\text { point }\end{array}$ & $\begin{array}{l}\text { If plot center falls on a building or other surface (such as a highway) } \\
\text { where plot center cannot be accessed, the plot is not moved; all distances } \\
\text { and directions to trees are measured and recorded from a recorded fixed } \\
\text { point (e.g., building corner) referred to as the TMP. }\end{array}$ \\
\hline Percent measured & $\begin{array}{l}\text { Proportion of the plot that is actually measured as portions of plot may be } \\
\text { inaccessible or outside project area of interest boundary. }\end{array}$ \\
\hline Actual land use & $\begin{array}{l}\text { As determined by field crew from a standard list of land uses (not used } \\
\text { for stratification) }\end{array}$ \\
\hline Percent in & Proportion of the plot in land uses identified by field crew to nearest $1 \%$ \\
\hline Tree cover $\%$ & Percent of plot area covered by tree canopies estimated to nearest $5 \%$ \\
\hline Shrub cover $\%$ & Percent of plot area covered by shrub canopies estimated to nearest $5 \%$ \\
\hline Plantable space \% & $\begin{array}{l}\text { Percent of plot that is plantable for trees (i.e., plantable soils space not } \\
\text { filled with tree canopies) and tree planting would not be restricted as a } \\
\text { result of land use (footpath, baseball field, and so on); to nearest } 5 \%\end{array}$ \\
\hline Ground cover & $\begin{array}{l}\text { Used to estimate the amount and distribution of various ground cover } \\
\text { types. Total individual covers must equal } 100 \%\end{array}$ \\
\hline \multicolumn{2}{|l|}{ Shrub Variables } \\
\hline Shrub species code & Species code selected from standard list of tree $\&$ shrub species \\
\hline $\begin{array}{l}\text { Average height of } \\
\text { shrub mass }\end{array}$ & $\begin{array}{l}\text { Where mass is a group of shrub species or genera of similar height (ft or } \\
\mathrm{m} \text { ) }\end{array}$ \\
\hline Percent area & Percent of the total shrub cover on plot occupied by shrub mass \\
\hline $\begin{array}{l}\text { Percent shrub mass } \\
\text { missing }\end{array}$ & $\begin{array}{l}\text { Percent of shrub mass volume (height } x \text { ground area) that is not occupied } \\
\text { by leaves estimated to nearest } 5 \%\end{array}$ \\
\hline
\end{tabular}


Table E - 1. (cont.)

\begin{tabular}{|c|c|}
\hline Variable Collected & Data Description \\
\hline Tree site & $\begin{array}{l}\mathrm{N} / \mathrm{S} \text { to indicate if a tree is a street tree. Used to estimate proportion of } \\
\text { population that is street trees }\end{array}$ \\
\hline \multicolumn{2}{|l|}{ Tree Variables } \\
\hline Tree ID & Unique tree number \\
\hline Status & $\begin{array}{l}\text { Indicates if a tree was planted }(\mathrm{P}) \text { or naturally regenerated }(\mathrm{I}) \text { in the } \\
\text { landscape. Remeasurement has additional tree status options as specified } \\
\text { in the manual }\end{array}$ \\
\hline $\begin{array}{l}\text { Distance (DS) in } \mathrm{ft} / \mathrm{m} \\
\text { and direction (DR) in } \\
\text { degrees from plot } \\
\text { center }\end{array}$ & Used to identify and locate trees for future measurements \\
\hline Tree species code & Species code from standard list of trees \& shrubs \\
\hline Land use & $\begin{array}{l}\text { Specifies the actual land use, as recorded in general plot data, in which } \\
\text { the tree is located }\end{array}$ \\
\hline $\begin{array}{l}\text { Height of DBH } \\
\text { measurement }\end{array}$ & Recorded if dbh is not measured at default height of $1.37 \mathrm{~m}(4.5 \mathrm{ft})$ \\
\hline DBH $1-6$ & $\begin{array}{l}\text { Diameter at breast height }(\mathrm{in} / \mathrm{cm}) \text { for all recorded trees. DBH } 2-6 \text { are } \\
\text { used for recording multi stem trees }\end{array}$ \\
\hline Total Height & Height to top of tree $(\mathrm{ft} / \mathrm{m})$ \\
\hline Live top height & $\begin{array}{l}\text { Height to live top of canopy. Used in cases where total tree height may be } \\
\text { void of canopy due to dieback }(\mathrm{ft} / \mathrm{m})\end{array}$ \\
\hline Crown base & Height to base of live crown $(\mathrm{ft} / \mathrm{m})$ \\
\hline Crown width & $\begin{array}{l}\text { Recorded by (2) measurements N-S (north - south) \& E-W (east - west) } \\
\text { widths }(\mathrm{ft} / \mathrm{m})\end{array}$ \\
\hline $\begin{array}{l}\text { Percent canopy } \\
\text { missing }\end{array}$ & $\begin{array}{l}\text { The percent of the crown volume that is not occupied by leaves; two } \\
\text { perpendicular measures of missing leaf mass are made and the average } \\
\text { result is recorded to nearest } 5 \%\end{array}$ \\
\hline Dieback & Percent crown dieback to nearest $5 \%$ \\
\hline Crown light exposure & $\begin{array}{l}\text { Number of sides of the tree receiving sunlight from above; used to } \\
\text { estimate competition and growth rates }\end{array}$ \\
\hline $\begin{array}{l}\text { Distance }(\mathrm{S} 1) \text { in } \mathrm{ft} / \mathrm{m} \\
\text { and direction (D1) in } \\
\text { degrees to space } \\
\text { conditioned residential } \\
\text { buildings }\end{array}$ & $\begin{array}{l}\text { Measured for trees at least } 6.1 \mathrm{~m}(20 \mathrm{ft}) \text { tall and within } 18.3 \mathrm{~m}(60 \mathrm{ft}) \text { of } \\
\text { structures (3) stories or less in height. Optional for energy effects analysis }\end{array}$ \\
\hline
\end{tabular}




\section{APPENDIX F - i-Tree Ecosystem Analysis Bangkok}

\section{Summary}

Understanding an urban forest's structure, function and value can promote management decisions that will improve human health and environmental quality. An assessment of the vegetation structure, function, and value of the Bangkok urban forest was conducted during 2013. Data from 184 field plots located throughout Bangkok were analyzed using the i-Tree Eco model developed by the U.S. Forest Service, Northern Research Station.

$\underline{\text { Key findings }}$

- $\quad$ Number of trees: 2,504,000

- $\quad$ Tree cover: $8.6 \%$

- Most common species: Cemetery tree, Mango, Monkeypod

- $\quad$ Percentage of trees less than 6" $(15.2 \mathrm{~cm})$ diameter: $53.8 \%$

- $\quad$ Pollution removal: 738 metric tons/year (THB6.17 million/year)

- $\quad$ Carbon storage: 310,000 metric tons (THB N/A)

- Carbon sequestration: 16,300 metric tons/year (THB N/A /year)

- $\quad$ Oxygen production: 40,900 metric tons/year (\$0 /year)

- $\quad$ Building energy savings: THB0/year

- Avoided carbon emissions: THB0/year

- $\quad$ Structural values: THB21.5 million

Metric Ton: 1000 kilograms

Carbon storage: the amount of carbon bound up in the above-ground and below-ground parts of woody vegetation Carbon sequestration: the removal of carbon dioxide from the air by plants Carbon storage and carbon sequestration values are calculated based on THB-1 per metric ton Structural value: value based on the physical resource itself (e.g., the cost of having to replace a tree with asimilar tree) Pollution removal value is calculated based on the prices of THB1592 per metric ton (carbon monoxide), THB11207 per metric ton (Ozone), THB11207 per metric ton (nitrogen dioxide), THB2744 per metric ton (sulfur dioxide), THB7482 per metric ton (PM10) Energy saving value is calculated based on the prices of THB0 per MWH and THB0 per MBTU Monetary values (THB) are reported in Bahts throughout the report except where noted 


\section{Tree Characteristics of the Urban Forest}

The urban forest of Bangkok has an estimated 2,504,000 trees with a tree cover of 8.60 percent. Trees that have diameters less than 6 -inches $(15.2 \mathrm{~cm})$ constitute 53.8 percent of the population. The three most common species are Cemetery tree (15.7 percent), Mango (13.0 percent), and Monkeypod (5.4 percent).

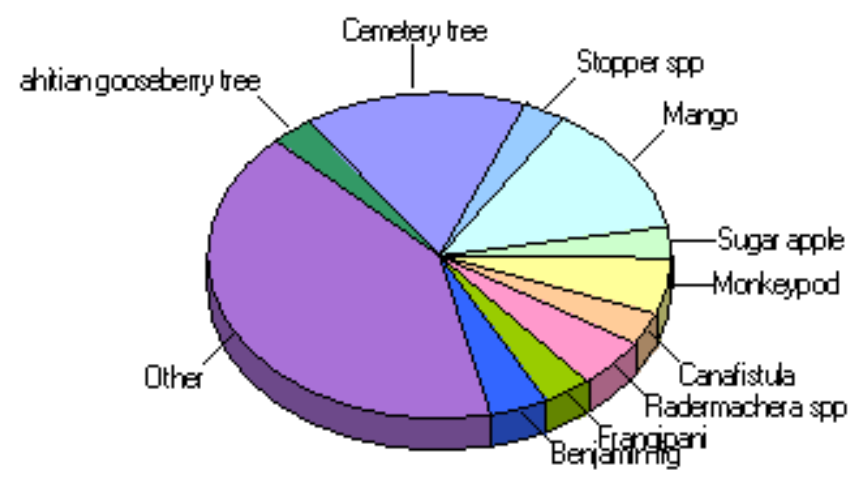

Fig. F-1. Tree species composition in Bangkok

The overall tree density in Bangkok is 27.1 trees/hectare. For stratified projects, the highest tree densities in Bangkok occur in Low Density Residential Area followed by Medium Density Residential Area and Commercial, Industrial, Ware house Areas.

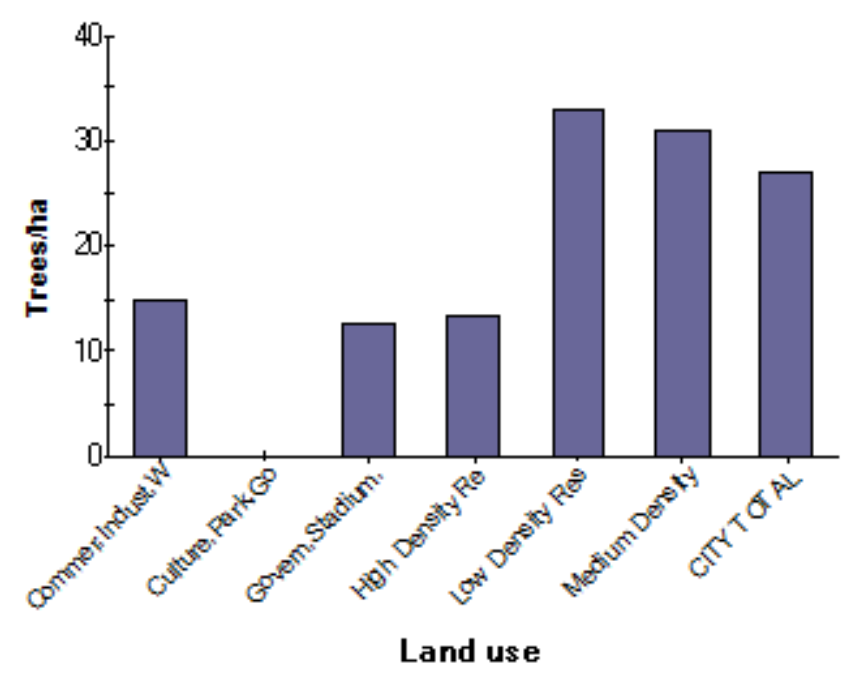

Fig. F-2. Number of trees/ha in Bangkok by land use 


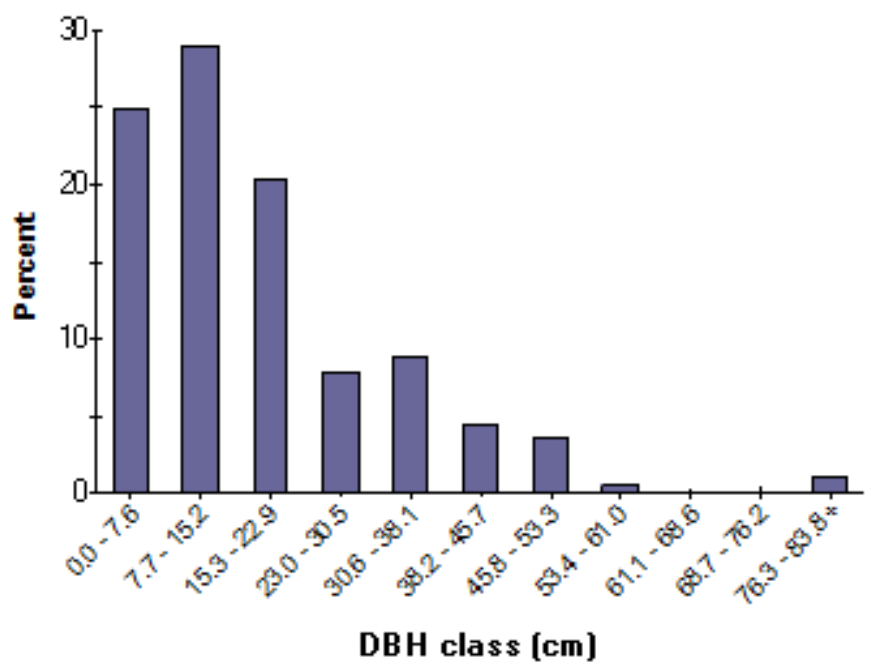

Fig. F-3. Percent of tree population by diameter class ( $\mathrm{DBH}=$ stem diameter at 1.30 meter)

Urban forests are composed of a mix of native and exotic tree species. Thus, urban forests often have a tree diversity that is higher than surrounding native landscapes. Increased tree diversity can minimize the overall impact or destruction by a species-specific insect or disease, but it can also pose a risk to native plants if some of the exotic species are invasive plants that can potentially out-compete and displace native species. In Bangkok, about 14 percent of the trees are from species native to Asia. Most exotic tree species have an origin from North \& South America (34.3 percent of the species).

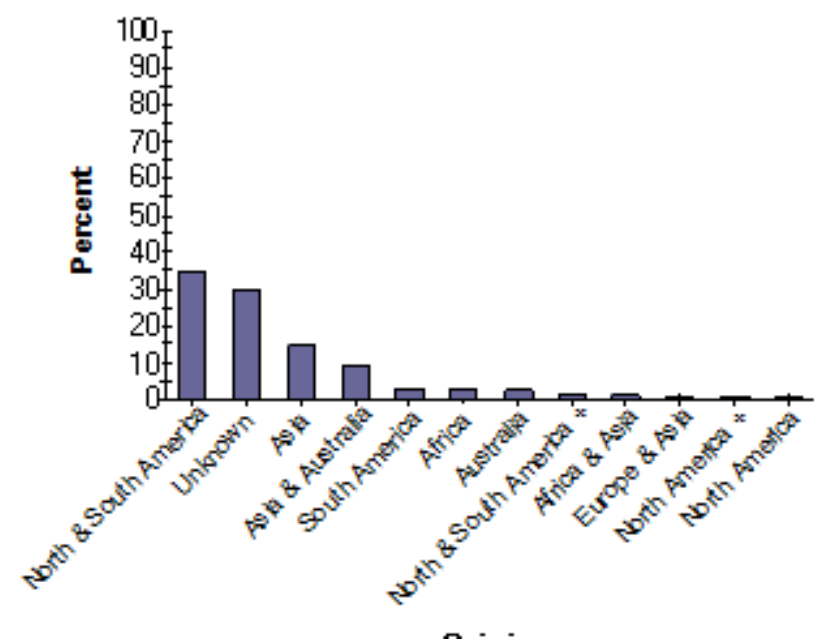

Fig. F-4. Percent of live trees by species origin

The plus sign (+) indicates the plant is native to another continent other than the ones listed in the grouping. 


\section{Urban Forest Cover and Leaf Area}

Many tree benefits equate directly to the amount of healthy leaf surface area of the plant. In Bangkok, the three most dominant species in terms of leaf area are Monkeypod, Mango, and Stopper spp. Trees cover about 8.6 percent of Bangkok, and shrubs cover 1.9 percent.

The 10 most important species are listed in Table 1. Importance values (IV) are calculated as the sum of relative leaf area and relative composition.

Table F-1. Most important species in BANGKOK

\begin{tabular}{|l|l|l|l|}
\hline \multicolumn{1}{|c|}{ Species Name } & $\begin{array}{c}\text { Percent } \\
\text { Population }\end{array}$ & $\begin{array}{c}\text { Percent } \\
\text { Leaf Area }\end{array}$ & IV \\
\hline Monkeypod & 5.4 & 20.7 & 26.1 \\
Mango & 13.0 & 10.0 & 23.1 \\
Cemetery tree & 15.7 & 0.9 & 16.5 \\
Stopper spp & 3.0 & 7.6 & 10.6 \\
Queens crapemyrtle & 1.5 & 7.0 & 8.6 \\
Apamate & 1.5 & 6.5 & 7.9 \\
Radermachera spp & 4.9 & 1.9 & 6.8 \\
Peepul tree & 2.2 & 4.5 & 6.8 \\
Sugar apple & 3.2 & 3.0 & 6.2 \\
Areca palm & 1.0 & 4.6 & 5.6 \\
\hline
\end{tabular}

The two most dominant ground cover types are Building (21.5 percent) and Cement (20.9 percent).

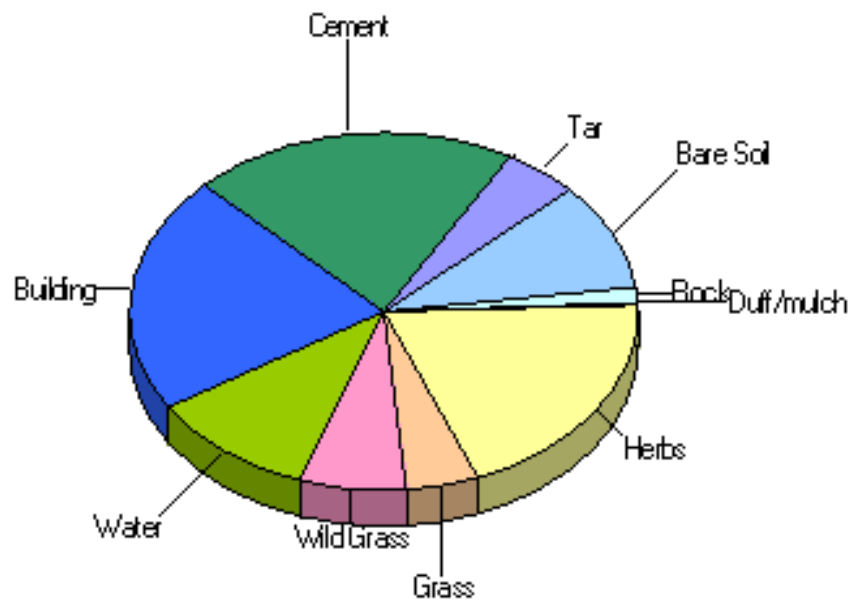

Fig. F-5. Percent ground cover in Bangkok 


\section{Air Pollution Removal by Urban Trees}

Poor air quality is a common problem in many urban areas. It can lead to decreased human health, damage to landscape materials and ecosystem processes, and reduced visibility. The urban forest can help improve air quality by reducing air temperature, directly removing pollutants from the air, and reducing energy consumption in buildings, which consequently reduces air pollutant emissions from the power plants. Trees also emit volatile organic compounds that can contribute to ozone formation. However, integrative studies have revealed that an increase in tree cover leads to reduced ozone formation.

Pollution removal by trees and shrubs in Bangkok was estimated using field data and recent available pollution and weather data. Pollution removal was greatest for particulate matter to 10 microns. It is estimated that trees and shrubs remove 738 metric tons of air pollution (ozone $\left(\mathrm{O}_{3}\right)$, carbon monoxide $(\mathrm{CO})$, nitrogen dioxide $\left(\mathrm{NO}_{2}\right)$, particulate matter less than 10 microns $\left(\mathrm{PM}_{10}\right)$, and sulfur dioxide $\left.\left(\mathrm{SO}_{2}\right)\right)$ per year with an associated value of THB6.17 million based on estimated customized/default national median externality costs associated with pollutants. United States externality pollution values will be substituted for international studies when pollutant values are not available.

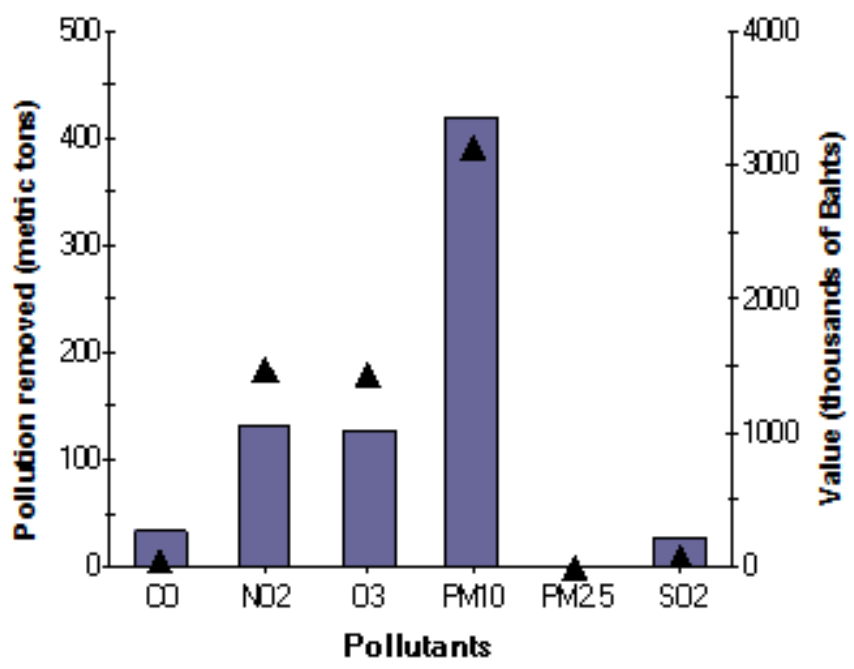

Fig. F-6. Pollution removal (bars) and associated value (points) for trees in Bangkok Pollution removal and value for PM10 excludes PM2.5 removal and value

Pollution Removal value is calculated based on the prices of THB1592 per metric ton (carbon monoxide), THB1 1207 per metric ton (Ozone), THB1 1207 per metric ton (nitrogen dioxide), THB2744 per metric ton (sulfur dioxide), THB7482 per metric ton (PM10particulate matter less than 10 microns) 


\section{Carbon Storage and Sequestration}

Climate change is an issue of global concern. Urban trees can help mitigate climate change by sequestering atmospheric carbon (from carbon dioxide) in tissue and by altering energy use in buildings, and consequently altering carbon dioxide emissions from fossil-fuel based power plants.

Trees reduce the amount of carbon in the atmosphere by sequestering carbon in new growth every year. The amount of carbon annually sequestered is increased with the size and health of the trees. The gross sequestration of Bangkok trees is about 16,300 metric tons of carbon per year with an associated value of THB N/A. Net carbon sequestration in the urban forest is about 15,400 metric tons. Carbon storage and carbon sequestration values are calculated based on THB-1 per metric ton.

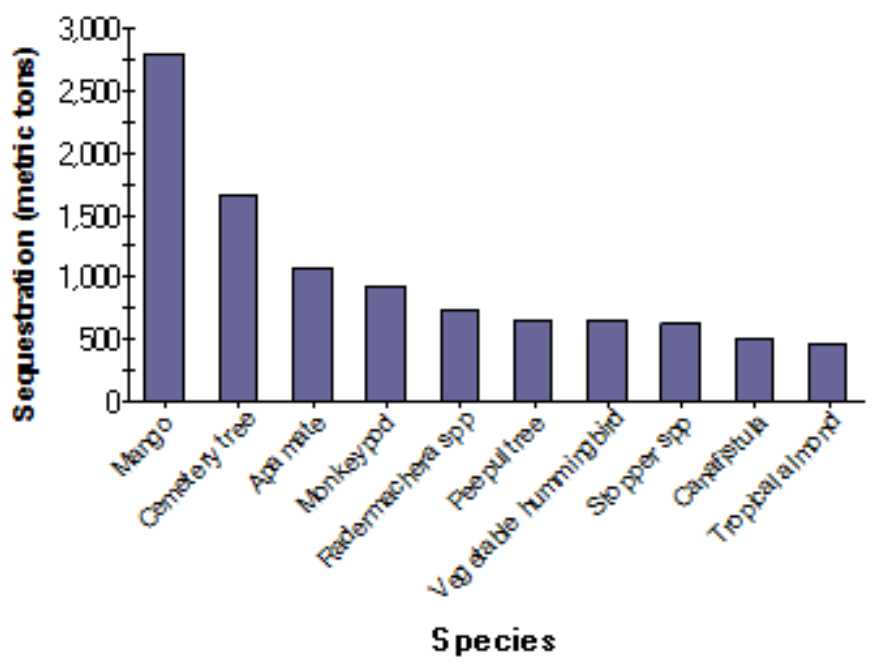

Fig. F-7. Carbon sequestration and value for species with greatest overall carbon sequestration in Bangkok

As trees grow they store more carbon as wood. As trees die and decay, they release much of the stored carbon back to the atmosphere. Thus, carbon storage is an indication of the amount of carbon that can be lost if trees are allowed to die and decompose. Trees in Bangkok are estimated to store 310,000 metric tons of carbon (THB N/A). Of all the species sampled, Apamate stores the most carbon (approximately 14.9\% of the total carbon stored. Mango sequesters the most carbon (18.2\% of all sequestered carbon.) 


\section{Oxygen Production}

Oxygen production is one of the most commonly cited benefits of urban trees. The net annual oxygen production of a tree is directly related to the amount of carbon sequestered by the tree, which is tied to the accumulation of tree biomass.

Trees in Bangkok are estimated to produce 40,900 metric tons of oxygen per year. However, this tree benefit is relatively insignificant because of the large and relatively stable amount of oxygen in the atmosphere and extensive production by aquatic systems. Our atmosphere has an enormous reserve of oxygen. If all fossil fuel reserves, all trees, and all organic matter in soils were burned, atmospheric oxygen would only drop a few percent.

Table F-2. The top 20 oxygen production species.

\begin{tabular}{|l|r|r|r|r|}
\hline \multicolumn{1}{|c|}{ Species } & $\begin{array}{c}\text { Net Carbon } \\
\text { Oxygen } \\
\text { (metric tons) }\end{array}$ & $\begin{array}{c}\text { Sequestration } \\
\text { (metric } \\
\text { tons/yr) }\end{array}$ & \multicolumn{1}{c|}{$\begin{array}{c}\text { Number of } \\
\text { trees }\end{array}$} & $\begin{array}{c}\text { Leaf Area } \\
\text { (square } \\
\text { kilometers) }\end{array}$ \\
\hline Mango & $7,471.68$ & $2,801.88$ & $326,598.00$ & 21.86 \\
\hline Cemetery tree & $4,417.73$ & $1,656.65$ & $392,746.00$ & 1.86 \\
\hline Apamate & $2,877.36$ & $1,079.01$ & $36,857.00$ & 14.09 \\
\hline Monkeypod & $2,469.60$ & 926.10 & $135,218.00$ & 45.17 \\
\hline Radermachera spp & $1,966.08$ & 737.28 & $122,549.00$ & 4.19 \\
\hline Peepul tree & $1,763.84$ & 661.44 & $56,232.00$ & 9.91 \\
\hline Vegetable hummingbird & $1,762.75$ & 661.03 & $63,346.00$ & 2.64 \\
\hline Stopper spp & $1,699.63$ & 637.36 & $75,646.00$ & 16.59 \\
\hline Canafistula & $1,328.77$ & 498.29 & $83,160.00$ & 4.91 \\
\hline Tropical almond & $1,249.89$ & 468.71 & $27,362.00$ & 8.37 \\
\hline White cheesewood & $1,182.72$ & 443.52 & $36,857.00$ & 3.50 \\
\hline Queens crapemyrtle & $1,128.51$ & 423.19 & $38,008.00$ & 15.38 \\
\hline India tamarind & $1,037.33$ & 389.00 & $35,245.00$ & 5.38 \\
\hline Mahogany spp & 997.17 & 373.94 & $63,346.00$ & 3.19 \\
\hline Raintree & 854.72 & 320.52 & $11,288.00$ & 6.76 \\
\hline India paduak & 850.45 & 318.92 & $38,008.00$ & 1.20 \\
\hline Jackfruit & 675.44 & 253.29 & $49,526.00$ & 5.30 \\
\hline Royal poinciana & 561.25 & 210.47 & $38,008.00$ & 1.45 \\
\hline Annona spp & 5455.81 & 204.68 & $36,626.00$ & 1.31 \\
\hline Frangipani & 526.85 & 197.57 & $84,541.00$ & 1.74 \\
\hline
\end{tabular}




\section{Structural and Functional Values}

Urban forests have a structural value based on the trees themselves (e.g., the cost of having to replace a tree with a similar tree); they also have functional values (either positive or negative) based on the functions the trees perform.

The structural value of an urban forest tends to increase with a rise in the number and size of healthy trees. Annual functional values also tend to increase with increased number and size of healthy trees, and are usually on the order of several million dollars per year. Through proper management, urban forest values can be increased; however, the values and benefits also can decrease as the amount of healthy tree cover declines.

Structural values:

- $\quad$ Structural value: THB N/A

- Carbon storage: THB N/A

Annual functional values:

- Carbon sequestration: THB N/A

- Pollution removal: THB6.17 million

- Lower energy costs and carbon emission reductions: THB0 (Note: negative value indicates increased energy cost and carbon emission value) 


\section{Relative Tree Effects}

The urban forest in Bangkok provides benefits that include carbon storage and sequestration, and air pollutant removal. To estimate the relative value of these benefits, tree benefits were compared to estimates of average municipal carbon emissions, average passenger automobile emissions, and average household emissions.

Carbon storage is equivalent to:

- Amount of carbon emitted in Bangkok in 3 days

- Annual carbon (C) emissions from 205,000 automobiles

- Annual C emissions from 103,000 single-family houses

Carbon monoxide removal is equivalent to:

- Annual carbon monoxide emissions from 143 automobiles

- Annual carbon monoxide emissions from 593 single-family houses

Nitrogen dioxide removal is equivalent to:

- Annual nitrogen dioxide emissions from 9,180 automobiles

- Annual nitrogen dioxide emissions from 6,120 single-family houses

Sulfur dioxide removal is equivalent to:

- Annual sulfur dioxide emissions from 45,200 automobiles

- Annual sulfur dioxide emissions from 758 single-family houses

Particulate matter less than 10 micron (PM10) removal is equivalent to:

- Annual PM10 emissions from 1,228,000 automobiles

- Annual PM10 emissions from 119,000 single-family houses

Annual carbon sequestration is equivalent to:

- Amount of carbon emitted in Bangkok in 0.2 days

- Annual C emissions from 10,800 automobiles

- Annual C emissions from 5,400 single-family houses

Note: estimates above are partially based on the user-supplied information on human population total for study area 


\section{Comparison of Urban Forests}

A common question asked is, "How does this city compare to other cities?" Although comparison among cities should be made with caution as there are many attributes of a city that affect urban forest structure and functions, summary data are provided from other cities analyzed using the i-Tree Eco model.

Table F-3. City totals for trees

\begin{tabular}{|c|c|c|c|c|c|}
\hline City & $\begin{array}{r}\text { \% Tree } \\
\text { Cover }\end{array}$ & $\begin{array}{r}\text { Number of } \\
\text { trees }\end{array}$ & $\begin{array}{r}\text { Carbon } \\
\text { storage } \\
\text { (metric tons) }\end{array}$ & $\begin{array}{r}\text { Carbon } \\
\text { Sequestration } \\
\text { (metric tons/yr) }\end{array}$ & $\begin{array}{r}\text { Pollution } \\
\text { removal } \\
\text { (metric } \\
\text { tons/yr) }\end{array}$ \\
\hline Calgary, Canada & 7.2 & $11,889,000$ & 404,000 & 19,400 & 296 \\
\hline Atlanta, GA & 36.8 & $9,415,000$ & $1,220,000$ & 42,100 & 1,508 \\
\hline Toronto, Canada & 20.5 & $7,542,000$ & 900,000 & 36,600 & 1,100 \\
\hline New York, NY & 21 & $5,212,000$ & $1,226,000$ & 38,400 & 1,521 \\
\hline Baltimore, MD & 21 & $2,627,000$ & 541,000 & 14,600 & 390 \\
\hline Philadelphia, PA & 15.7 & $2,113,000$ & 481,000 & 14,600 & 523 \\
\hline Washington, DC & 28.6 & $1,928,000$ & 474,000 & 14,600 & 379 \\
\hline Boston, MA & 22.3 & $1,183,000$ & 289,000 & 9,500 & 258 \\
\hline Woodbridge, NJ & 29.5 & 986,000 & 145,000 & 5,000 & 191 \\
\hline Minneapolis, MN & 26.5 & 979,000 & 227,000 & 8,100 & 277 \\
\hline Syracuse, NY & 23.1 & 876,000 & 157,000 & 4,900 & 99 \\
\hline Morgantown, WV & 35.9 & 661,000 & 85,000 & 2,700 & 60 \\
\hline Moorestown, NJ & 28 & 583,000 & 106,000 & 3,400 & 107 \\
\hline Jersey City, NJ & 11.5 & 136,000 & 19,000 & 800 & 37 \\
\hline Freehold, NJ & 34.4 & 48,000 & 18,000 & 500 & 19 \\
\hline
\end{tabular}

Table F-4. Per hectare values of tree effects

\begin{tabular}{|l|c|c|c|c|}
\hline City & $\begin{array}{c}\text { No. of } \\
\text { trees }\end{array}$ & $\begin{array}{c}\text { Carbon Storage } \\
\text { (metric tons) }\end{array}$ & $\begin{array}{c}\text { Carbon } \\
\text { sequestration } \\
(\mathrm{kqs} / \mathrm{yr})\end{array}$ & $\begin{array}{c}\text { Pollution } \\
\text { removal } \\
\text { (kqs/yr) }\end{array}$ \\
\hline Calgary, Canada & 164.8 & 5.60 & 0.13 & 4.0 \\
Atlanta, GA & 275.8 & 35.64 & 0.62 & 44.2 \\
Toronto, Canada & 119.4 & 14.35 & 0.29 & 17.5 \\
New York, NY & 65.2 & 15.24 & 0.24 & 19.1 \\
Baltimore, MD & 125.5 & 25.78 & 0.35 & 18.6 \\
Philadelphia, PA & 61.8 & 14.12 & 0.21 & 15.2 \\
Washington, DC & 121.1 & 29.81 & 0.46 & 23.8 \\
Boston, MA & 82.8 & 20.18 & 0.33 & 17.9 \\
Woodbridge, NJ & 164.3 & 24.21 & 0.42 & 31.8 \\
Minneapolis, MN & 64.7 & 15.02 & 0.27 & 18.4 \\
Syracuse, NY & 134.7 & 24.21 & 0.38 & 15.2 \\
Morgantown, WV & 295.8 & 38.11 & 0.60 & 26.7 \\
Moorestown, NJ & 153.2 & 28.02 & 0.45 & 28.2 \\
Jersey City, NJ & 35.3 & 4.93 & 0.11 & 9.6 \\
Freehold, NJ & 95.1 & 35.87 & 0.49 & 37.7 \\
\hline
\end{tabular}




\section{APPENDIX G- Land Use's Population Density, FAR, and BCR Regulation}

Table G-1. Land use's population density, floor area ratio (FAR) and building cover ratio (BCR) of Ministerial Regulation on the Bangkok Comprehensive Plan B.E.2549 (2006 A.D.)

\section{Land use area}

\section{Population density Floor area Building coverage} (people per $\mathrm{km}^{2}$ ) ratio (FAR) ratio (BCR)

Low Density Residential Area

The Medium Density Residential Area

High Density Residential Area

Commercial Area
$6,250-15,000$

$1-2$

$18,750-37,500$

$37,500-62,500$

$50,000-62,500$
$2-3.5$

4-8

6-10
$50-70 \%$

$70 \%$

$70 \%$

$80-90 \%$ 


\section{APPENDIX H- CTLA’s Tree Appraisal Method}

The Guide for Plant Appraisal, 9th Edition, authored by the Council of Tree and Landscape Appraisers (CTLA)*

*adapt from Tree Appraisal by Lindsey Purcell

The four major elements involved in properly assessing the value of a tree are size, species, condition and location. A thorough understanding of each is imperative; otherwise, the appraisal will lack credibility and significance for the case.

The species rating is a comparative value given to the tree or plant based upon its individual characteristics. Consideration is given to the plant's assets and its inherent qualities. This rating is provided by a council of experts in the area and will vary within regions around the country. Additionally, there can be variations in ratings within the state, relative to hardiness zones. Adjustments will be necessary based on subjective observation. Check the local chapter of the International Society of Arboriculture for more information on the ratings for your state.

The condition of the tree is a subjective determination made by the appraiser during the inspection. It is an assessment of the tree's structural integrity and health at the time of appraisal. Thought should be given to rooting, branching, health and vigor, any damage or wounds, and evidence of pest infestation. It is important to note the current condition as the most reasonable gauge for the rating determination.

The size of the plant is measured using common tools and industry standards. A diameter tape or tape measure can be used to measure trunk size, and is typically recorded as the diameter at 4.5 feet above grade, or shoulder height. Consult with the appraisal guide on proper sizing procedures. 
The location factor involves the landscape value of the site and the placement of the tree on the property. Consider the location of the property, overall quality of the landscape, hardscape and related elements. Understand the tree's contribution to the site, its function and the aesthetics to determine how effectively the placement of the tree provides these benefits.

The Cost Approach considers the amount in dollars to either repair damage to the tree or replace the tree. There are various methods to use within this approach:

Replacement Cost estimates the cost of replacing a tree in the same location with the same species and, if possible, of similar size. However, in most cases a tree is too large to be replaced by a single tree and still be of equal value. In those cases, appraisers may designate several smaller trees deemed collectively to be equivalent to the original tree. This becomes a matter of calculating the value of the replacement trees and their associated costs. Often, some type of settlement is involved in the negotiations, as well. This usually is found to be the most accurate determination of market value of the tree. The formula used in the process is stated as:

\section{Appraised Value $=[$ installed plant $\operatorname{cost} \mathbf{x}$ species value $\mathbf{x}$ condition value $\mathbf{x}$ location value] + removal and cleanup cost]}

Trunk Formula (TFM) defines value in comparison to other trees of the same species. However, it does not necessarily provide adequate market value of the tree. The TFM often is used when the tree is too large to be replaced with typical nursery stock, and can be a good representation of overall value to the property. The basic value of a tree is the sum of two factors: the cost of transplanting the largest normally available tree of the same or comparable species, and the increase in value because of the larger size of the tree being appraised compared 
to the size of the replacement tree. An example can be found at the end of this publication. The formula used in the process is stated as:

\section{Value = Basic Tree Cost $x$ Species Rating \% x Condition Rating \% x Location Rating \%}

Basic Tree Cost is the Replacement Tree Cost + (Base Price x Adjusted Trunk Area, or ATA). Base price is determined to be $\$ 65$ for Indiana. ATA is the area of the tree trunk in square inches measured at standard height of 4.5 feet, less the area of the largest available transplantable tree, which is determined to be $\$ 800$ in Indiana. A table of conversions from Diameter at Breast Height, or DBH, to ATA is available in the CTLA guide.

Species rating is the factor assigned to a given tree species, based on the list provided in this publication. This subjective rating is based on individual qualities and traits, which may vary geographically within the state because of local climate and environmental influences.

Location rating is a value determined by the tree's placement in the landscape and the overall area in which the property is located. It is derived by the following equation: $($ Site $\%+$ Contribution $\%+$ Placement $\%) \div 3$

Condition rating is determined by establishing the overall health and structural integrity of the tree. An assessment of condition includes roots, trunk and canopy. The appraiser and the appraisal situation determine the amount of detail in this assessment. 
Replacement Tree Costs are the cost of the tree, cost of transporting the tree to the site, planting it in the same location as the appraised tree and monitoring it during the maintenance period. This cost is subjective to location. 